\title{
RESSONÂNCIA ELETROMAGNÉTICA EM CAVIDADES TOROIDAIS TEORIA E EXPERIÊNCIA
}

\author{
DOUGLAS CAVALLI GIRALDEZ
}

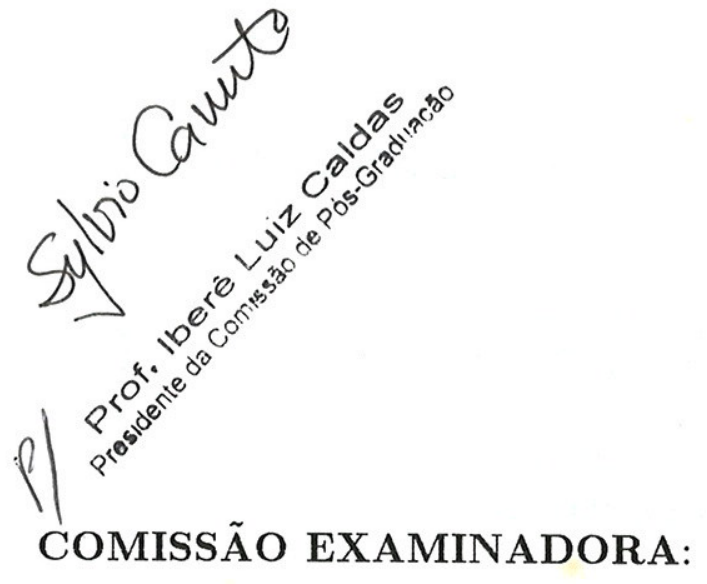

Tese apresentada ao Instituto de Física da Universidade de São Paulo para obtenção do título de Doutor em Ciências.

Orientador: Ivan C. Nascimento

PROF. DR. IVAN CUNHA NASCIMENTO (IFUSP)

PROF. DR. JOAQUIM JOSF́, BARROSO DE CASTRO (INPF)

PROF. DR. LUIZ FERNANDO ZIEBELL (UFRS)

PROF. DR. RUY PEPE DA SILVA (IFUSP)

PROF. DR. JOSIF FRENKEL (IFUSP)

São Paulo

396

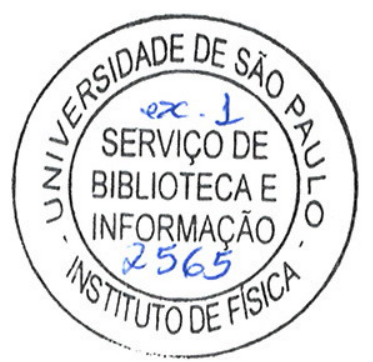




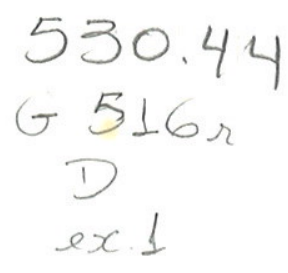

FICHA CATALOGRÁFICA

Preparada pelo Serviço de Biblioteca e Informação do Instituto de Física da Universidade de São Paulo

Giraldez, Douglas Cavalli

Ressonância Eletromagnética em Cavidades ToroidaisTeoria e Experiência.

Tese (Doutorado) Universidade de São Paulo. Instituto de Física. Departamento de Física Aplicada.

Área de Concentração: Física Nuclear

Orientador: Prof. Dr. Ivan Cunha Nascimento

Unitermos: 1. Aquecimento de Plasmas por RF;

2. Cavidades Ressonantes; 3. Ressonâncias Eletromagnéticas (ondas); 4. Solução da Equação de Onda. 


\section{RESUMO}

Este trabalho procura caracterizar uma cavidade eletromagnética ressonante toroidal teórica e experimentalmente. Do ponto de vista teórico, foi obtida a relação de dispersão para as auto-freqüências da cavidade resolvendo as equações de Maxwell usando teoria de perturbação. Duas soluções em ordem zero foram obtidas: uma em termos de funções hipergeométricas e outra em termos de uma série de Frobenius. Os resultados foram comparados com a literatura. Baseado nestes autovalores calculados, foi projetado e construído um toróide em cobre, com seç̧ão transversal circular e razão de aspecto 1,25 $\left(R_{0}=0.125 \mathrm{~m}\right.$ e $\left.r_{0}=0.100 \mathrm{~m}\right)$. As medidas experimentais realizadas incluem as autofreqüências e seus respectivos índices de mérito. Pelo que se sabe, estas medidas foram as primeiras feitas num toróide. Os dados experimentais também foram comparados com os resultados teóricos, permitindo estabelecer qual dos tratamentos é mais compatível com a realidade e fornecendo elementos para um aprimoramento da teoria. 


\section{ABSTRACT}

Electromagnetic resonances in a toroidal cavity are studied both theoretically and experimentally. In the theory the dispersion relation is obtained solving Maxwell's equations in the cavity using perturbation theory, as in the literature, but with two different expansions which keep the singularity for unit aspect ratio. The results are obtained in zeroth order, including toroidal effects, in terms of Frobenius series and in terms of hypergeometric functions for which the values of the eigenfrequencies can be calculated. Based on these results, a toroidal cavity in copper was constructed with aspect ratio $1.25\left(R_{0}=0.125\right.$ $\mathrm{m}$ and $\left.r_{0}=0.100 \mathrm{~m}\right)$ and circular cross section. In the experiment the eigenfrequencies and quality factor " $Q$ " are measured. This measurements are the first realized in a toroidal cavity. The experimental measurements are compared with the theoretical results, establishing the better approach and indicating new direction to the theory. 
Este trabalho é dedicado ao meu pai, que garantiu os meios para que eu chegasse até aqui. 


\section{AGRADECIMENTOS}

- Ao Prof. Dr. Ivan Cunha Nascimento pela orientação neste trabalho, mas, sobretudo, pelo incentivo e confiança em todas as minhas iniciativas.

- Ao Prof. Dr. Ricardo M.O. Galvão pela disposição em discutir inúmeros aspectos teóricos e experimentais deste trabalho.

- Ao Prof. Dr. José Kleber C. Pinto pelo empréstimo dos equipamentos do Laboratório de Micro-Eletrônica da EPUSP, o que viabilizou as medidas experimentais deste trabalho.

- Ao Prof. Dr. Antonio Ferreira pela colaboração no desenvolvimento da teoria.

- Ao Francisco Tadeu Degasperi pelas sugestões na solução dos problemas mecânicos envolvendo a cavidade.

- Ao Sr. Donato (Chefe da Oficina Mecânica Central do IFUSP) por ter atendido prontamente, e sempre com boa vontade, às minhas solicitações por serviços da Oficina.

- Ao Jair (Pereira de Souza, Técnico do Laboratório de Micro-Eletrônica da EPUSP) pela ajuda no manuseio dos equipamentos de medida.

- Entre os meus colegas bolsistas, quero agradecer especialmente ao José Antonio e ao Ibrahim pela amizade e confiança; que, espero, não terminem junto com este trabalho.

- Finalmente, quero agradecer a todos os demais membros do Laboratório de Física de Plasma do IFUSP pelo bom ambiente de trabalho proporcionado. 


\section{Índice}

1 INTRODUÇÃO

2 TEORIA 6

2.1 Contribuições Anteriores ao Problema . . . . . . . . . . . . . . . . . 6

2.2 O Vetor de Hertz . . . . . . . . . . . . . . . . . . . . . . . . . . . 12

2.3 As Coordenadas Toroidais . . . . . . . . . . . . . . . . . . . . . 14

2.4 A Equação de Onda para o Vetor de Hertz . . . . . . . . . . . . . . . . . . 20

2.5 As Expansões do Termo de Propagação . . . . . . . . . . . . . . . . . . 21

2.6 As Soluções da Equação de Onda . . . . . . . . . . . . . . . . . . . . . 24

2.6.1 A Solução usando a Série de Fourier . . . . . . . . . . . . . . . . . 24

2.6.2 A Solução usando a Série de Senos . . . . . . . . . . . . . 28

2.7 As Condições de Contorno e a Relação de

Dispersão . . . . . . . . . . . . . . . . . . . . . . . . 32

2.7.1 Compatibilização da Representação dos Campos . . . . . . . . . . . 32

2.7.2 A Relação de Dispersão . . . . . . . . . . . . . . . . . . . . . . 34

3 ARRANJO EXPERIMENTAL $\quad 40$

3.1 Projeto e Construção da Cavidade Toroidal . . . . . . . . . . . . . . . 40

3.2 Preparação da Cavidade . . . . . . . . . . . . . . . . . . . 41

3.2.1 Conferindo as Dimensões da Câmara Toroidal com os

Valores de Projeto . . . . . . . . . . . . . . . . . . . . . . 42 
3.2.2 Regularização das Bordas das Conchas Toroidais . . . . . . . . . . . . 42

3.2.3 Projeto e Construção do Suporte para a Cavidade . . . . . . . . . . 43

3.2.4 Construção e Instalaçãa das Antenas para Fxcitação da Cavidade . . . . . . . . . . . . . . . . . . 43

3.2.5 Cuidados Finais com a Cavidade . . . . . . . . . . . . . 45

4 DADOS EXPERIMENTAIS $\quad 49$

4.1 Últimos Ajustes Experimentais da Cavidade . . . . . . . . . . . . . . . . . 50

4.2 Descrição do Equipamento de Medida . . . . . . . . . . . . . . . . . . 50

4.3 Aspectos Experimentais da Instalação das

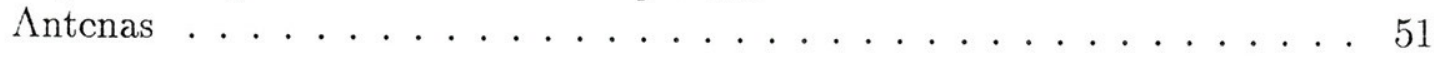

4.4 Obtenção dos Dados . . . . . . . . . . . . . . . . . . 52

4.4 .1 Excitação da Cavidade pelo Topo . . . . . . . . . . . . . . . . 53

4.4 .2 Excitação da Cavidade pelo Equador . . . . . . . . . . . . . . . 54

4.4 .3 Dados Complementares . . . . . . . . . . . . . . . 55

4.5 Resumo dos Dados Obtidos . . . . . . . . . . . . . 55

$5 \quad$ ANÁlise dos RESULTADOS

5.1 Análise dos Resultados Teóricos . . . . . . . . . . . . . . . . . 73

5.2 Análise dos Dados Experimentais . . . . . . . . . . . . . 75

6 OBSERVAÇÕES FINAIS

6.1 Conclusões . . . . . . . . . . . . . . . . . . . 81

6.2 Indicações para Desenvolvimentos Futuros . . . . . . . . . . . . . . . . 82

A DESENHOS TÉCNICOS

B REFERENCIAS $\quad 92$ 


\section{Capítulo 1}

\section{INTRODUÇÃO}

$\mathrm{O}$ aquecimento do plasma por ondas eletromagnéticas na faixa de rádio-frequiência apresenta um bom número de alternativas [1]: ondas de Alfvén, ressonância íon-ciclotrônica, amortecimento de Landau dos elétrons na região da frequiência híbrida inferior e ressonância elétron-ciclotrônica. Cada um destes esquemas, cujas frequiências se estendem desde alguns $\mathrm{MHz}$ até centenas de $\mathrm{GHz}$, têm características próprias que limitam o seu desempenho; em alguns casos o limite é de natureza física, mas aspectos tecnológicos são relevantes, também.

As antenas para aquecimento por ondas de Alfvén [1] precisam estar muito próximas da borda do plasma para permitir o acoplamento. Isto pode provocar a contaminação do plasma pelo material da antena, aumentando o $Z_{\text {ef }}$ e as perdas por radiação; paralelamente, um acoplamento parasita, na forma de uma corrente fluindo da antena para o plasma, pode se estabelecer também. Para evitar estes problemas, os elementos constitutivos da antena precisam ser recobertos com nitreto de boro, por exemplo; o que altera as características da sua superfície, tornando-a mais resistente à agressão do plasma. Além disto, todo o conjunto deve scr blindado por uma tcla de Faraday. É claro que dependendo da complexidade do desenho da antena estas providências não são tarefas simples.

$\mathrm{O}$ aquecimento do plasma por ondas íon-ciclotrônicas [1] é o mais difundido e bem sucedido até o momento. Ele é muito eficiente no aumento da temperatura eletrônica, mas pode reduzir bastante o tempo de confinamento de energia, se não forem tomados certos cuidados que evitem a contaminação do plasma por impurezas; assim, embora as antenas sejam de um desenho mais simples, comparadas com aquelas para as ondas de Alfvén, elas requerem uma proteção de carbono ou outro elemento de baixo número atômico. Além disto, elas também precisam estar protegidas por uma tela de Faraday. Adicionalmente, em tokamaks onde é possível a transição entre os modos L e H, o sistema de aquecimento pode apresentar um outro problema. Nesta transição, costuma ocorrer um aumento da. distância que separa o plasma da antena; se o sistema tiver um circuito de realimentação para manter a potência de entrada constante, o que é freqüente, ele pode interpretar aquele aumento como uma redução no nível de potência, o que levaria a um acréscimo da tensão no conjunto do sistema, com a possibilidade de ruptura. 
Vê-se, portanto, que o aquecimento do plasma por ondas íon-ciclotrônicas num futuro reator seria muito complexo.

As experiências recentes na faixa de freqüência da ressonância híbrida inferior [1] têm apresentado resultados muito promissores. Contudo, por força das condições físicas necessárias à propagação da onda $\left(n_{\text {corte }}<n_{p}<n_{\text {acess }}\right)$, a antena para acoplamento da onda com o plasma fica em contato permanente com a borda deste, recebendo uma fração grande da energia e das partículas perdidas pelo plasma, o que provoca "sputtering" do material da antena. Isto compromete a durabilidade da estrutura radiante, cujo custo é expressivo, e num reator exigiria a troca freqüente da própria estrutura, com a consequente interrupção do funcionamento do reator, o que tornaria o sistema inviável comercialmente. Além disto, é preciso cuidar da contaminação do plasma por partículas provenientes daquele "sputtering". Da mesma forma, devido à sua concepção (uma grade de guias de onda retangulares) a antena para aquecimento por onda híbrida inferior precisa estar sob vácuo permanentemente, para evitar descargas entre as paredes dos guias, o que pode ocorrer se partículas do plasma penetrarem na antena.

Ao contrário dos outros três esquemas de aquecimento do plasma por rádio-freqüência, a antena para ressonância elétron-ciclotrônica é bastante simples [1]. Pode ser a saída de um guia de onda, por exemplo. Isto minimiza os problemas de contaminação do plasma. por impurezas provenientes da antena; do mesmo modo, a alta freqüência da onda permite que a antena fique distante da borda do plasma. No entanto, as fontes de potência nesta faixa de freqüência ainda estão em desenvolvimento (gyrotrons e lasers de elétrons livres), o que tem limitado o número de experimentos e torna incerta a aplicabilidade deste tipo de aquecimento.

A motivação para este trabalho foi buscar uma alternativa a todos os problemas envolvendo o aquecimento do plasma por rádio-freqüêencia. A idéia é tratar o toróide como uma cavidade ressonante na faixa de microondas, cujo meio - no caso o plasma - absorveria energia dos modos normais de oscilação. Este trabalho descreve, estritamente, as etapas iniciais desta nova abordagem. Assim, procurou-se caracterizar teórica e experimentalmente uma cavidade toroidal ressonante, mas sem plasma. A posterior inclusão do plasma no problema poderá permitir a implantação de um sistema radiante no tokamak TCA/BR, que está em fase de montagem no Laboratório de Física de Plasma do IFUSP, ou mesmo num tokamak esférico, uma vez que pelos resultados a serem apresentados, quanto menor a razão de aspecto do toróide, maior a separação entre as freqüências dos modos ressonantes. Além disto, note-se que os resultados, de um modo geral, são de intcresse cm Tcoria de Circuitos de Microondas, Física das Fibras Ópticas c $\Lambda$ nćis de Armazenagem.

A caracterização experimental de uma cavidade toroidal com secção transversal circular não foi empreendida ainda, pelo que se sabe. Por outro lado, o cálculo das auto-freqüências e dos automodos eletromagnéticos da cavidade já foi tentado por inúmeros autores [ 2 a 11], mas permanece um problema em aberto, pois todas as soluções obtidas até aqui são aproximadas. A dificuldade central está no fato de a equação de Helmholtz não ser separável em nenhum dos sistemas de coordenadas que possuam o toróide como uma das superfícies coordenadas. 
Os primeiros autores a conceberem o toróide como uma cavidade ressonante foram N.V.Ivanov, I.A.Kovan e E.V.Los'[2]. Neste trabalho pioneiro, eminentemente experimental, eles estavam interessados em excitar no toróide um modo semelhante aos modos $\mathrm{TM}_{01 p}$ do cilindro, com o objetivo de pré-ionizar a massa de gás a ser convertida em plasma numa descarga tokamak, e isto de tal maneira que o plasma se mantivesse longe das paredes da câmara; evitando, desse modo, a sua contaminação por impurezas de íons pesados. A relação de dispersão utilizada no modelo da descarga é a do cilindro, na qual é introduzida empiricamente uma correção toroidal.

J.D.Love [3] procurou resolver o problema na aproximação quase-eletrostática. Contudo, o primeiro trabalho que se propôs a calcular as auto-freqüências e os automodos do toróide, chamando a atenção para a sua importância no aquecimento do plasma por rádio-freqüência, foi o de M.Brambilla e U.Finzi [4]. Posteriormente, B.A.Mishustin e V.I.Shcherbakov [5] desenvolveram um modelo muito semelhante ao de Brambilla e Finzi, mas encontraram uma maneira matematicamente mais elegante de formular o problema. Fntre o final dos anos 70 até meados dos anos 80, F.Cap e diversos colaboradores produziram uma série de trabalhos em que o toróide é tratado como uma cavidade ressonante, mas somente nos dois primeiros [6,7] é que os campos foram calculados no vácuo. Além disto, ele foi o primeiro a propor uma classificação dos modos que rompeu com o padrão TE/TM encontrado no cilindro, dando inclusive esboços das configurações de campo para os modos toroidais mais baixos.

J.Lileg, B.Schnizer e, principalmente, R.Keil $[8,9,10]$ produziram em meados dos anos 80 uma série de trabalhos utilizando métodos variacionais e obtiveram resultados que concordavam com os anteriores.

Finalmente, M.S.Janaki e B.Dasgupta [11] publicaram em 1991 um trabalho que segue de perto aquele de F.Cap, mas que inovou ao fazer uso do sistema de coordenadas toroidal $(\sigma, \psi, \phi)$ para descrever as equações. Este trabalho serviu, também, de ponto de partida para a nossa tentativa de melhorar a descrição do problema; os resultados deste esforço serão apresentados no próximo Capítulo, juntamente com um resumo dos pontos mais relevantes de cada um dos trabalhos citados acima.

No Capítulo 3 é descrita a montagem do arranjo experimental, enquanto o Capítulo 4 é dedicado à obtenção dos dados.

O Capítulo 5 traz a análise dos resultados teóricos e experimentais e o Capítulo 6 as conclusões e sugestões para trabalhos futuros. 


\section{Capítulo 2}

\section{TEORIA}

Este capítulo é dedicado à apresentação dos resultados obtidos no tratamento teórico da excitação de uma cavidade ressonante toroidal com ondas eletromagnéticas.

Como observado anteriormente, a dificuldade central do problema está no fato de a equação de onda não ser separável em nenhum dos sistemas de coordenadas ortogonais, que possuam o toróide como uma de suas superfícies coordenadas.

Os avanços no tratamento teórico, obtidos neste trabalho, foram possíveis, tomando como ponto de partida trabalhos pioneiros de outros pesquisadores. Assim, para melhor clareza, é preciso apresentar um resumo das contribuições mais relevantes ao desenvolvimento do problema, onde um grande número de recursos teóricos será introduzido, mas sem uma explicação detalhada; contudo, em sua maioria, estes recursos serão explicados em detalhe, quando descrevermos o nosso próprio esforço teórico.

\subsection{Contribuições Anteriores ao Problema}

O primeiro trabalho que se prôpos a calcular as auto-freqüências e os automodos do toróide, chamando a atenção para a sua importância no aquecimento do plasma por rádio-freqüência, foi o de M.Brambilla e U.Finzi [4]. Partindo das equações de Maxwell num meio isotrópico, homogêneo e livre de cargas e correntes, e usando as coordenadas toroidais locais $(r, \theta, \phi)$, definidas como:

$$
\begin{aligned}
& x=\left(R_{0}+r \cos \theta\right) \cos \phi \\
& y=\left(R_{0}+r \cos \theta\right) \operatorname{sen} \phi \\
& z=r \operatorname{sen} \theta
\end{aligned}
$$

onde $R_{0}$ é o raio maior, $r$ é o raio da secção transversal do toróide, $\theta$ é o ângulo poloidal e $\phi$ é o ângulo toroidal; eles obtiveram um sistema de duas equações diferenciais acopladas para as componentes $F_{\phi}$ e $H_{\phi}$ do campo, ou seja: 


$$
\begin{aligned}
& \triangle_{\perp}^{c} \mathcal{E}_{\phi}+\kappa^{2} \mathcal{E}_{\phi}+\frac{\gamma^{2}+\mathrm{h}^{2}}{\gamma^{2}-\mathrm{h}^{2}} \frac{1}{\mathrm{~h}} \vec{\nabla}_{\perp} \mathrm{h} \cdot \vec{\nabla}_{\perp} \mathcal{E}_{\phi}+\frac{2 \gamma}{\gamma^{2}-\mathrm{h}^{2}}\left(\vec{\nabla}_{\perp} \mathrm{h} \times \vec{\nabla}_{\perp} \mathcal{H}_{\phi}\right) \cdot \overrightarrow{\mathrm{e}}_{\phi}=0 \\
& \triangle_{\perp}^{c} \mathcal{H}_{\phi}+\kappa^{2} \mathcal{H}_{\phi}+\frac{\gamma^{2}+\mathrm{h}^{2}}{\gamma^{2}-\mathrm{h}^{2}} \frac{1}{\mathrm{~h}} \vec{\nabla}_{\perp} \mathrm{h} \cdot \vec{\nabla}_{\perp} \mathcal{H}_{\phi}-\frac{2 \gamma}{\gamma^{2}-\mathrm{h}^{2}}\left(\vec{\nabla}_{\perp} \mathrm{h} \times \vec{\nabla}_{\perp} \mathcal{E}_{\phi}\right) \cdot \overrightarrow{\mathrm{e}}_{\phi}=0
\end{aligned}
$$

aqui $\triangle_{\perp}^{c}$ e $\vec{\nabla}_{\perp}$ são os operadores cilíndricos laplaciano e gradiente, nas variáveis $r$ e $\theta$; e $\vec{e}_{\phi}$ é o vetor unitário na direção toroidal. Além disso, eles definiram:

$$
\begin{aligned}
& h=1+\frac{r}{R_{0}} \cos \theta \\
& \mathcal{E}_{\phi}=\mathrm{h} \mathrm{E}_{\phi} \\
& \mathcal{H}_{\phi}=\mathrm{h} \mathrm{H}_{\phi} \\
& \kappa^{2}=1-\frac{\gamma^{2}}{h^{2}} \\
& \gamma=\frac{m}{R_{0}}
\end{aligned}
$$

onde $m$ é um inteiro qualquer.

O sistema foi resolvido com o uso do método de perturbação até primeira ordem, tendo como parâmetro de expansão o inverso da razão de aspecto $\left(r / R_{0}\right)$. As soluções obtidas foram expressas em termos das funções de Bessel, devendo-se notar a semelhança formal com o problema da cavidade cilíndrica. Não por acaso, os autores classificaram os modos toroidais obtidos como quase- $T E$ e quase- $T M$, dependendo do seu limite cilíndrico. As relações de dispersão são encontradas por meio das condições $E_{\phi} \cong 0$ e $\partial H_{\phi} / \partial r \cong 0$, sendo formalmente idênticas àquelas do cilindro, ou seja:

$$
\frac{\omega_{T M}}{c}=\sqrt{\frac{x_{l j}^{2}}{r_{0}^{2}}+\frac{m^{2}}{R_{0}^{2}}} \quad \text { e } \quad \frac{\omega_{T E}}{c}=\sqrt{\frac{y_{l j}^{2}}{r_{0}^{2}}+\frac{m^{2}}{R_{0}^{2}}}
$$

onde $\omega$ é a freqüência angular, $c$ é a velocidade da luz, $r_{0}$ é o raio menor do toróide e $J_{l}\left(x_{l j}\right)=0$ e $J_{l}^{\prime}\left(y_{l j}\right)=0$, onde $J_{l}$ e $J_{l}^{\prime}$ são a função de Bessel de primeira espécie e sua derivada, respectivamente.

B.A.Mishustin e V.I.Shcherbakov [5] desenvolveram um modelo muito semelhante ao de Brambilla e Finzi, pois utilizaram o mesmo sistema de coordenadas e as equações de Maxwell, mas encontraram uma maneira matematicamente mais elegante de formular o problema, introduzindo os potenciais $V$ e $U$ para a descrição do campo eletromagnético:

$$
V \cos (m \phi)=h E_{\phi} \quad \text { e } \quad U \cos (m \phi)=\sqrt{\frac{\mu_{0}}{\epsilon_{0}}} h H_{\phi}
$$


onde $m$ é um número inteiro, $\mu_{0}$ e $\epsilon_{0}$ são a permeabilidade e a permissividade do vácuo e $h$ tem o mesmo significado anterior. Do mesmo modo, foram definidos dois operadores diferenciais:

$$
\mathcal{L}=\vec{\nabla}_{\perp} \cdot\left[\frac{\mathrm{h} \vec{\nabla}_{\perp}}{(\mathrm{h} \chi)^{2}-\mathrm{m}^{2}}\right]+\frac{1}{\mathrm{~h}} \quad \text { e } \quad \mathcal{M}=-\frac{\mathrm{m}}{\chi} \overrightarrow{\mathrm{e}}_{\phi} \cdot \vec{\nabla}_{\perp} \times\left[\frac{\vec{\nabla}_{\perp}}{(\mathrm{h} \chi)^{2}-\mathrm{m}^{2}}\right]
$$

aqui $\chi=2 \pi R_{0} / \lambda$, com $R_{0}$ o raio maior do toróide e $\lambda$ o comprimento de onda do modo ressonante; $\vec{\nabla}_{\perp}$ tem o mesmo significado atribuído anteriormente.

Desta abordagem resultou um sistema de duas equações diferenciais acopladas:

$$
\mathcal{L V}+\mathcal{M U}=0 \quad \text { e } \quad \mathcal{L} \mathrm{U}-\mathcal{M V}=0
$$

Este sistema foi resolvido com o uso do método de perturbação até primeira ordem, tendo como parâmetro pequeno o inverso da razão de aspecto. As condições de contorno adequadas eram: $V\left(r_{0}\right)=0$ e $\partial U\left(r_{0}\right) / \partial r=0$. As relações de dispersão obtidas por eles foram as mesmas que Brambilla e Finzi encontraram.

Apesar das semelhanças entre os dois trabalhos, a formulação proposta por Mishustin e Shcherbakov permitiu obter um resultado original, o qual sugere que a correção de segunda ordem na descrição dos campos, só é necessária para toróides com razão de aspecto $<1.75$. Uma outra novidade introduzida por eles foi a utilização de métodos variacionais para calcular a correção de segunda ordem na freqüência de ressonância.

F.Cap e R.Deutsch [6], aparentemente sem conhecer o trabalho de Mishustin e Shcherbakov, propuseram o uso de um potencial para descrever o campo eletromagnético também. Contudo, a escolha do vetor de Hertz como potencial eletromagnético, permitiu uma grande simplificação do problema, pois o sistema de equações acopladas dos dois trabalhos anteriores, foi trocado por uma única equação de Helmholtz para qualquer uma das componentes cartesianas $\left(\Pi_{j}\right)$ do vetor de Hertz (note-se que esta equação é derivada da equação de onda):

$$
\vec{\nabla}^{2} \Pi_{j}+\mu_{0} \epsilon_{0} \omega^{2} \Pi_{j}=0
$$

Esta equação foi reescrita usando as coordenadas toroidais locais, de modo que as $\Pi_{j}$ passam a ser funções de $r, \theta$ e $\phi$ :

$\frac{\partial}{\partial \rho} \rho(1-\rho \cos \theta) \frac{\partial \Pi_{j}}{\partial \rho}+\frac{\partial}{\partial \theta} \frac{(1-\rho \cos \theta)}{\rho} \frac{\partial \Pi_{j}}{\partial \theta}+\frac{\rho}{(1-\rho \cos \theta)} \frac{\partial^{2} \Pi_{j}}{\partial \phi^{2}}+k^{2} \rho(1-\rho \cos \theta) \Pi_{j}=0$

onde $k^{2}=\mu_{0} \epsilon_{0} \omega^{2} R_{0}^{2}$ e $\rho=r / R_{0}$, com $R_{0}$ o raio maior do toróide. 
Apesar da equação acima ser inseparável, ela foi resolvida mediante a aplicação de três recursos teóricos. O primeiro deles foi a substituição de $\Pi_{j}$ por:

$$
\Pi_{j}(\rho, \theta, \phi)=\frac{\psi_{m}(\rho, \theta) e^{i m \phi}}{\sqrt{1-\rho \cos \theta}}
$$

o que conduziu à. seguinte equação:

$$
\frac{\partial^{2} \psi_{m}}{\partial \rho^{2}}+\frac{1}{\rho} \frac{\partial \psi_{m}}{\partial \rho}+\frac{1}{\rho^{2}} \frac{\partial^{2} \psi_{m}}{\partial \theta^{2}}+k^{2} \psi_{m}=\frac{m^{2}-1 / 4}{(1-\rho \cos \theta)^{2}} \psi_{m}
$$

O segundo foi a expansão do denominador $(1-\rho \cos \theta)^{2}$ em série de Taylor, o que transformou a equação acima em:

$$
\frac{1}{\rho} \frac{\partial}{\partial \rho}\left(\rho \frac{\partial \psi_{m}}{\partial \rho}\right)+\frac{1}{\rho^{2}} \frac{\partial^{2} \psi_{m}}{\partial \theta^{2}}+\kappa^{2} \psi_{m}=\mu^{2} \psi_{m} \sum_{n=1}^{\infty}(n+1) \rho^{n} \cos ^{n} \theta
$$

onde $\kappa^{2}=k^{2}-m^{2}+1 / 4$ e $\mu^{2}=m^{2}-1 / 4$.

O último recurso foi o uso do método de perturbação para resolver a equação acima, tendo como parâmetro de expansão $\rho=r / R_{0}(<1)$.

Ao aplicar o método perturbativo, Cap e Deutsch apresentam as equações de ordem zero, um, dois e três, onde se torna claro que as variáveis radial $(\rho)$ e poloidal $(\theta)$ se separam. Contudo, somente as soluções de ordem zero e um são dadas explicitamente, as quais foram obtidas em termos das funções de Bessel. No entanto, para construir a solução aproximada da equação acima, Cap e Deutsch fizeram uso das soluções de ordem superior não apresentadas, ao proporem que:

$$
\psi_{m} \cong \psi_{m, \nu=0}+\psi_{m, \nu=1}+\psi_{m, \nu=2}+\psi_{m, \nu=3}+\psi_{m, \nu=4}
$$

$\operatorname{com} \nu$ a constante de separação da variável poloidal $(\theta)$. Além disso, cada parcela $\psi_{m, \nu}$ inclui termos até $\cos (4 \theta)$, que só aparecem à medida que ordens superiores são consideradas também.

Analizando a condição de contorno $B_{\rho}=0$, Cap e Deutsch chegaram à conclusão que ela é equivalente a $\psi_{m}=0$. Esta equação corresponde à relação de dispersão procurada e as suas raízes, encontradas numericamente, foram comparadas com 2,4048255577, a primeira raiz de $J_{0}(\kappa \rho)$. O resultado foi:

$$
\frac{\kappa \rho_{0}-2,4048255577}{\kappa \rho_{0}}<10^{-3}
$$


com $\kappa \rho_{0}$ uma raiz numérica de $\psi_{m}$.

Baseados neste resultado, eles concluiram que a aproximação $\psi_{m}=A J_{0}(\kappa \rho)$ era bastante boa para descrever os campos no interior do toróide e que $\kappa \rho_{0}=2.4028$ era, igualmente, uma boa aproximação para o a.utovalor.

A partir destas considerações chegaram à relação de dispersão final:

$$
\omega^{2}=\left(\frac{5,7832}{\rho_{0}^{2}}+m^{2}-\frac{1}{4}\right) \frac{c^{2}}{R_{0}^{2}}
$$

Observe-se que o termo 1/4 na expressão acima, corresponde a uma correção toroidal na relação de dispersão; um fato novo, se comparado aos resultados precedentes.

A partir deste ponto, Cap e Deutsch se dedicaram à descrição da estrutura dos modos ressonantes, dando esboços das linhas de campo no interior do toróide e esquemas das distribuições de cargas e correntes na superfície da cavidade. Este esforço deu origem a uma classificação dos modos inteiramente nova, rompendo com o padrão $T E / T M$ herdado do cilindro, pois reconheceu que os campos numa cavidade toroidal apresentam sempre seis componentes. Este fato, embora observado nos trabalhos anteriores, não tinha sido considerado em toda sua extensão. Outra consequência desta descrição, foi reconhecer que os modos são degenerados.

O trabalho de Cap e Deutsch ainda influenciou o de M.S.Janaki e B.Dasgupta [11], pois estes dois indianos tomaram como ponto de partida a mesma descrição do campo eletromagnético pelo vetor de Hertz. No entanto, as equações foram escritas usando as coordenadas toroidais $(\sigma, \psi, \phi)$, cuja transformação é dada por:

$$
\begin{aligned}
& x=\frac{a \operatorname{senh} \sigma}{\cosh \sigma-\cos \psi} \cos \phi \\
& y=\frac{a \operatorname{senh} \sigma}{\cosh \sigma-\cos \psi} \operatorname{sen} \phi \\
& z=\frac{a \operatorname{sen} \psi}{\cosh \sigma-\cos \psi}
\end{aligned}
$$

onde $a$ é um parâmetro, $\sigma$ é a coordenada radial, $\psi$ assemelha-se ao ângulo poloidal e $\phi$ é o ângulo toroidal. Com isso, a equação de Helmholtz para qualquer uma das componentes cartcsianas do vetor de Hcrtz ficou:

$$
\frac{\partial}{\partial s}\left[\left(s^{2}-1\right) \frac{\partial P_{j}}{\partial s}\right]+\frac{\partial^{2} P_{j}}{\partial \psi^{2}}+\frac{P_{j}}{4}+\frac{1}{s^{2}-1} \frac{\partial^{2} P_{j}}{\partial \phi^{2}}+\frac{k^{2} a^{2}}{(s-\cos \psi)^{2}} P_{j}=0
$$

onde as definições:

$$
s=\cosh \sigma \quad \text { e } \quad P_{j}(s, \psi, \phi)=\frac{\Pi_{j}(s, \psi, \phi)}{\sqrt{s-\cos \psi}}
$$


foram usadas. Reitere-se que $\Pi_{j}$ é uma componente cartesiana do vetor de Hertz.

A equação acima é inseparável, tal como a sua congênere em coordenadas toroidais locais, mas foi resolvida por Janaki e Dasgupta mediante os mesmos recursos teóricos usados por Cap e Deutsch. Primeiro a substituição $P_{j}(s, \psi, \phi)=P(s, \psi) e^{i m \phi}$ separou a coordenada toroidal $\phi$; em seguida, a expansão em série de Taylor, em torno de $s=0$, do fator $(s-\cos \psi)^{-2}$ e a aplicação do método de perturbação, adotando como parâmetro pequeno $1 / s$, produziu um conjunto de equações ordenadas, das quais a equação de ordem zero é:

$$
\frac{\partial}{\partial s}\left[\left(s^{2}-1\right) \frac{\partial P_{0}}{\partial s}\right]+\frac{\partial^{2} P_{0}}{\partial \psi^{2}}+\left(\frac{1}{4}-\frac{m^{2}}{s^{2}-1}\right) P_{0}+\frac{k^{2} a^{2}}{s^{2}} P_{0}=0
$$

onde $P_{0}$ é o termo de ordem zero na expansão de $P(s, \psi)$.

A equação acima é separável e foi resolvida por Janaki e Dasgupta, conduzindo a uma relação de dispersão para os modos ressonantes numa cavidade toroidal. Para encontrar a sua solução as seguintes substituições foram feitas:

$$
\begin{aligned}
& P_{0}(s, \psi)=\sum_{l=0}^{\infty} P_{0 l}(s) \cos (l \psi) \\
& y=1 / s^{2} \\
& P_{0 l}=\left(s^{2}-1\right)^{m / 2} s^{-(m+l+1 / 2)} F(s)
\end{aligned}
$$

convertendo a. equação anterior em:

$$
y(y-1) \frac{d^{2} F}{d y^{2}}+[(\alpha+\beta+1) y-\gamma] \frac{d F}{d y}+\alpha \beta F=0
$$

onde:

$$
\begin{aligned}
\alpha & =\frac{1}{2}[m+l+1+\chi] \\
\beta & =\frac{1}{2}[m+l+1-\chi] \\
\gamma & =l+1 \\
\chi & =\sqrt{\frac{1}{4}+k^{2} a^{2}}
\end{aligned}
$$

A equação acima é a equação hipergeométrica de Gauss, cujas soluções são conhecidas e representadas por uma série infinita.

A partir deste resultado, Janaki e Dasgupta, reconstruiram o vetor de Hertz e por meio dele obtiveram as componentes do campo eletromagnético sobre as quais recaem as condições de contorno $\left(B_{\sigma}\left(s_{0}\right)=E_{\psi}\left(s_{0}\right)=E_{\phi}\left(s_{0}\right)=0\right)$. Note-se que as componentes 
do campo que se anulam na superfície $s_{0}$ da cavidade são as componentes toroidais. Como o vetor de Hertz é obtido em coordenadas cartesianas, foi preciso encontrar as suas componentes toroidais por meio de uma transformação adequada, para em seguida calcular os campos. Neste processo, os autores fizeram a hipótese complementar: $\Pi_{x}=\Pi_{y}=0$, $\operatorname{com} \Pi_{z} \neq 0$. As expressões para $B_{\sigma}, E_{\psi}$ e $E_{\phi}$, resultaram numa soma envolvendo parcelas proporcionais a $F(m, l, s)$ e à sua derivada, onde:

$$
F(m, l, s) \equiv\left(s^{2}-1\right)^{m / 2} s^{-(m+l+1 / 2)} \cdot{ }_{2} F_{1}\left(\alpha, \beta, \gamma, 1 / s^{2}\right)
$$

Finalmente, a imposição das condições de contorno $\left(B_{\sigma}\left(s_{0}\right)=E_{\psi}\left(s_{0}\right)=E_{\phi}\left(s_{0}\right)=0\right)$ conduziı à. relação de dispersão procurada:

$$
F\left(m, l, s_{0}\right)=0
$$

Janaki e Dasgupta fazem dois comentários sobre esta relação: primeiro que para obtêla, as parcelas proporcionais à derivada de $F(m, l, s)$ foram descartadas em comparação com aquelas proporcionais à própria função, uma vez que a derivada é um termo de ordem superior em $1 / s$ e, portanto, de menor magnitude. Segundo, as raízes da equação só podem ser encontradas numericamente, o que eles fizeram para os casos $l=0,1$ e 2 e $m=0,1$ e 2 , apresentando os resultados graficamente.

Assim como Cap e Deutsch, Janaki e Dasgupta também reconhecem que a classificação dos modos toroidais não admite o padrão $T E / T M$ do cilindro. Apesar disso, eles demonstram que as suas soluções se reduzem àquelas do cilindro no limite apropriado.

No decorrer deste trabalho, os resultados de todos estes autores serão comparados com os nossos próprios resultados, para os quais se adotou o seguinte esquema de apresentação: introduz-se o vetor de Hertz $\vec{\Pi}$ e as coordenadas toroidais, em seguida se apresentam a equação a ser resolvida e as dificuldades a serem contornadas, bem como a maneira escolhida para isso; posteriormente, as expansões usadas são mostradas e as suas soluções correspondentes obtidas. A partir das soluções e das condições de contorno chega-se à relação de dispersão, que serviu de base para o projeto e construção de uma cavidade toroidal a ser utilizada nas medidas experimentais.

\subsection{O Vetor de Hertz}

O ponto de partida para se definir o vetor de Hertz $\vec{\Pi}$ são as equações de Maxwell num meio isotrópico, homogêneo e livre de cargas e correntes, ou seja [12]:

$$
\vec{\nabla} \times \vec{E}+\frac{\partial \vec{B}}{\partial t}=0 \quad(a) \quad \vec{\nabla} \cdot \vec{B}=0
$$




$$
\vec{\nabla} \times \vec{H}-\frac{\partial \vec{D}}{\partial t}=0 \quad(b) \quad \vec{\nabla} \cdot \vec{D}=0 \quad(d)
$$

Posteriormente, admite-se que o potencial vetor $\vec{A}$ seja proporcional à derivada temporal deste vetor $\vec{\Pi}$, isto é:

$$
\vec{A}=\mu \epsilon \frac{\partial \vec{\Pi}}{\partial t}
$$

consequentemente,

$$
\vec{B}=\mu \epsilon \vec{\nabla} \times \frac{\partial \vec{\Pi}}{\partial t}
$$

e

$$
\vec{E}=-\vec{\nabla} \Phi-\mu \epsilon \frac{\partial^{2} \vec{\Pi}}{\partial t^{2}}
$$

onde $\Phi$ é o potencial escalar.

Substituindo (3) e (4) em (1b), obtém-se:

$$
\frac{\partial}{\partial t}\left(\vec{\nabla} \times \vec{\nabla} \times \vec{\Pi}+\vec{\nabla} \Phi+\mu \epsilon \frac{\partial^{2} \vec{\Pi}}{\partial t^{2}}\right)=0
$$

Dada as condições do meio, a função escalar $\Phi$ é inteiramente arbitrária, desde que satisfaça a equação:

$$
\vec{\nabla}^{2} \Phi-\mu \epsilon \frac{\partial^{2} \Phi}{\partial t^{2}}=0
$$

Por ora se escolhe,

$$
\Phi=-\vec{\nabla} \cdot \vec{\Pi}
$$

Integrando a equação (5) com relação ao tempo vem:

$$
\vec{\nabla} \times \vec{\nabla} \times \vec{\Pi}-\vec{\nabla}(\vec{\nabla} \cdot \vec{\Pi})+\mu \epsilon \frac{\partial^{2} \vec{\Pi}}{\partial t^{2}}=0
$$

onde a constante de integração foi escolhida igual a zero.

Usando a seguinte identidade vetorial,

$$
\vec{\nabla}^{2} \vec{u}=\vec{\nabla}(\vec{\nabla} \cdot \vec{u})-\vec{\nabla} \times \vec{\nabla} \times \vec{u}
$$


a equação (8) pode ser reescrita, dando finalmente:

$$
\vec{\nabla}^{2} \vec{\Pi}-\mu \epsilon \frac{\partial^{2} \vec{\Pi}}{\partial t^{2}}=0
$$

onde deve ficar claro que o laplaciano atua sobre as componentes cartesianas de $\vec{\Pi}$. Observe-se que aplicando o operador $(-\vec{\nabla}$. $)$ sobre a equação acima e considerando a definição de $\Phi$, dada pela equação (7), se obtém a equação (6). No entanto, ainda falta determinar o significado físico do vetor de Hertz $\vec{\Pi}$. Para isso, é preciso encontrar as suas fontes, o que requer que o vetor deslocamento elétrico $\vec{D}$ seja escrito como:

$$
\vec{D}=\epsilon_{0} \vec{E}+\vec{P}
$$

Substituindo esta expressão na equação (1b) e repetindo todo o procedimento exposto acima, se chega a:

$$
\vec{\nabla}^{2} \vec{\Pi}-\mu \epsilon_{0} \frac{\partial^{2} \vec{\Pi}}{\partial t^{2}}=-\frac{\vec{P}}{\epsilon_{0}}
$$

Pela equação (12), vê-se que o vetor de Hertz $\vec{\Pi}$ corresponde ao campo produzido por uma distribuição volumétrica de momemto de dipolo elétrico $\vec{P}$ [12].

Diante destes resultados, os campos elétrico $\vec{E}$ e magnético $\vec{B}$ são obtidos a partir das seguintes equações [12]:

$\mathrm{e}$

$$
\vec{E}=\vec{\nabla}(\vec{\nabla} \cdot \vec{\Pi})-\mu_{0} \epsilon_{0} \frac{\partial^{2} \vec{\Pi}}{\partial t^{2}}
$$

$$
\vec{B}=\mu_{0} \epsilon_{0} \vec{\nabla} \times \frac{\partial \vec{\Pi}}{\partial t}
$$

Note-se que a equação (10), escrita em coordenadas torodais, é o ponto de partida para a. formulação do problema.

\subsection{As Coordenadas Toroidais}

As coordenadas toroidais $(\sigma, \psi, \phi)$ pertencem a uma família de sistemas coordenados que derivam do sistema de coordenadas bipolar. Este, por sua vez, provem de uma transformação conforme aplicada ao plano xy. Esta transformação, dada por [13]: 


$$
x=\frac{a \operatorname{senh} \sigma}{\cosh \sigma-\cos \psi}
$$

e

$$
y=\frac{a \operatorname{sen} \psi}{\cosh \sigma-\cos \psi}
$$

gera dois conjuntos de circunferências ortogonais entre si $(\sigma=C T E$ e $\psi=C T E)$, como mostrado na figura abaixo.

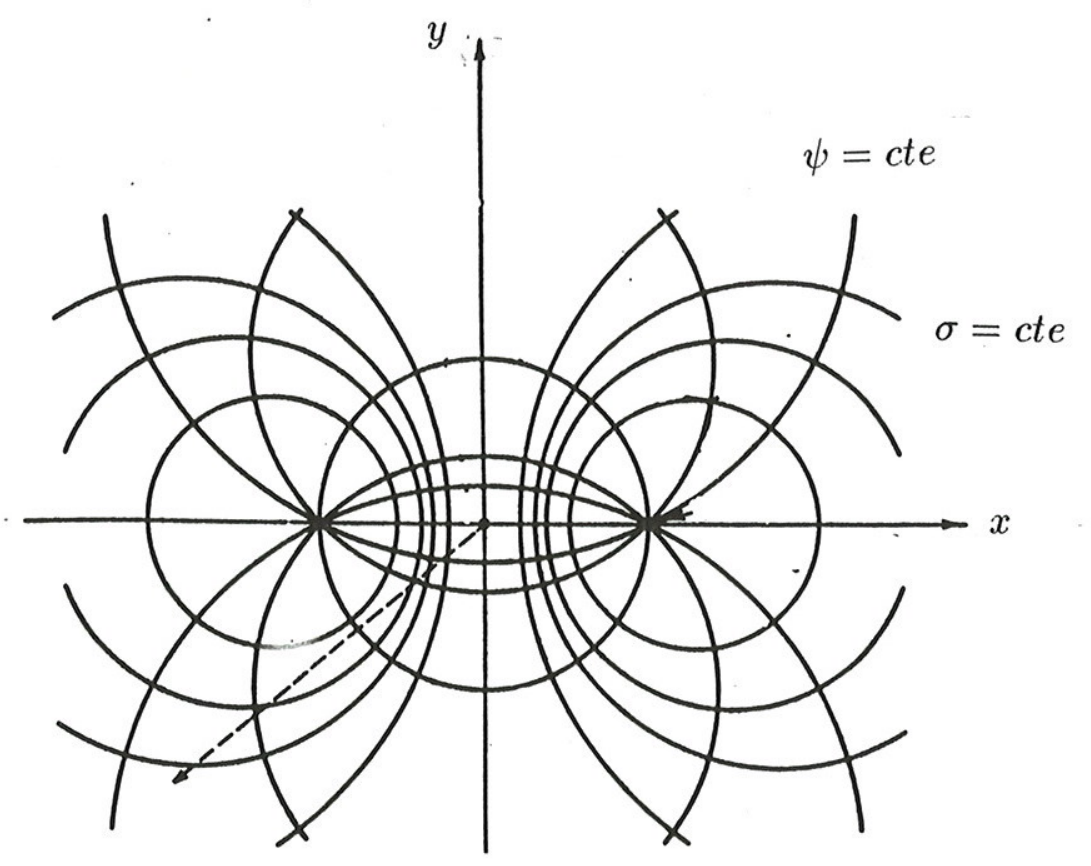

Figura 2.1 : Sistema de Coordenadas Bipolar.

$\sigma=c t e$ geram circunferências com centro sobre o eixo $\mathrm{x}$ $\psi=$ cte geram circunferências com centro sobre o eixo $\mathrm{y}$ 
O sistema de coordenadas toroidal é obtido rodando as circunferências da figura acima em torno do eixo y, rebatizado de eixo z depois da rotação (Figura 2). As superfícies com $\sigma=C T E$ são toróides, aquelas com $\psi=C T E$ são calotas esféricas e $\phi=C T E$ define semi-planos através do eixo de simetria (Figura 2). Este eixo, como observado acima, é chamado o eixo $z$ no espaço tridimensional. Os pontos em que $z>0(z<0)$ correspondem a $\psi>0(\psi<0)$ também (Figura 2). Por isso, $\psi$ varia de $-\pi$ a $\pi$, enquanto $\sigma$ varia de 0 a $\infty$ e $\phi$ de 0 a $2 \pi$. As coordenadas são caracterizadas pelas equações [13]:

$$
\begin{aligned}
& x=\frac{a \operatorname{senh} \sigma}{\cosh \sigma-\cos \psi} \cos \phi \\
& y=\frac{a \operatorname{senh} \sigma}{\cosh \sigma-\cos \psi} \operatorname{sen} \phi
\end{aligned}
$$

$\mathrm{e}$

$$
z=\frac{a \operatorname{sen} \psi}{\cosh \sigma-\cos \psi}
$$

e os coeficientes métricos, por sua vez, são dados por:

$$
h_{\sigma}=h_{\psi}=\frac{a}{\cosh \sigma-\cos \psi}
$$

$\mathrm{e}$

$$
h_{\phi}=\frac{a \operatorname{senh} \sigma}{\cosh \sigma-\cos \psi}
$$

Tomando $\phi=0$ nas equações (17), (18) e (19), a transformação de coordenadas reduzse a:

$$
\begin{aligned}
& x=\frac{a \operatorname{senh} \sigma}{\cosh \sigma-\cos \psi} \\
& y=0
\end{aligned}
$$

$\mathrm{e}$

$$
z=\frac{a \operatorname{sen} \psi}{\cosh \sigma-\cos \psi}
$$

As curvas onde $\sigma=C T E$ (secções transversais dos toróides) e $\psi=C T E$ (secções transversais das calotas esféricas) estão representadas na Figura 1. Note que as circunferências de $\sigma=C T E$ têm o seu centro sobre o eixo $x$, enquanto que as circunferências de $\psi=C T E$ estão centradas sobre o eixo $z$. Considerando as equações acima e dividindo $x$ por $z$, se obtem:

$$
\frac{x}{z}=\frac{\operatorname{senh} \sigma}{\operatorname{sen} \psi}
$$




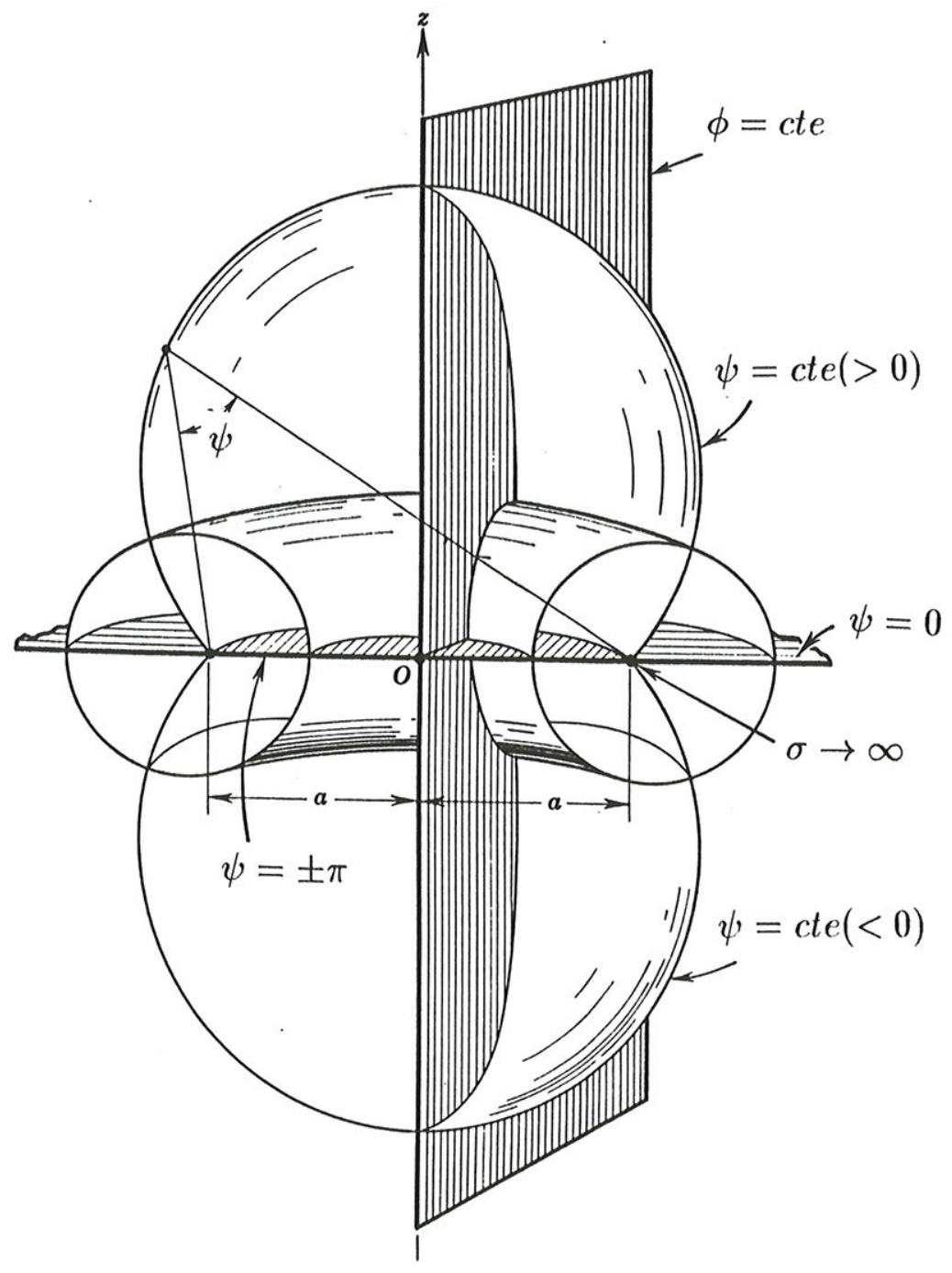

Figura 2.2 : Sistema de Coordenadas Toroidal.

$\sigma=c t e$ gera uma superfície toroidal

$\psi=$ cte gera uma calota esférica

$\phi=$ cte gera um semi-plano infinito 
Esta relação pode ser usada para eliminar a variável $\psi$ na equação (22), o que conduz a:

$$
(x-a \operatorname{cotgh} \sigma)^{2}+z^{2}=a^{2} \operatorname{cosech}^{2} \sigma
$$

Comparando esta equação com a equação de uma circunferência com centro sobre o eixo $x$ :

$$
(x-R)^{2}+z^{2}=r^{2}
$$

é imediato que:

$$
R=a \operatorname{cotgh} \sigma \quad e \quad r=a \operatorname{cosech} \sigma
$$

Lembrando que esta circunferência corresponde à secção transversal de um toróide, $\mathbf{R}$ pode ser interpretado como o seu raio maior e $\mathbf{r}$ como o seu raio menor. Note que tanto $11 \mathrm{~m}$, como o outro, depende de $\sigma$; em particular, se $\sigma \rightarrow \infty, R \rightarrow a$ e $r \rightarrow 0$; o que leva as soluções da equação (27) a: $x=a$ e $z=0$. Neste limite, portanto, o toro se degenera numa circunferência de raio "a", inserida no plano $x y$ (Figura 2).

É possível, agora, montar o seguinte quadro: $\sigma=\sigma_{0}=C T E$ define um toróide de raio maior $R_{0}\left(=a \operatorname{cotgh} \sigma_{0}\right)$ e raio menor $r_{0}\left(=a \operatorname{cosech} \sigma_{0}\right)$; à medida que se consideram valores de $\sigma>\sigma_{0}$, pontos internos ao toróide inicial são atingidos, uma vez que $R$ e $r$ diminuem até o limite em que $R=a$ e $r=0$. Como todo $\sigma$ define uma superfície toroidal, o aspecto do conjunto é o de uma "cebola"(Figura 3).

A partir das definições dadas em (28) é fácil verificar que:

$$
s \equiv \frac{R}{r}=\cosh \sigma
$$

$\mathrm{e}$

$$
a^{2}=R^{2}-r^{2}
$$

$\operatorname{com} \boldsymbol{s}=\frac{\boldsymbol{R}}{\boldsymbol{r}}$ a razão de aspecto do toróide . Note-se que $\sigma=\sigma_{0}=C T E$ implica que o $\cosh \sigma_{0}=\frac{R_{0}}{r_{0}}=s_{0}=C T E$, o que permite identificar uma dada superfície toroidal pelo valor de $s_{0}$ também. Observe-se, ainda, que $s$ varia desde 1 até $+\infty$ e que o interior de um particular toróide $s=s_{0}$, é descrito por $s_{0}<s<+\infty$. Isto possibilita a troca de $\sigma$ por $s$ como coordenada nas equações (17), (18) e (19); com a vantagem que o significado geométrico de $s$ é bastante claro.

Do mesmo modo, é preciso chamar a atenção para o fato do ponto à distância " $a$ " do eixo de simetria (Figuras 1 e 2) desempenhar o papel de um foco no sistema de coordenadas, sendo o valor desta distância arbitrário inicialmente. Esta arbitrariedade é que permite varrer todo o espaço físico, uma vez que o valor de " $a^{3}$ " determina a ordem de grandeza do volume descrito. 


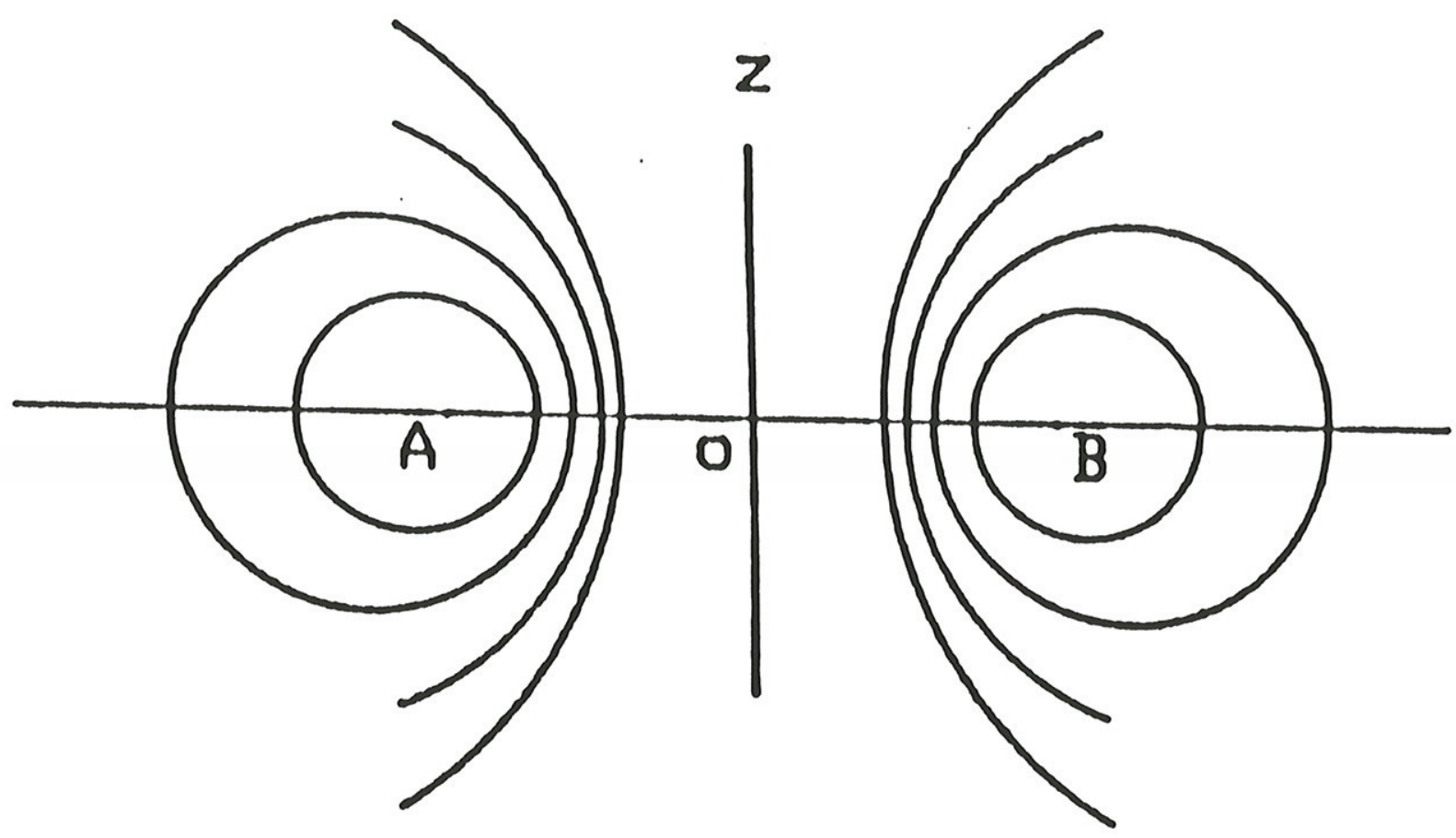

Figura 2.3 : Seç̧ão Transversal de um Conjunto de Superfícies Toroidais $\left(s_{0}=\right.$ cte). 
A representação de um vetor em coordenadas toroidais, partindo das suas componentes cartesianas, também requer uma transformação apropriada. Esta é [11]:

$$
\begin{gathered}
\Pi_{\sigma}=\frac{1-\cosh \sigma \cos \psi}{\cosh \sigma-\cos \psi}\left[\cos \phi \Pi_{x}+\operatorname{sen} \phi \Pi_{y}\right]-\frac{\operatorname{senh} \sigma \operatorname{sen} \psi}{\cosh \sigma-\cos \psi} \Pi_{z} \\
\Pi_{\psi}=-\frac{\operatorname{senh} \sigma \operatorname{sen} \psi}{\cosh \sigma-\cos \psi}\left[\cos \phi \Pi_{x}+\operatorname{sen} \phi \Pi_{y}\right]-\frac{1-\cosh \sigma \cos \psi}{\cosh \sigma-\cos \psi} \Pi_{z} \\
\Pi_{\phi}=-\operatorname{sen} \phi \Pi_{x}+\cos \phi \Pi_{y}
\end{gathered}
$$

onde $\Pi_{\sigma, \psi, \phi}$ e $\Pi_{x, y, z}$ representam as componentes toroidais e cartesianas do vetor $\vec{\Pi}$, respectivamente.

\subsection{A Equação de Onda para o Vetor de Hertz}

O laplaciano presente na equação (10) deve ser entendido como atuando sobre as componentes cartesianas do vetor de Hertz $\vec{\Pi}$, que se supõe seja proporcional a $e^{i \omega t}$, já que o interesse está em determinar os modos normais da cavidade toroidal. Considerando isto, a equação (10) pode ser reescrita como:

$$
\vec{\nabla}^{2} \Pi_{j}+\mu_{0} \epsilon_{0} \omega^{2} \Pi_{j}=0
$$

onde $j=x, y, z$ e $\omega$ é a freqüência angular de um modo normal.

Resolvendo esta equação, as expressões para $\Pi_{x, y, z}$ são encontradas e através da transformação (31) as expressões para $\Pi_{\sigma, \psi, \phi}$ também. Destas, se obtêm os campos elétrico $\vec{E} \mathrm{e}$ magnético $\vec{B}$ fazendo uso das equações (13) e (14). Este procedimento, devido a Cap [6], evita o sistema de equações acopladas que caracterizaram os primeiros trabalhos teóricos sobre o assunto $[4,5]$.

O primeiro passo para tentar resolver a equação (32), é promover uma mudança de variável usando as equações (17), (18) e (19), isto é:

$$
\begin{aligned}
\Pi_{j}(x, y, z) & \longrightarrow \Pi_{j}(\sigma, \psi, \phi) \\
\vec{\nabla}^{2}(x, y, z) & \longrightarrow \vec{\nabla}^{2}(\sigma, \psi, \phi)
\end{aligned}
$$

Deste modo, a equação (32) torna-se:

$$
\begin{gathered}
\frac{\partial}{\partial \sigma}\left(\frac{\operatorname{senh} \sigma}{\cosh \sigma-\cos \psi} \frac{\partial \Pi_{j}}{\partial \sigma}\right)+\frac{\partial}{\partial \psi}\left(\frac{\operatorname{senh} \sigma}{\cosh \sigma-\cos \psi} \frac{\partial \Pi_{j}}{\partial \psi}\right)+ \\
\frac{1}{\operatorname{senh} \sigma(\cosh \sigma-\cos \psi)} \frac{\partial^{2} \Pi_{j}}{\partial \phi^{2}}+\frac{k^{2} a^{2} \operatorname{senh} \sigma}{(\cosh \sigma-\cos \psi)^{3}} \Pi_{j}=0
\end{gathered}
$$


onde $k^{2}=\mu_{0} \epsilon_{0} \omega^{2}$.

Introduzindo:

$$
s=\cosh \sigma \text { e } \Pi_{j}=\sqrt{s-\cos \psi} P_{j},
$$

a equação (34) fica:

$$
\frac{\partial}{\partial s}\left[\left(s^{2}-1\right) \frac{\partial P_{j}}{\partial s}\right]+\frac{\partial^{2} P_{j}}{\partial \psi^{2}}+\frac{1}{s^{2}-1} \frac{\partial^{2} P_{j}}{\partial \phi^{2}}+\left(\frac{1}{4}+\frac{k^{2} a^{2}}{(s-\cos \psi)^{2}}\right) P_{j}=0
$$

Multiplicando a equação acima por $\left(s^{2}-1\right)$, é fácil verificar que a variável $\phi$ pode ser separada. Desta maneira, a equação (36) se transforma em:

$$
\frac{\partial}{\partial s}\left[\left(s^{2}-1\right) \frac{\partial P_{j}}{\partial s}\right]+\frac{\partial^{2} P_{j}}{\partial \psi^{2}}+\left(\frac{1}{4}-\frac{m^{2}}{s^{2}-1}+\frac{k^{2} a^{2}}{(s-\cos \psi)^{2}}\right) P_{j}=0
$$

$\operatorname{com} P_{j}(s, \psi, \phi)=P_{j}(s, \psi) e^{i m \phi}$, onde $m$ é inteiro.

Observe na equação acima o fator $(s-\cos \psi)^{2}$ no denominador do termo de propagação; ele é o responsável pela impossibilidade de se separar as variáveis $s$ e $\psi$. Tanto isto é verdade, que se fizermos $k=0$ na equação (37), ela não só admite a separação como tem uma solução dada em termos de Funções Associadas de Legendre e de Funções Harmônicas [13]:

$$
\Phi(s, \psi, \phi)=\sqrt{s-\cos \psi} P_{l-\frac{1}{2}}^{m}(s) e^{i l \psi} e^{i m \phi}
$$

ou

$$
\Phi(s, \psi, \phi)=\sqrt{s-\cos \psi} Q_{l-\frac{1}{2}}^{m}(s) e^{i l \psi} e^{i m \phi}
$$

onde $\Phi(s, \psi, \phi)$ é o potencial eletrostático, $l$ é a constante de separação da variável $\psi$ e $P_{l-\frac{1}{2}}^{m}(s)$ e $Q_{l-\frac{1}{2}}^{m}(s)$ designam as Funções Associadas de Legendre de primeira e segunda espécie, respectivamente.

\subsection{As Expansões do Termo de Propagação}

A maneira encontrada para contornar a inseparabilidade da equação (37), foi conjugar a expansão do termo de propagação com o método de perturbação. Duas expansões foram utilizadas, sendo que a primeira delas teve como ponto de partida a relação [14]:

$$
Q_{-\frac{1}{2}}^{\mu}(w)+2 \sum_{n=1}^{\infty} Q_{n-\frac{1}{2}}^{\mu}(w) \cos (n v)=e^{i \mu \pi} \sqrt{\frac{\pi}{2}} \Gamma\left(\mu+\frac{1}{2}\right)\left(w^{2}-1\right)^{\frac{\mu}{2}}(w-\cos v)^{-\mu-\frac{1}{2}}
$$


com $\mu>-\frac{1}{2}$; e que foi citada por J.D.Love [3] num artigo em 1975, onde $Q_{\nu}^{\mu}(w)$ é, novamente, a. Função Associada de Legendre de segunda espécie.

Tomando $\mu=\frac{3}{2}$ e identificando $w \equiv s$ e $v \equiv \psi$, obtem-se:

$$
\frac{1}{(s-\cos \psi)^{2}}=i \sqrt{\frac{2}{\pi}}\left(s^{2}-1\right)^{-\frac{3}{4}}\left[Q_{-\frac{1}{2}}^{\frac{3}{2}}(s)+2 \sum_{n=1}^{\infty} Q_{n-\frac{1}{2}}^{\frac{3}{2}}(s) \cos (n \psi)\right]
$$

Esta equação pode ser simplificada por meio das relações [15]:

$$
Q_{\nu}^{\mu+1}(w)=\left(w^{2}-1\right)^{-\frac{1}{2}}\left\{(\nu-\mu) w Q_{\nu}^{\mu}(w)-(\nu+\mu) Q_{\nu-1}^{\mu}(w)\right\}
$$

$\mathrm{e}$

$$
Q_{\nu}^{\frac{1}{2}}(w)=i \sqrt{\frac{\pi}{2}}\left(w^{2}-1\right)^{-\frac{1}{4}}\left[w+\left(w^{2}-1\right)^{\frac{1}{2}}\right]^{-\nu-\frac{1}{2}}
$$

desde que $\mu$ e $\nu$ sejam escolhidos convenientemente. Feito isto, chega-se ao resultado final:

$$
\frac{1}{(s-\cos \psi)^{2}}=\frac{1}{\left(s^{2}-1\right)^{\frac{3}{2}}}\left[s+2 \sum_{n=1}^{\infty} \frac{s+n \sqrt{s^{2}-1}}{\left[s+\sqrt{s^{2}-1}\right]^{n}} \cos (n \psi)\right]
$$

$\operatorname{com} s>1$.

A equação (43) pode ser obtida de um modo mais simples [16], mas o procedimento adotado aqui tem o mérito de evidenciar a afinidade da equação (37) com a Equação Associada de Legendre; um fato do qual se tentou extrair algum resultado, embora sem sucesso.

Note-se que a expressão (43) corresponde à expansão em série de Fourier da função $(s-\cos \psi)^{-2}$, sendo fácil verificar que a razão entre dois termos sucessivos da série é da ordem de $1 / s$; o que induz à aplicação do método de pertubação na equação (37).

A segunda expansão para o denominador do termo de propagação foi proposta pelo Prof. Dr. Antonio Ferreira [17]. A decisão de utilizá-la no trabalho, se deu por causa da dificuldade em encontrar uma solução analítica fechada para a equação que resulta da combinação das equações (37) e (43). É interessante verificar como esta segunda expansão foi obtida. Considerc:

$$
F(\sigma, \psi)=\frac{1}{\cosh \sigma-\cos \psi}
$$

Fazendo $\zeta=e^{\sigma}$, a expressão acima pode ser reescrita como:

$$
F(\zeta, \psi)=\frac{2 \zeta}{\zeta^{2}+1-2 \zeta \cos \psi}
$$

Sabendo que: 


$$
\zeta^{2}+1-2 \zeta \cos \psi=\left(\zeta-e^{i \psi}\right)\left(\zeta-e^{-i \psi}\right)
$$

e multiplicando tanto o numerador como o denominador da equação (45) por $\left(e^{i \psi}-e^{-i \psi}\right)$, ela se torna:

$$
F(\zeta, \psi)=2 \zeta \frac{\left(\zeta-e^{-i \psi}\right)-\left(\zeta-e^{i \psi}\right)}{\left(\zeta-e^{i \psi}\right)\left(\zeta-e^{-i \psi}\right)} \frac{1}{\left(e^{i \psi}-e^{-i \psi}\right)}
$$

Lembrando que $\sigma \geq 0$, tem-se $\zeta \geq 1$, assim:

$$
F(\zeta, \psi)=\frac{1}{i \operatorname{sen} \psi}\left\{\frac{1}{1-e^{i \psi} / \zeta}-\frac{1}{1-e^{-i \psi} / \zeta}\right\}
$$

onde $\left|e^{i \psi} / \zeta\right|=\left|e^{-i \psi} / \zeta\right|<1$.

Expandindo a equação (48) em série geométrica, chega-se a:

$$
F(\zeta, \psi)=\frac{1}{i \operatorname{sen} \psi}\left\{\sum_{n=0}^{\infty}\left(\frac{e^{i \psi}}{\zeta}\right)^{n}-\sum_{n=0}^{\infty}\left(\frac{e^{-i \psi}}{\zeta}\right)^{n}\right\}
$$

Simplificando a equação acima se obtem:

$$
\frac{1}{\cosh \sigma-\cos \psi}=2 \sum_{n=1}^{\infty} e^{-n \sigma} \frac{\operatorname{sen}(n \psi)}{\operatorname{sen} \psi}
$$

onde, obviamente, a variável original foi retomada.

Derivando a equação (50) com relação a $\sigma$ chega-se ao resultado final, que expresso como função de $s(=\cosh \sigma)$ dá:

$$
\frac{1}{(s-\cos \psi)^{2}}=\frac{2}{\sqrt{s^{2}-1}} \sum_{n=1}^{\infty} \frac{n}{\left(s+\sqrt{s^{2}-1}\right)^{n}} \frac{\operatorname{sen}(n \psi)}{\operatorname{sen} \psi}
$$

Do mesmo modo que aconteceu com a expressão (43), é fácil verificar que a razão entre dois termos sucessivos da série acima é da ordem de $1 / s$; o que induz à aplicação do método de perturbação na equação (37), também. Note que tanto a expansão (43) como a (51) são pares em $\psi$, mas a expansão (43) é mais simples na sua dependência em $\psi$. Quando se considera a variável $s$, a situação se inverte, e a expansão (51) é significativamente mais simples.

Assim como se identificou a equação (43) com a série de Fourier, a expressão (51) será identificada como a "série dos senos". 


\subsection{As Soluções da Equação de Onda}

Uma vez que as duas expansões encontradas têm os seus sucessivos termos decrescendo à razão de $1 / s$, pareceu apropriado aplicar à equação (37) o método de perturbação. Note-se que $1 / s$ é o inverso da razão de aspecto do toróide.

\subsubsection{A Solução usando a Série de Fourier}

Retomando a equação (37) e considerando a expansão (43), pode-se escrever:

$$
\mathrm{L}\left(P_{j}\right)+\frac{k^{2} a^{2} s}{\left(s^{2}-1\right)^{\frac{3}{2}}}\left[1+2 \sum_{n=1}^{\infty} \frac{q_{n}(s)}{s} \cos (n \psi)\right] P_{j}=0
$$

onde

$$
\mathrm{L}\left(P_{j}\right) \equiv \frac{\partial}{\partial s}\left[\left(s^{2}-1\right) \frac{\partial P_{j}}{\partial s}\right]+\frac{\partial^{2} P_{j}}{\partial \psi^{2}}+\left[\frac{1}{4}-\frac{m^{2}}{s^{2}-1}\right] P_{j}
$$

$\mathrm{e}$

$$
q_{n}(s) \equiv \frac{s+n \sqrt{s^{2}-1}}{\left[s+\sqrt{s^{2}-1}\right]^{n}}
$$

Fazendo a hipótese que $P_{j}=P_{j 0}+\epsilon P_{j 1}+\epsilon^{2} P_{j 2}+\ldots$, com $\epsilon \sim 1 / s$, substituindo esta expressão em (52), lembrando que $\mathrm{\iota}\left(P_{j}\right)$ é linear e sabendo que $q_{n}(s) / s \sim \epsilon^{n}$, se obtém um conjunto de equações diferenciais, onde cada equação corresponde a uma ordem de aproximação diferente do problema, sendo as três primeiras as seguintes:

$$
\begin{aligned}
\mathrm{L}\left(P_{j 0}\right)+\frac{k^{2} a^{2} s}{\left(s^{2}-1\right)^{\frac{3}{2}}} P_{j 0} & =0 \\
\mathrm{~L}\left(P_{j 1}\right)+\frac{k^{2} a^{2} s}{\left(s^{2}-1\right)^{\frac{3}{2}}} P_{j 1} & =\frac{-k^{2} a^{2} s}{\left(s^{2}-1\right)^{\frac{3}{2}}}\left(\frac{2 q_{1}(s)}{s} \cos \psi\right) P_{j 0} \\
\mathrm{~L}\left(P_{j 2}\right)+\frac{k^{2} a^{2} s}{\left(s^{2}-1\right)^{\frac{3}{2}}} P_{j 2}= & \frac{-k^{2} a^{2} s}{\left(s^{2}-1\right)^{\frac{3}{2}}}\left(\frac{2 q_{2}(s)}{s} \cos (2 \psi)\right) P_{j 0} \\
& -\frac{k^{2} a^{2} s}{\left(s^{2}-1\right)^{\frac{3}{2}}}\left(\frac{2 q_{1}(s)}{s} \cos \psi\right) P_{j 1}
\end{aligned}
$$


Neste trabalho, somente a equação de ordem zero, ou seja, a equação (55), é considerada. Esta equação é separável e a solução na variável $\psi$ é trivial $\left(P_{j 0}(s, \psi)=P_{j 0}(s) e^{i l \psi}\right.$; onde $l$, a constante de separação, é um número inteiro). A equação remanescente fica:

$$
\frac{d}{d s}\left[\left(s^{2}-1\right) \frac{d P_{j 0}}{d s}\right]-\left[n^{\prime}\left(n^{\prime}+1\right)+\frac{m^{2}}{s^{2}-1}-\frac{k^{2} a^{2} s}{\left(s^{2}-1\right)^{\frac{3}{2}}}\right] P_{j 0}=0
$$

onde se deve notar, mais uma vez, que $P_{j 0}$ é uma função que agora só depende de $s$, sendo $\mathbf{n}^{\prime} \equiv \mathbf{l}-\mathbf{1} / \mathbf{2}$; observe-se, também, que o número de modo poloidal é l e não $n^{\prime}$.

Introduzindo-se as transformações:

$$
P_{j 0}=\sqrt{u^{2}-1} Q_{j 0} \quad \text { e } \quad u=\frac{1}{\sqrt{1-1 / s^{2}}}
$$

consegue-se eliminar o expoente fracionário no termo em $k^{2}$ e obter:

$$
\left(1-u^{2}\right) \frac{d^{2} Q_{j 0}}{d u^{2}}-3 u \frac{d Q_{j 0}}{d u}+\left[m^{2}-1-\frac{n^{\prime}\left(n^{\prime}+1\right)}{1-u^{2}}-k^{2} a^{2} u\right] Q_{j 0}=0
$$

Esta equação foi resolvida pelo método de Frobenius em torno do ponto $u=1(s \rightarrow \infty)$. Para tanto, escreve-se a equação (60) da seguinte maneira:

$$
Q_{j 0}^{\prime \prime}+\frac{F(u)}{u-1} Q_{j 0}^{\prime}+\frac{G(u)}{(u-1)^{2}} Q_{j 0}=0
$$

com

$$
\begin{aligned}
& F(u)=\frac{3}{2}\left[1+\frac{u-1}{u+1}\right] \\
& G(u)=-\left[\left(m^{2}-1\right) \frac{u-1}{u+1}+\frac{n^{\prime}\left(n^{\prime}+1\right)}{(u+1)^{2}}-k^{2} a^{2} u \frac{u-1}{u+1}\right]
\end{aligned}
$$

em seguida, substitui-se na equação acima as séries:

$$
\begin{aligned}
& Q_{j 0}(u)=(u-1)^{b} \sum_{r=0}^{\infty} a_{r}(u-1)^{r} \\
& F(u)=\sum_{n=0}^{\infty} \frac{F^{n}}{n !}(u-1)^{n} \\
& G(u)=\sum_{i=0}^{\infty} \frac{G^{i}}{i !}(u-1)^{i}
\end{aligned}
$$


onde os supra-índices em $F^{n}$ e $G^{i}$, indicam a ordem da derivada das funções $F(u)$ e $G(u)$ calculadas no ponto $u=1$.

A separação dos termos de mesma potência em $(u-1)$ produz o seguinte sistema de equações algébricas:

$$
\begin{aligned}
& a_{0} b(b-1)+a_{0} F^{0} b+a_{0} G^{0}=0 \\
& a_{1} b(b+1)+F^{0} a_{1}(b+1)+F^{1} a_{0} b+G^{0} a_{1}+G^{1} a_{0}=0 \\
& a_{2}(b+2)(b+1)+F^{0} a_{2}(b+2)+F^{1} a_{1}(b+1)+\frac{F^{2}}{2 !} a_{0} b+G^{0} a_{2}+G^{1} a_{1}+\frac{G^{2}}{2 !} a_{0}=0 \\
& a_{N}(b+N)(b+N-1)+\sum_{r=0}^{N} \frac{F^{r}}{r !} a_{N-r}(b+N-r)+\sum_{r=0}^{N} \frac{G^{r}}{r !} a_{N-r}=0
\end{aligned}
$$

onde $N$ é um número inteiro positivo qualquer.

É fácil verificar que a primeira das equações (65) corresponde à equação indicial, cujas soluções encontradas são:

$$
b=\frac{n^{\prime}}{2}
$$

e

$$
b=-\frac{\left(n^{\prime}+1\right)}{2}
$$

As demais equações do sistema (65) vão prover as relações de recorrência necessárias ao cálculo dos coeficientes $a_{r}$. Fsstas relações, contudo, não podem ser reduzidas a uma relação de dois termos, como acontece com algumas equações conhecidas, como a equação de Bessel por exemplo. Desse modo, o cálculo de um determinado $a_{r}$ depende do cálculo de todos os coeficientes anteriores a ele; isto torna a tarefa de calculá-los extremamente penosa, e na prática, isto só é possível computacionalmente. Usando o "Mathematica"montou-se um programa para calcular os $a_{r}$, cujos comandos são:

$$
\begin{aligned}
& a[0]=1 \\
& a[1]=(1 /(2 * b+1.5)) *\left(-3 * b / 4+(m \wedge 2-1) / 2-\left(n^{\prime} *\left(n^{\prime}+1\right)\right) / 4-((k a) \wedge 2) / 2\right) \\
& a\left[r_{-}\right]:=(1 /(r *(2 * b+r+0.5))) * \\
& \left(a[r-1] *\left(-3 *(b+r-1) / 4+(m \wedge 2-1) / 2-\left(n^{\prime} *\left(n^{\prime}+1\right)\right) / 4-((k a) \wedge 2) / 2\right)+\right. \\
& \operatorname{SUM}\left[a [ j ] * ( - 1 / 2 ) \wedge ( r - j ) * \left(3 *(b+j) / 2-(m \wedge 2-1)+\left(n^{\prime} *\left(n^{\prime}+1\right) *\right.\right.\right. \\
& (r-j+1)) / 4-(k a) \wedge 2),\{j, 0, r-2\}])
\end{aligned}
$$

$\operatorname{com} r$ e $j$ sendo variáveis indexadas.

Observe-se que os coeficientes $a_{r}$ dependem de $m, n^{\prime}$ e $k a$, cujos valores definem uma particular onda estacionária no interior do toróide, uma vez que $m$ é o número de modo 
toroidal, $n^{\prime}$ está relacionado com o número de modo poloidal $l$ e $k$ é o módulo do vetor de onda.

Considerando todos os elementos expostos acima, a solução formal da equação (60) pode ser escrita:

$$
\begin{aligned}
Q_{j 0}(u)= & A(u-1)^{\frac{n^{\prime}}{2}} \sum_{r=0}^{\infty} a_{r}\left(m, n^{\prime}, k a, \frac{n^{\prime}}{2}\right)(u-1)^{r}+ \\
& B(u-1)^{-\frac{\left(n^{\prime}+1\right)}{2}} \sum_{r=0}^{\infty} a_{r}\left(m, n^{\prime}, k a,-\frac{\left(n^{\prime}+1\right)}{2}\right)(u-1)^{r}
\end{aligned}
$$

Note-se que $A$ e $B$ são constantes arbitrárias a serem fixadas pelas condições do problema e que cada uma das séries corresponde a uma solução da equação indicial.

A convergência das séries em (69) foi verificada numericamente, escolhendo-se valores típicos para $m, n^{\prime}$ e $k a$, substituindo-os nas expressões para $a_{r}$ e calculando os valores dos coeficientes. Não se encontrou problemas. No entanto, se descobriu que a convergência da série correspondente a $b=n^{\prime} / 2=(l-1 / 2) / 2$ requer que $l \geq 0$; da mesma maneira, a série relacionada com $b=-\left(n^{\prime}+1\right) / 2=-(l+1 / 2) / 2$ requer que $l \leq 0$. Se a escolha do sinal de $l$ não é apropriada as séries divergem. A causa desta distinção está na forma das expressões para $a_{r}$, pois sendo elas funções racionais, o seu denominador não pode se anular; o que ocorre quando a escolha de $l$ é inadequada. Para ilustrar se transcreve abaixo os coeficientes $a_{1}$ nos dois casos:

$$
\begin{aligned}
& a_{1}=\frac{a_{0}}{l+1}\left[\frac{m^{2}-1}{2}-\frac{(l-1 / 2)(l+2)}{4}-\frac{k^{2} a^{2}}{2}\right] ; \quad b=\frac{(l-1 / 2)}{2} ; \quad l \geq 0 \\
& a_{1}=\frac{a_{0}}{1-l}\left[\frac{m^{2}-1}{2}-\frac{(l+1 / 2)(l-2)}{4}-\frac{k^{2} a^{2}}{2}\right] ; b=-\frac{(l+1 / 2)}{2} ; l \leq 0
\end{aligned}
$$

É importante salientar que, assim como em $a_{1}$ aparece no denominador $(l \pm 1)$, nos demais $a_{r}$ o denominador corresponde a um produto de fatores do tipo ( $l \pm n$ o inteiro); de modo que sempre há um valor de $l$ a ser evitado. É preciso notar, também, que apesar dos sinais diferentes, os l's de mesmo módulo produzem $a_{r}$ 's iguais; o que reduz a solução (69) a uma única série. Contudo, lembrando que $l$ é a constante de separação da variável $\psi$, cuja equação tem a solução $e^{i l \psi}$; vê-se que os dois sinais admitidos por $l$ vão gerar campos com sentido de rotação opostos. Isto determina uma degenerescência dos modos, assunto ao qual se retornará quando a relação de dispersão for obtida. Por ora, é importante escrever a solução obtida para as componentes cartesianas do vetor de Hertz em termos de $s$ :

$$
\Pi_{j 0}(s, \psi, \phi)=\sqrt{s-\cos \psi} \frac{1}{\sqrt{s^{2}-1}} Q_{j 0}(s) e^{i l \psi} e^{i m \phi}
$$

com

$$
Q_{j 0}(s)=A\left(\frac{s}{\sqrt{s^{2}-1}}-1\right)^{n^{\prime} / 2} \sum_{r=0}^{\infty} a_{r}\left(m, n^{\prime}, k a, \frac{n^{\prime}}{2}\right)\left(\frac{s}{\sqrt{s^{2}-1}}-1\right)^{r} \quad ; \quad l \geq 0
$$




$$
Q_{j 0}(s)=B\left(\frac{s}{\sqrt{s^{2}-1}}-1\right)^{-\left(n^{\prime}+1\right) / 2} \sum_{r=0}^{\infty} a_{r}\left(m, n^{\prime}, k a, \frac{-\left(n^{\prime}+1\right)}{2}\right)\left(\frac{s}{\sqrt{s^{2}-1}}-1\right)^{r} \quad ; \quad l \leq 0
$$

\subsubsection{A Solução usando a Série de Senos}

A combinação das equações (37) e (51) produz a expressão:

$$
\frac{\partial}{\partial s}\left[\left(s^{2}-1\right) \frac{\partial P_{j}}{\partial s}\right]+\frac{\partial^{2} P_{j}}{\partial \psi^{2}}+\left(\frac{1}{4}-\frac{m^{2}}{s^{2}-1}\right) P_{j}+\frac{2 k^{2} a^{2}}{\sqrt{s^{2}-1}} \sum_{n=1}^{\infty} \frac{n}{\left(s+\sqrt{s^{2}-1}\right)^{n}} \frac{\operatorname{sen}(n \psi)}{\operatorname{sen} \psi} P_{j}=0
$$

Para aplicar o método perturbativo à equação acima, é preciso reescrevê-lá introduzindo as transformações:

$$
s=\cosh \sigma \quad \text { e } \quad e^{\sigma}=x
$$

Com isto a expressão (72) fica:

$$
\frac{x^{2}}{x^{2}-1} \frac{\partial}{\partial x}\left[\left(x^{2}-1\right) \frac{\partial P_{j}}{\partial x}\right]+\frac{\partial^{2} P_{j}}{\partial \psi^{2}}+\left(\frac{1}{4}-\frac{4 m^{2} x^{2}}{\left(x^{2}-1\right)^{2}}\right) P_{j}+\frac{4 k^{2} a^{2}}{x^{2}-1} \sum_{n=1}^{\infty} \frac{n}{x^{n-1}} \frac{\operatorname{sen}(n \psi)}{\operatorname{sen} \psi} P_{j}=0
$$

Fazendo, novamente, a hipótese que $P_{j}=P_{j 0}+\epsilon P_{j 1}+\epsilon^{2} P_{j 2}+\ldots$, com $\epsilon \sim 1 / s$, substituindo esta expressão em (74) e lembrando que a equação é linear e que $1 / x^{n-1} \sim$ $\epsilon^{n-1}$, obtém-se um conjunto de equações diferenciais onde cada equação corresponde a uma ordem de aproximação diferente do problema, sendo as três primeiras as seguintes:

$$
\begin{aligned}
& \mathcal{L}\left(P_{j 0}\right)+\frac{4 k^{2} a^{2}}{x^{2}-1} P_{j 0}=0 \\
& \mathcal{L}\left(P_{j 1}\right)+\frac{4 k^{2} a^{2}}{x^{2}-1} P_{j 1}=-\frac{4 k^{2} a^{2}}{x^{2}-1} \frac{2}{x} \frac{\operatorname{sen}(2 \psi)}{\operatorname{sen} \psi} P_{j 0} \\
& \mathcal{L}\left(P_{j 2}\right)+\frac{4 k^{2} a^{2}}{x^{2}-1} P_{j 2}=-\frac{4 k^{2} a^{2}}{x^{2}-1} \frac{3}{x^{2}} \frac{\operatorname{sen}(3 \psi)}{\operatorname{sen} \psi} P_{j 0} \\
&-\frac{4 k^{2} a^{2}}{x^{2}-1} \frac{2}{x} \frac{\operatorname{sen}(2 \psi)}{\operatorname{sen} \psi} P_{j 1}
\end{aligned}
$$


onde

$$
\mathcal{L}(P) \equiv \frac{x^{2}}{x^{2}-1} \frac{\partial}{\partial x}\left[\left(x^{2}-1\right) \frac{\partial P}{\partial x}\right]+\frac{\partial^{2} P}{\partial \psi^{2}}+\left(\frac{1}{4}-\frac{4 m^{2} x^{2}}{\left(x^{2}-1\right)^{2}}\right) P
$$

Neste trabalho, somente a equação de ordem mais baixa, a equação (75), é resolvida. Esta equação é separável e a solução na variável $\psi$ é trivial $\left(P_{j 0}(x, \psi)=F(x) e^{i l \psi}\right.$; onde $l$, a constante de separação, é um número inteiro). A equação remanescente fica:

$$
x^{2} \frac{d^{2} F}{d x^{2}}+\frac{2 x^{3}}{x^{2}-1} \frac{d F}{d x}+\left[\frac{1}{4}-l^{2}-\frac{4 m^{2} x^{2}}{\left(x^{2}-1\right)^{2}}+\frac{4 k^{2} a^{2}}{x^{2}-1}\right] F=0
$$

Ao contrário da equação (58), a expressão acima não apresenta expoentes fracionários; o que levou à análise dos seus pontos singulares: $x=-1,0,1$ e $\infty$. Como todos se mostraram singulares regulares, a possibilidade de reescrever a equação (79) como uma equação hipergeométrica passou a ser considerada. Para tanto, a seguinte transformação foi introduzida:

$$
v=\frac{1}{x^{2}}
$$

Deste modo, a equação anterior passou a:

$$
v(1-v) \frac{d^{2} F}{d v^{2}}+\frac{1-3 v}{2} \frac{d F}{d v}+\left[k^{2} a^{2}-\frac{1}{4}\left(\frac{1}{4}-l^{2}\right)+\frac{\frac{1}{4}\left(\frac{1}{4}-l^{2}\right)}{v}-\frac{m^{2}}{1-v}\right] F=0
$$

Posteriormente, $F(v)$ foi substituída por:

$$
F(v)=K(v) G(v)
$$

onde

$$
K(v)=v^{-\lambda}(1-v)^{-\mu}
$$

$\operatorname{com} \lambda$ e $\mu$ a determinar. Isto transformou a equação (81) em:

$$
\begin{gathered}
v(1-v) \frac{d^{2} G}{d v^{2}}+\left[v(1-v) \frac{2}{K} \frac{d K}{d v}+\frac{1-3 v}{2}\right] \frac{d G}{d v}+ \\
{\left[v(1-v) \frac{1}{K} \frac{d^{2} K}{d v^{2}}+\frac{1-3 v}{2} \frac{1}{K} \frac{d K}{d v}+k^{2} a^{2}-\frac{1}{4}\left(\frac{1}{4}-l^{2}\right)+\frac{\frac{1}{4}\left(\frac{1}{4}-l^{2}\right)}{v}-\frac{m^{2}}{1-v}\right] G=0}
\end{gathered}
$$

As derivadas de $K(v)$ resultaram em:

$$
\frac{1}{K} \frac{d K}{d v}=-\frac{\lambda}{v}+\frac{\mu}{1-v} \quad \text { e } \quad \frac{1}{K} \frac{d^{2} K}{d v^{2}}=\frac{\lambda+\lambda^{2}}{v^{2}}-\frac{2 \lambda \mu}{v(1-v)}+\frac{\mu+\mu^{2}}{(1-v)^{2}}
$$


Substituindo-as na equação (83) e impondo que os coeficientes das parcelas em $\mathbf{1} / \mathbf{v}$ e $\mathbf{1} / \mathbf{1}-\mathbf{v}$ sejam iguais a zero, se obteve os valores de $\lambda$ e $\mu$ :

$$
\lambda=-\frac{1}{4} \pm \frac{l}{2} \quad \text { e } \quad \mu= \pm m
$$

Usando estes valores, foi possível reescrever a equação (83) como:

$$
\begin{gathered}
v(1-v) \frac{d^{2} G}{d v^{2}}+\left[\left(2 \lambda+2 \mu-\frac{3}{2}\right) v-2 \lambda+\frac{1}{2}\right] \frac{d G}{d v}+ \\
{\left[\lambda-\mu^{2}-\mu\left(2 \lambda-\frac{1}{2}\right)+k^{2} a^{2}\right] G=0}
\end{gathered}
$$

A expressão acima é a equação hipergeométrica de Gauss, ela apenas não se encontra na forma canônica, a qual é:

$$
v(1-v) \frac{d^{2} G}{d v^{2}}+[\gamma-(1+\alpha+\beta) v] \frac{d G}{d v}-\alpha \beta G=0
$$

Para poder colocar a equação (86) na forma canônica, é preciso relacionar $\lambda, \mu$ e $k^{2} a^{2}$ com $\alpha, \beta$ e $\gamma$; feito isto se encontra:

$$
\begin{gathered}
\alpha=-\lambda-\mu+\frac{1}{4} \pm \sqrt{\frac{l^{2}}{4}+k^{2} a^{2}} \\
\gamma=\frac{1}{2}-2 \lambda
\end{gathered}
$$

Considerando as soluções obtidas para $\lambda$ (eq.(85)), verifica-se que $\gamma$ pode ter os seguintes valores: $\gamma=1-l$ e $\gamma=1+l$. Contudo, para o valor $\gamma=1-l$, que corresponde a $\lambda=-\frac{1}{4}+\frac{l}{2}$, a solução da equação diferencial não está definida [15] e, portanto, este valor de $\gamma$ não pode ser admitido como um parâmetro da solução física do problema. Do mesmo modo, a simetria existente entre as expressões para $\alpha$ e $\beta$ e o papel que estes parâmetros desempenham na função hipergeométrica [15], conduzem à igualdade:

$$
\begin{gathered}
{ }_{2} F_{1}\left(-\lambda-\mu+\frac{1}{4}+\sqrt{\frac{l^{2}}{4}+k^{2} a^{2}},-\lambda-\mu+\frac{1}{4}-\sqrt{\frac{l^{2}}{4}+k^{2} a^{2}}, 1+l ; v\right)= \\
{ }_{2} F_{1}\left(-\lambda-\mu+\frac{1}{4}-\sqrt{\frac{l^{2}}{4}+k^{2} a^{2}},-\lambda-\mu+\frac{1}{4}+\sqrt{\frac{l^{2}}{4}+k^{2} a^{2}}, 1+l ; v\right)
\end{gathered}
$$

o que torna o jogo de sinais em $\alpha$ e $\beta$ sem interesse físico. 
Levando em conta os fatos expostos acima, as expressões (88) podem ser reescritas como:

$$
\begin{gathered}
\alpha=\frac{l}{2}-\mu+\frac{1}{2}+\sqrt{\frac{l^{2}}{4}+k^{2} a^{2}} \quad \quad \beta=\frac{l}{2}-\mu+\frac{1}{2}-\sqrt{\frac{l^{2}}{4}+k^{2} a^{2}} \\
\gamma=1+l
\end{gathered}
$$

Retomando as soluções encontradas para $\mu$ (eq.(85)), vê-se que as equações acima determinam dois conjuntos distintos de parâmetros. Estes, por sua vez, definem duas funções ${ }_{2} F_{1}(\alpha, \beta, \gamma ; v)$ diferentes, embora elas se relacionem por meio de [15]:

$$
{ }_{2} F_{1}(\alpha, \beta, \gamma ; v)=(1-v)^{\gamma-\alpha-\beta}{ }_{2} F_{1}(\gamma-\alpha, \gamma-\beta, \gamma ; v)
$$

Isto mostra que a solução $\mu= \pm m$ determina uma degenerescência dos modos, pois as duas funções acima têm os mesmos zeros, apesar de serem diferentes; e estes zeros correspondem aos autovalores procurados.

É evidente que, sendo a equação hipergeométrica uma equação diferencial de segunda ordem, ela apresenta duas soluções linearmente independentes. No entanto, uma delas é divergente no intervalo de variação de $v[15] \mathrm{e}$, portanto, não tem significado físico. Desta maneira, a solução da equação (79) pode ser escrita como:

$$
\begin{gathered}
F(s)=\left(s+\sqrt{s^{2}-1}\right)^{(-1 / 2-l+2 \mu)}\left[\left(s+\sqrt{s^{2}-1}\right)^{2}-1\right]^{-\mu} \\
{ }_{2} F_{1}\left(\alpha, \beta, \gamma ; \frac{1}{\left(s+\sqrt{s^{2}-1}\right)^{2}}\right)
\end{gathered}
$$

onde a variável $s$ foi retomada e $\alpha, \beta$ e $\gamma$ são dados pelas expressões (90).

A partir da equação (92) se obtem a expressão para uma componente cartesiana qualquer do vetor de Hertz $\vec{\Pi}$, exatamente como já aconteceu em (71); esta nova equação é:

$$
\Pi_{j 0}(s, \psi, \phi)=\sqrt{s-\cos \psi} F(s) e^{i l \psi} e^{i m \phi}
$$

Observe-se que, apesar da função hipergeométrica ${ }_{2} F_{1}\left(\alpha, \beta, \gamma ; \frac{1}{\left(s+\sqrt{s^{2}-1}\right)^{2}}\right)$ ser bastante complexa, ela é uma função conhecida; o que não ocorre com a série $Q_{j 0}(s)$, igualmente complexa. Isto criou a expectativa que as condições de contorno, a relação de dispersão e os autovalores do problema pudessem ser encontrados mais facilmente e de forma mais elegante no caso das funções hipergeométricas. Do mesmo modo, o sucesso na obtenção da solução fechada $F(s)$ levou à iniciativa de incluir efeitos de primeira ordem na equação (74). Neste sentido, foi feita uma tentativa expandindo não apenas a autofunção $P_{j}$, mas 
o autovalor ka também. A equação de ordem zero, neste caso, corresponde à Equação (75), mas a equação para a primeira ordem é:

$$
\mathcal{L}\left(P_{j 1}\right)+\frac{4\left[(k a)_{0}^{2} P_{j 1}+(k a)_{1}^{2} P_{j 0}\right]}{x^{2}-1}=-\frac{4(k a)_{0}^{2}}{x^{2}-1} \frac{2}{x} \frac{\operatorname{sen}(2 \psi)}{\operatorname{sen} \psi} P_{j 0}
$$

onde $\mathcal{L}\left(P_{j 1}\right)$ é dado pela Equação $(78)$ e os sub-índices 0 e 1 designam a ordem de aproximação do autovalor $k a$. Note-se os termos cruzados do lado esquerdo do sinal de igual, eles tornam a equação acima de difícil solução, e impediram que fosse tentada a inclusão de efeitos de primeira ordem no problema.

\subsection{As Condições de Contorno e a Relação de Dispersão}

Embora tenham sido obtidas duas soluções aproximadas para a equação (37), a solução física do problema requer que estas soluções satisfaçam as condições de contorno. Admitindo que a superfície da cavidade seja de um material condutor ideal, as condições se resumem a:

$$
B_{\sigma}\left(s_{0}\right)=E_{\psi}\left(s_{0}\right)=E_{\phi}\left(s_{0}\right)=0
$$

onde $s_{0}\left(=\cosh \sigma_{0}\right)$ designa a superfície da cavidade, $B_{\sigma}$ representa a componente radial do campo magnético e $E_{\psi}$ e $E_{\phi}$ as componentes tangenciais (poloidal e toroidal) do campo elétrico. Na prática, as equações de Maxwell acoplam as três componentes, de modo que basta impor a condição de nulo sobre uma delas apenas. Note-se também, que estas componentes de campo estão em coordenadas toroidais, enquanto as componentes do vetor de Hertz $\Pi_{j 0}$ estão em coordenadas cartesianas. É óbvio, portanto, que as representações precisam ser compatibilizadas.

\subsubsection{Compatibilização da Representação dos Campos}

Examinando a transformação (31), verifica-se que existe uma simetria entre os termos que envolvem as componentes $\Pi_{x}$ e $\Pi_{y}$ e que os termos em $\Pi_{z}$ não dependem da coordenada $\phi$. Estes fatos sugerem que a transformação pode ser desmembrada em duas: uma incluindo apenas $\Pi_{z}$ e a outra $\Pi_{x}$ e $\Pi_{y}$. Uma possível consequência física deste desmembramento, seria a existência de diferenças na polarização do campo eletromagnético.

Lembrando que $\Pi_{x, y, z} \cong \Pi_{j 0}$, define-se:

$$
\Pi_{\mathrm{xy}} \equiv \Pi_{\mathrm{x}} \cong \Pi_{\mathrm{x} 0} \quad ; \quad \Pi_{\mathrm{xy}} \equiv \Pi_{\mathrm{y}} \cong \Pi_{\mathrm{y} 0} \quad ; \quad \Pi_{\mathrm{z}} \equiv \Pi_{\mathrm{z}} \cong \Pi_{\mathrm{z} 0}
$$

Considerando as equações (31), o desmembramento proposto e as definições acima, as 
componentes toroidais do vetor de Hertz se escrevem:

$$
\begin{gathered}
\Pi_{\sigma}=\frac{1-\cosh \sigma \cos \psi}{\cosh \sigma-\cos \psi}[\cos \phi+\operatorname{sen} \phi] \Pi_{x y} \\
\Pi_{\psi}=-\frac{\operatorname{senh} \sigma \operatorname{sen} \psi}{\cosh \sigma-\cos \psi}[\cos \phi+\operatorname{sen} \phi] \Pi_{x y} \\
\Pi_{\phi}=[\cos \phi-\operatorname{sen} \phi] \Pi_{x y}
\end{gathered}
$$

quando se toma $\boldsymbol{\Pi}_{\boldsymbol{z}}=\mathbf{0}$.

Analogamente, se $\boldsymbol{\Pi}_{x y}=\mathbf{0}$ as componentes ficam:

$$
\begin{gathered}
\Pi_{\sigma}=-\frac{\operatorname{senh} \sigma \operatorname{sen} \psi}{\cosh \sigma-\cos \psi} \Pi_{z} \\
\Pi_{\psi}=-\frac{1-\cosh \sigma \cos \psi}{\cosh \sigma-\cos \psi} \Pi_{z} \\
\Pi_{\phi}=0
\end{gathered}
$$

As transformações (96) e (97) são introduzidas nas equações (13) e (14), onde os operadores diferenciais também são reescritos em coordenadas toroidais. Deste modo, se obtém:

$$
\begin{gathered}
B_{\sigma}=i \omega \epsilon_{0} \mu_{0}(\vec{\nabla} \times \vec{\Pi})_{\sigma} \\
E_{\psi}=\epsilon_{0} \mu_{0} \omega^{2} \Pi_{\psi}+\vec{\nabla}_{\psi}(\vec{\nabla} \cdot \vec{\Pi}) \\
E_{\phi}=\epsilon_{0} \mu_{0} \omega^{2} \Pi_{\phi}+\vec{\nabla}_{\phi}(\vec{\nabla} \cdot \vec{\Pi})
\end{gathered}
$$

onde $\partial / \partial t=i \omega, \vec{\nabla}_{\psi, \phi}$ designa as componentes $\psi$ e $\phi$ do operador gradiente e $(\vec{\nabla} \times \vec{\Pi})_{\sigma}$ representa a componente $\sigma$ do rotacional de $\vec{l}$.

Os operadores vetoriais presentes nas expressões acima se escrevem:

$$
\begin{gathered}
(\vec{\nabla} \times \vec{\Pi})_{\sigma}=\frac{(\cosh \sigma-\cos \psi)^{2}}{a \operatorname{senh} \sigma}\left[\frac{\partial}{\partial \psi}\left(\frac{\operatorname{senh} \sigma}{\cosh \sigma-\cos \psi} \Pi_{\phi}\right)-\frac{\partial}{\partial \phi}\left(\frac{1}{\cosh \sigma-\cos \psi} \Pi_{\psi}\right)\right] \\
\vec{\nabla}_{\psi}=\frac{\cosh \sigma-\cos \psi}{a} \frac{\partial}{\partial \psi} \quad \mathrm{e} \quad \vec{\nabla}_{\phi}=\frac{\cosh \sigma-\cos \psi}{a \operatorname{senh} \sigma} \frac{\partial}{\partial \phi} \\
\vec{\nabla} \cdot \vec{\Pi}=\frac{(\cosh \sigma-\cos \psi)^{3}}{a \operatorname{senh} \sigma}\left[\frac{\partial}{\partial \sigma}\left(\frac{\operatorname{senh} \sigma}{(\cosh \sigma-\cos \psi)^{2}} \Pi_{\sigma}\right)+\right. \\
\frac{\partial}{\partial \psi}\left(\frac{\operatorname{senh} \sigma}{(\cosh \sigma-\cos \psi)^{2}} \Pi_{\psi}\right)+ \\
\left.\frac{\partial}{\partial \phi}\left(\frac{1}{(\cosh \sigma-\cos \psi)^{2}} \Pi_{\phi}\right)\right]
\end{gathered}
$$


Observe-se que todas as componentes toroidais do vetor de Hertz $\vec{\Pi}$ comparecem no cálculo de $E_{\psi}$ e $E_{\phi}$, devido ao $\vec{\nabla} \cdot \vec{\Pi}$. Este divergente também é responsável pelo aparecimento de um termo em primeira ordem de aproximação em $1 / \sigma$, como pode ser visto na primeira parcela da expressão (103). Ao contrário, $B_{\sigma}$ apresenta apenas termos em ordem zero.

Agora, conjugando as transformações (96) e (97) e as equações (98), (99), (100), (101), (102) e (103), é possível calcular as componentes $B_{\sigma}, E_{\psi}$ e $E_{\phi}$ de modo consistente.

\subsubsection{A Relação de Dispersão}

A compatibilização da representação dos campos foi apresentada em termos de $\sigma, \psi$ e $\phi$, mas os cálculos e a forma final das componentes $B_{\sigma}, E_{\psi}$ e $E_{\phi}$ se deram em termos de $\mathbf{s}$, $\psi$ e $\phi$. Deste modo, é importante lembrar que:

$$
\cosh \sigma=s \quad ; \quad \operatorname{senh} \sigma=\sqrt{s^{2}-1} \quad ; \quad \frac{\partial}{\partial \sigma}=\sqrt{s^{2}-1} \frac{\partial}{\partial s}
$$

Considerando as igualdades acima e as informações da subseção anterior, o caso em que $\Pi_{z}=0$ e $\Pi_{x y} \neq 0$ leva às seguintes expressões:

$$
\begin{gathered}
\mathbf{B}_{\sigma}=-\frac{(k a)}{a^{2} \mathbf{c}} \sqrt{s-\cos \psi} \mathcal{F}(s, l, m, k a)\{[m \operatorname{sen} \psi(\cos \phi+\operatorname{sen} \phi)+ \\
\left.l(s-\cos \psi)(\cos \phi-\operatorname{sen} \phi)] \cos (l \psi+m \phi)+\frac{\operatorname{sen} \psi}{2}(\cos \phi-\operatorname{sen} \phi) \operatorname{sen}(l \psi+m \phi)\right\} \\
\mathbf{E}_{\psi}=-\frac{(s-\cos \psi)^{3 / 2}}{a^{2} \sqrt{s^{2}-1}} \mathcal{F}(s, l, m, k a)\{\quad[l m(s-\cos \psi)(\cos \phi-\operatorname{sen} \phi)+ \\
\left.\left(s^{2}-1\right) \operatorname{sen} \psi(\cos \phi+\operatorname{sen} \phi)\left(\frac{k^{2} a^{2}}{(s-\cos \psi)^{2}}+\frac{\cos \psi}{4(s-\cos \psi)}-l^{2}-\frac{1}{2}\right)\right] \cos (l \psi+m \phi)+ \\
\left.\frac{3}{2} m \operatorname{sen} \psi(\cos \phi-\operatorname{sen} \phi)-l\left(s^{2}-1\right)(\cos \phi+\operatorname{sen} \phi)\left(2 \cos \psi+\frac{1-s \cos \psi}{2(s-\cos \psi)}\right)\right] \\
\frac{\partial e n(l \psi+m \phi)}{\partial \psi}[\sqrt{s-\cos \psi}(1-s \cos \psi) \cos (l \psi+m \phi)] \frac{d}{d s} \mathcal{F}(s, l, m, k a) \\
s^{2}-1(s-\cos \psi)(\cos \phi+\operatorname{sen} \phi)
\end{gathered}
$$




$$
\begin{gathered}
\mathbf{E}_{\phi}=\frac{(s-\cos \psi)^{3 / 2}}{a^{2}\left(s^{2}-1\right)} \mathcal{F}(s, l, m, k a)\left\{\quad \left[l m\left(s^{2}-1\right) \operatorname{sen} \psi(\cos \phi+\operatorname{sen} \phi)+\right.\right. \\
\left.\left(s^{2}-1\right)(s-\cos \psi)(\cos \phi-\operatorname{sen} \phi)\left(\frac{k^{2} a^{2}}{(s-\cos \psi)^{2}}-\frac{\cos \psi}{2(s-\cos \psi)}-\frac{m^{2}}{s^{2}-1}\right)\right] \cos (l \psi+m \phi)+ \\
\left.\left[m\left(s+\frac{s^{2}-3}{2} \cos \psi\right)(\cos \phi+\operatorname{sen} \phi)+l \operatorname{sen} \psi\left(s^{2}-1\right)(\cos \phi-\operatorname{sen} \phi)\right] \operatorname{sen}(l \psi+m \phi)\right\}+ \\
\frac{(1-s \cos \psi)(s-\cos \psi)^{3 / 2}}{a^{2}} \frac{\partial}{\partial \phi}[(\cos \phi+\operatorname{sen} \phi) \cos (l \psi+m \phi)] \frac{d}{d s} \mathcal{F}(s, l, m, k a)
\end{gathered}
$$

onde $k a$ é o autovalor procurado, sendo $a$ o parâmetro do sistema de coordenadas toroidal que aparece nas transformações (17), (18) e (19); c é a velocidade da luz no vácuo e $\mathcal{F}(s, l, m, k a)$ corresponde às soluções das equações (58) e (79), representadas respectivamente pelas expressões (71) e (92); ou seja:

$$
\mathcal{F}(s, l, m, k a)=\left\{\begin{array}{cl}
\frac{1}{\sqrt{s^{2}-1}} Q_{j 0}(s) & \text { equação }(71) \\
F(s) & \text { equação }(92)
\end{array}\right.
$$

Os termos proporcionais à derivada em $s$ da função $\mathcal{F}(s, l, m, k a)$, provêm do $\vec{\nabla} \cdot \vec{\Pi}$, como observado anteriormente; e correspondem aos termos em primeira ordem de aproximação em $1 / s$. Observe-se que estas derivadas não aparecem na expressão de $B_{\sigma}$.

$O$ caso em que $\Pi_{x y}=0$ e $\Pi_{z} \neq 0$ conduz à:

$$
\begin{gathered}
\mathbf{B}_{\sigma}=-\frac{(k a)}{a^{2} \mathbf{c}} \sqrt{s-\cos \psi} \mathcal{F}(s, l, m, k a) m \frac{1-s \cos \psi}{\sqrt{s^{2}-1}} \cos (l \psi+m \phi) \\
\mathbf{E}_{\psi}=-\frac{(s-\cos \psi)^{3 / 2}}{a^{2}} \mathcal{F}(s, l, m, k a)\left\{\quad \left[\frac{3}{4} s \cos \psi+\right.\right. \\
\left.(1-s \cos \psi)\left(\frac{k^{2} a^{2}}{(s-\cos \psi)^{2}}+\frac{s}{4(s-\cos \psi)}-l^{2}\right)\right] \cos (l \psi+m \phi)- \\
\left.l \operatorname{sen} \psi\left[2 s-\frac{s^{2}-1}{2(s-\cos \psi)}\right] \operatorname{sen}(l \psi+m \phi) \quad\right\}-\frac{\left(s^{2}-1\right)(s-\cos \psi)^{3 / 2}}{a^{2}} \frac{d}{d s} \mathcal{F}(s, l, m, k a) \\
\left\{\left[\frac{1-s \cos \psi}{2(s-\cos \psi)}+\frac{3 \cos \psi}{2}\right] \cos (l \psi+m \phi)-l \operatorname{sen} \psi \operatorname{sen}(l \psi+m \phi)\right\}
\end{gathered}
$$




$$
\begin{gathered}
\mathbf{E}_{\phi}=\frac{(s-\cos \psi)^{3 / 2}}{a^{2} \sqrt{s^{2}-1}} \mathcal{F}(s, l, m, k a)\{l m(1-s \cos \psi) \cos (l \psi+m \phi)+ \\
m \frac{s}{2} \operatorname{sen} \psi \operatorname{sen}(l \psi+m \phi) \\
-\frac{\sqrt{s^{2}-1}(s-\cos \psi)^{3 / 2}}{a^{2}} \frac{d}{d s} \mathcal{F}(s, l, m, k a) m \operatorname{sen} \psi \operatorname{sen}(l \psi+m \phi)
\end{gathered}
$$

Obviamente, a nomenclatura adotada em (105) continua válida aqui. Note-se, também, que os termos de primeira ordem aparecem apenas em $E_{\psi}$ e $F_{\phi}$.

A relação de dispersão para os modos ressonantes eletromagnéticos da cavidade toroidal resulta das condições de contorno. Considerando-as (expressão (94)) e às observações do início desta seção, pode-se perguntar porque calcular todas as três componentes de campo, se as equações de Maxwell as acoplam. A resposta diz respeito às soluções encontradas, pois se (71) e (92) fossem soluções exatas, bastaria fazer $B_{\sigma}\left(s_{0}\right)=0$ para que as componentes $E_{\psi}$ e $E_{\phi}$ também se anulassem. No entanto, (71) e (92) são soluções aproximadas do problema, e desse modo $B_{\sigma}\left(s_{0}\right)=0$ não garante que $E_{\psi}$ e $E_{\phi}$ se anulem. De fato, a condição para que $B_{\sigma}\left(s_{0}\right)=0$, tanto em (105) como em (107), corresponde a:

$$
\mathcal{F}\left(s_{0}, l, m, k a\right)=0
$$

Fsta condição, porém, não é suficiente para anular $F_{\psi}$ e $F_{\phi}$, pois os termos de primeira ordem não se tornam iguais a zero, seja em (105) ou em (107). Isto ocorre porque não se considerou todos os efeitos de primeira ordem na solução e, portanto, estes termos estão incompletos. Apesar disto, os termos de primeira ordem têm magnitude inferior àqueles de ordem zero e, comparativamente, podem ser desprezados. Isto mostra que a equação (108) é uma aproximação para a relação de dispersão verdadeira.

Outra característica de (108) é que suas raízes $(k a)$ só podem ser calculadas numericamente, o que no caso da solução (92) é relativamente simples, pois a função hipergeométrica é conhecida e suas raízes são tabeladas. Basta definir os valores de $s_{0}, l$ e $m$, que o "Mathematica" encontra o valor correspondente de $k a$ que satisfaz a relação de dispersão. No caso da solução (71) esta tarefa é mais trabalhosa, pois é preciso calcular a própria série antes de encontrar a sua raiz para um dado conjunto $s_{0}, l$ e $m$. Esta operação envolve o cálculo dos coeficientes $a_{r}$, com o uso de (68). No entanto, a série precisa ser truncada em algum ponto, o qual é escolhido de maneira prática, limitando o tempo de processamento da raiz, pelo "Mathematica", em dez minutos. Por causa disto, as raízes obtidas da solução por Frobenius são as raízes de um polinômio de grau 10 em $s_{0}$.

Nas tabelas abaixo, são apresentados os valores de $k a$ para as duas soluções encontradas e diversas escolhas dos parâmetros $s_{0}$ (razão de aspecto), $l$ (número de modo poloidal) e $m$ (número de modo toroidal). Note-se que, no caso da solução dada em termos da função hipergeométrica, se escolheu $\mu=-m$ para efeito de cálculo. Além disto, os valores tabelados correspondem à primeira raiz que ocorre para cada conjunto de parâmetros $\left(s_{0}, l\right.$ e $\left.m\right)$. 


\begin{tabular}{|c|c|c|c|c||c|c|c|c|}
\hline & \multicolumn{5}{|c||}{$l=0$} & \multicolumn{4}{c|}{$l=1$} \\
\hline$s_{0}$ & $m=0$ & $m=1$ & $m=2$ & $m=3$ & $m=0$ & $m=1$ & $m=2$ & $m=3$ \\
\hline 20,0 & 48,051 & 48,061 & 48,092 & 48,144 & 76,553 & 76,559 & 76,579 & 76,609 \\
\hline 5,00 & 11,839 & 11,881 & 12,006 & 12,212 & 18,829 & 18,856 & 18,934 & 19,065 \\
\hline 2,50 & 5,6285 & 5,7149 & 5,9667 & 6,3643 & 8,8974 & 8,9518 & 9,1130 & 9,3754 \\
\hline 1,50 & 2,8983 & 3,0548 & 3,4821 & 4,0960 & 4,4916 & 4,5905 & 4,8751 & 5,3155 \\
\hline 1,25 & 2,0677 & 2,2695 & 2,7877 & 3,4815 & 3,1340 & 3,2621 & 3,6190 & 4,1447 \\
\hline 1,10 & 1,4191 & 1,6631 & 2,2506 & 2,9612 & 2,0791 & 2,2191 & 2,6380 & 3,2238 \\
\hline
\end{tabular}

Tabela 2.1: Autovalores $(k a)$ associados à solução por Frobenius.

\begin{tabular}{|c|c|c|c|c||c|c|c|c|}
\hline & \multicolumn{5}{|c||}{$l=0$} & \multicolumn{4}{c|}{$l=1$} \\
\hline$s_{0}$ & $m=0$ & $m=1$ & $m=2$ & $m=3$ & $m=0$ & $m=1$ & $m=2$ & $m=3$ \\
\hline 20,0 & 48,061 & 48,071 & 48,102 & 48,154 & 76,577 & 76,583 & 76,603 & 76,635 \\
\hline 5,00 & 11,879 & 11,921 & 12,046 & 12,253 & 18,926 & 18,953 & 19,032 & 19,163 \\
\hline 2,50 & 5,7114 & 5,7991 & 6,0547 & 6,4582 & 9,0982 & 9,1538 & 9,3186 & 9,5870 \\
\hline 1,50 & 3,0540 & 3,2189 & 3,6696 & 4,3172 & 4,8624 & 4,9696 & 5,2780 & 5,7554 \\
\hline 1,25 & 2,2773 & 2,5000 & 3,0725 & 3,8409 & 3,6240 & 3,7726 & 4,1868 & 4,7978 \\
\hline 1,10 & 1,6990 & 2,0016 & 2,7119 & 3,5922 & 2,7020 & 2,9135 & 3,4704 & 4,2355 \\
\hline
\end{tabular}

Tabela 2.2: Autovalores $(k a)$ associados à solução hipergeométrica. 


\begin{tabular}{|c|c|c|c|c||c|c|c|c|}
\hline & \multicolumn{9}{|c||}{$l=2$} & \multicolumn{4}{c|}{$l=3$} \\
\hline$s_{0}$ & $m=0$ & $m=1$ & $m=2$ & $m=3$ & $m=0$ & $m=1$ & $m=2$ & $m=3$ \\
\hline 20,0 & 102,59 & 102,60 & 102,61 & 102,64 & 127,45 & 127,45 & 127,46 & 127,48 \\
\hline 5,00 & 25,201 & 25,221 & 25,280 & 25,378 & 31,275 & 31,291 & 31,339 & 31,418 \\
\hline 2,50 & 11,853 & 11,894 & 12,015 & 12,214 & 14,659 & 14,691 & 14,789 & 14,950 \\
\hline 1,50 & 5,8952 & 5,9691 & 6,1857 & 6,5305 & 7,2089 & 7,2685 & 7,4445 & 7,7288 \\
\hline 1,25 & 4,0466 & 4,1426 & 4,4181 & 4,8419 & 4,8888 & 4,9663 & 5,1919 & 5,5477 \\
\hline 1,10 & 2,8184 & 2,8136 & 3,0363 & 3,5365 & 5,0204 & 4,9393 & 3,7880 & 3,8779 \\
\hline
\end{tabular}

Tabela 2.3: Autovalores $(k a)$ associados à solução por Frobenius.

\begin{tabular}{|c|c|c|c|c||c|c|c|c|}
\hline & \multicolumn{5}{|c||}{$l=2$} & \multicolumn{4}{c|}{$l=3$} \\
\hline$s_{0}$ & $m=0$ & $m=1$ & $m=2$ & $m=3$ & $m=0$ & $m=1$ & $m=2$ & $m=3$ \\
\hline 20,0 & 102,64 & 102,64 & 102,66 & 102,70 & 127,52 & 127,53 & 127,54 & 127,56 \\
\hline 5,00 & 25,361 & 25,380 & 25,440 & 25,538 & 31,479 & 31,495 & 31,545 & 31,643 \\
\hline 2,50 & 12,182 & 12,224 & 12,348 & 12,553 & 15,120 & 15,154 & 15,254 & 15,421 \\
\hline 1,50 & 6,4943 & 6,5759 & 6,8148 & 7,1952 & 8,0421 & 8,1087 & 8,3052 & 8,6228 \\
\hline 1,25 & 4,8270 & 4,9420 & 5,2718 & 5,7795 & 5,9621 & 6,0570 & 6,3332 & 6,7683 \\
\hline 1,10 & 3,5819 & 3,7503 & 4,2147 & 4,8892 & 4,4041 & 4,5461 & 4,9471 & 5,5498 \\
\hline
\end{tabular}

Tabela 2.4: Autovalores $(k a)$ associados à solução hipergeométrica. 
Examinando as tabelas, o fato que mais chama atenção é a pequena separação entre os a.11tovalores associados a uma mesma razão de aspecto. Nos casos em que $s_{0}=20$ os autovalores são coincidentes, caracterizando uma completa degenerescência dos modos. A medida que valores menores de $s_{0}$ são considerados, a separação aumenta e a degenerescência desaparece. Na Tabela 4, por exemplo, se $\boldsymbol{l}=\mathbf{2}$ e $\boldsymbol{s}_{0}=\mathbf{2 0}$, a diferença de valores entre os casos $\boldsymbol{m}=\mathbf{0}$ e $\boldsymbol{m}=\mathbf{3}$ é de apenas $0,06 \%$. Para os mesmos valores de $l$ e $m$, mas com $\boldsymbol{s}_{\mathbf{0}}=\mathbf{1 , 2 5}$, a diferença aumenta para cerca de $20 \%$. Este comportamento, que é típico de todos os resultados mostrados acima, tem grande importância experimental, pois a possibilidade de verificar a validade destes resultados teóricos fica restrita a toróides de baixa razão de aspecto, onde se espera que os modos estejam separados.

Outra característica é a coincidência entre os autovalores obtidos de soluções diferentes, quando a razão de aspecto é grande. Nas Tabelas 1 e 2, por exemplo, quando se considera os casos correspondentes de $l$ e $m$, e $\boldsymbol{s}_{0}=\mathbf{2 0}$, a diferença entre os autovalores é de $0,025 \%$, em média. Se $\boldsymbol{s}_{\mathbf{0}}=\mathbf{5}$, a diferença vai a $0,4 \%$, aproximadamente. É evidente que nestes dois casos os resultados devem ser considerados como sendo iguais. Por outro lado, a distinção dos autovalores começa em $\boldsymbol{s}_{0}=\mathbf{2 , 5}$, quando a diferença relativa fica entre $1,5 \%$ e $2,25 \%$, dependendo do caso. Para os três valores restantes de $s_{0}$, os autovalores são, efetivamente, diferentes.

O motivo deste comportamento pode ser explicado pela análise das equações (58) e (79), pois se nestas duas equações for feita a aproximação $s \gg 1$, elas se igualam e passam a:

$$
\frac{d}{d s}\left[s^{2} \frac{d P_{j 0}}{d s}\right]-\left[l^{2}-\frac{1}{4}+\frac{m^{2}}{s^{2}}-\frac{k^{2} a^{2}}{s^{2}}\right] P_{j 0}=0
$$

O que os resultados numéricos dizem, é que $\boldsymbol{s}>\mathbf{2 , 5}$ já pode ser considerado muito maior que um.

A última observação diz respeito aos autovalores do caso $\boldsymbol{s}_{\mathbf{0}}=\mathbf{1}, \mathbf{1}$. De um modo geral, a medida que o valor de $m$ a.umenta, o a.utovalor correspondente também aumenta. No entanto, para a solução por Frobenius e $\boldsymbol{l}=\mathbf{3}$, este comportamento se inverte completamente. Isto sugere que os resultados para $s_{0}=1,1$ não merecem confiança. Provavelmente, isto ocorre devido ao fato de $s_{0}=1,1$ estar muito próximo do limite de validade das expansões (43) e (51), em que se admite que $s>1$. Sendo assim, este valor da razão de aspecto não foi considerado para efeito de projeto da cavidade toroidal, construída a fim de verificar experimentalmente os resultados teóricos obtidos. A montagem do arranjo experimental é o assunto do próximo capítulo. 


\section{Capítulo 3}

\section{ARRANJO EXPERIMENTAL}

Fste capítulo é dedicado à descrição da montagem do arranjo experimental, desde o projeto da cavidade toroidal, até os últimos cuidados com a sua superfície interna, antes dos primeiros ensaios experimentais. Assim como o capítulo anterior ele está estruturado em seções, as quais refletem as várias fases da montagem.

\subsection{Projeto e Construção da Cavidade Toroidal}

As dimensões de um toróide são definidas pelos valores do raio maior $\left(R_{0}\right)$ e do raio menor $\left(r_{0}\right)$. A razão de aspecto $\left(s_{0}=R_{0} / r_{0}\right)$, por outro lado, define o que se poderia chamar a toroidicidade, pois quanto menor o seu valor mais compacto e curvo é o sólido. Deste modo, quando se quer construir um toróide são estes parâmetros que devem ser considerados.

Neste trabalho, o interesse é medir as auto-freqüências da cavidade ressonante toroidal, o que exige uma separação entre elas que possibilite as medidas. De acordo com os resultados teóricos apresentados no final do capítulo anterior, esta condição só pode ser satisfeita se a razão de aspecto for pequena. A menor razão de aspecto, cujos autovalores calculados merecem confiança, é $s_{0}=1,25$. Além de permitir um teste severo da teoria, este valor tem a. vantagem de estar na região proposta para os tokamaks esféricos. Paralelamente, as perdas resistivas tendem a ser menores e a acurácia na medida do índice de mérito $(Q)$ tende a ser maior num toróide compacto. Por isto, $s_{0}=1,25$ foi escolhido como a razão de aspecto da cavidade a ser construída.

Os valores do raio maior $\left(R_{0}\right)$ e do raio menor $\left(r_{0}\right)$ foram definidos levando-se em conta mais dois fatores: primeiro, a conveniência em acomodar o arranjo sobre uma mesa comum (o que delimita o valor de $R_{0}$ ) e, segundo, a necessidade de acesso à superfície da parte central do toróide, junto ao eixo de simetria (o que delimita o valor de $r_{0}$ ). Dois valores que satisfizeram a todos os requisitos foram: $R_{0}=12,5 \mathrm{~cm}$ e $r_{0}=10,0 \mathrm{~cm}$. Desta maneira, a cavidade toroidal ficou definida como: $\boldsymbol{R}_{0}=\mathbf{1 2 , 5} \mathrm{cm}, r_{0}=10,0 \mathrm{~cm}$ e $s_{0}=\mathbf{1 , 2 5}$. 
A etapa seguinte no projeto da cavidade foi a escolha do material a ser usado e a técnica construtiva a ser empregada. Fntre os metais condutores disponíveis para uso num dispositivo como a cavidade, aquele que apresenta a melhor relação custo/benefício é a prata; no entanto, mesmo a simples prateação da superfície interna do toróide levaria a uma alta expressiva nos custos de construção, dada a necessidade de controle sobre a espessura do filme; isto sem considerar as dificuldades impostas pela geometria da superfície. Pensando nestes detalhes, é que o cobre foi escolhido como o material do toróide.

A primeira alternativa para a construção da cavidade foi a compra de seç̧ões curvas de tubos de cobre, as quais soldadas dariam origem ao toróide. No entanto, as peças necessárias para esta montagem não foram encontradas, tornando-se evidente que a cavidade precisaria ser fabricada. Quatro técnicas em metalurgia foram consideradas para a fabricação. A primeira foi estamparia, que terminou sendo descartada por motivos técnicos. A segunda foi a usinagem de anéis de cobre, os quais seriam soldados posteriormente para formar o toróide. Esta alternativa foi deixada de lado devido aos custos, prazo de execução e possíveis problemas com a soldagem dos anéis. A terceira técnica considerada. foi a fundição. Infelizmente, depois que alguns ensaios construtivos mostraram problemas na solidificação do cobre, ela também foi abandonada. Finalmente, a técnica empregada na fabricação da cavidade foi o repuxo. Por este método, uma chapa de cobre recozida foi empurrada contra um molde preso num torno. Alavancas foram utilizadas para fazer a chapa se amoldar. No caso da nossa cavidade foram usados dois moldes. Um para a parte central do toróide, junto ao eixo de simetria, e outro para a parte mais externa. $\mathrm{O}$ primeiro foi confeccionado em aço, e o segundo em madeira. A câmara toroidal assim moldada, é constituída de duas peças (conchas) que se assemelham a essas formas de bolo com um orifício no centro; e da sobreposição delas se forma o toróide.

A técnica de repuxo apresentou três desvantagens: a primeira foi a dificuldade de controlar as dimensões das duas conchas toroidais, de modo que elas tivessem os mesmos valores, embora as diferenças verificadas sejam toleráveis. A segunda foi a irregularidade no acabamento das bordas das conchas, que demandou um grande esforço para ser eliminada. A terceira foi a limitação imposta às soldas; pois como o processo é conduzido a quente, a chapa já moldada, ao esfriar, guarda tensões elevadas e numa solda elas poderiam relaxar deformando a cavidade.

Note-se que, a partir da definição do projeto da cavidade, todo o processo construtivo levou cerca de seis meses.

\subsection{Preparação da Cavidade}

Embora a cavidade toroidal se confunda com a própria câmara, para medir as suas autofreqüências foi necessário providenciar uma série de outros dispositivos; como por exemplo: um suporte para o toróide, as antenas para excitação da cavidade e um apoio para elas serem instaladas na câmara. Além disto, foram feitas intervenções diretas nas conchas toroidais para adaptá-las às necessidades experimentais. Por isto, esta seção é dedicada à descrição destas intervenções e implantação dos dispositivos. 


\subsubsection{Conferindo as Dimensões da Câmara Toroidal com os Valores de Projeto}

A primeira providência, depois que a câmara toroidal ficou pronta, foi conferir as suas dimensões com os valores de projeto. Os resultados destas medidas foram:

$$
\begin{array}{rlll}
R_{0_{1}} & =(12,55 \pm 0,02) \mathrm{cm} & \text { e } & R_{0_{2}}=(12,56 \pm 0,01) \mathrm{cm} \\
r_{0_{1}} & =(10,00 \pm 0,02) \mathrm{cm} & \text { e } & r_{0_{2}}=(9,99 \pm 0,02) \mathrm{cm}
\end{array}
$$

Nos dados acima, os sub-índices 1 e 2 designam cada uma das conchas toroidais, sendo que os valores representam médias sobre várias medidas feitas em diferentes pontos das conchas. A medida do raio menor $r_{0}$ tem uma particularidade: ela corresponde ao raio da secção transversal da concha toroidal, e foi obtida de modo indireto através do perímetro interno da secção. Como observado anteriormente, as diferenças entre os valores de projeto e os dados acima derivam do método de fabricação da cavidade.

As razões de aspecto correspondentes a cada uma das conchas ficaram:

$$
s_{0_{1}}=1,255 \pm 0,003 \quad \text { e } \quad s_{0_{2}}=1,257 \pm 0,003
$$

No capítulo precedente, as Tabelas 1, 2, 3 e 4 mostram que os autovalores dependem da razão de aspecto. Como a razão de aspecto real é ligeiramente diferente daquela que consta nas tabelas, alguns autovalores foram recalculados para comparação com o caso em que $s_{0}=1,25$. Por exemplo: se $s_{0}=1,26, l=2$ e $m=0$, o autovalor é $1,5 \%$ maior que aquele em que $s_{0}=1,25$. Esta diferença, porém, não tem importância do ponto de vista experimental, de modo que as variações nas dimensões da cavidade podem ser toleradas.

\subsubsection{Regularização das Bordas das Conchas Toroidais}

O passo seguinte, na preparação da cavidade, foi eliminar as irregularidades nas bordas interna e externa das conchas toroidais. Isto foi necessário para acabar com as frestas que se formavam na junção das conchas quando elas eram sobrepostas. Para regularizar as bordas foi preciso desbastá-las com o uso de lixas-pano de duas granulações diferentes. Uma mais grossa ( $\left.\mathrm{n}^{\underline{0}} 100\right)$, para desgastar o cobre; e outra mais fina ( $\left.\mathrm{n} \underline{0} 150\right)$, para acabamento. A folha de lixa-pano era assentada sobre uma mesa de desempeno e as conchas friccionadas sobre ela, de modo a produzir um desgaste uniforme. Depois de cada seção de desbaste, o estado das frestas era verificado através de teste, o qual consistia na colocação de uma lanterna no interior da câmara toroidal e verificação da passagem de luz pela junção das conchas. Foram necessárias várias seções de desbaste até que se conseguisse o resultado desejado; mesmo assim, este procedimento se mostrou eficiente apenas para a junção externa. Na parte interna, a persistência das frestas foi mais um resultado da dificuldade de controlar as dimensões das conchas toroidais durante a sua fabricação, pois a borda interna da concha $n^{0} 2$ ficou mais baixa que a sua borda externa. 
Por isto, as frestas na junção interna só foram eliminadas com a introdução de um anel de estanho entre as conchas. Fste anel se assemelha a um antigo chapéu de palha com aba larga (a palheta), e devido a sua forma exigiu o desenvolvimento de um estampo em aço para sua confecção. Um esboço do molde é dado nas Figuras 1 e 2 no Apêndice.

O estanho para os anéis foi obtido a partir de uma barra de solda, a qual foi fundida em dois pequenos lingotes. Estes, por sua vez, foram laminados até atingirem a espessura de 0,18 mm. Em seguida, as lâminas foram recortadas em pequenos discos, os quais foram prensados no estampo de aço produzindo os anéis. Na prensagem, os anéis se encharcavam de óleo e por isto, foi preciso lavá-los com acetona posteriormente. O acabamento final era o recorte das abas, para que elas adquirissem a largura apropriada.

O estanho foi escolhido como material para os anéis por ser um metal muito maleável, que se moldaria com facilidade às superfícies das bordas internas das conchas, quando elas estivessem sobrepostas e comprimidas uma contra a outra.

\subsubsection{Projeto e Construção do Suporte para a Cavidade}

Paralelamente à eliminação das frestas na junção das conchas toroidais, foi projetado e construído um suporte que mantém as duas metades da câmara unidas rigidamente. Além desta função mecânica, o suporte é o responsável pelo contato elétrico entre as duas metades, sendo composto por dois discos de alumínio, dois discos de isopor com $10 \mathrm{~cm}$ de altura e varetas de rosca para fixação (veja os esboços dos discos nas Figuras 3 e 4 no Apêndice). É importante salientar que foi usado o isopor de mais alta densidade, classificado comercialmente como "P3", dada a sua maior resistência à deformação por compressão.

A montagem do suporte segue a seguinte seqüência: sobre um dos discos de alumínio assenta-se um dos discos de isopor, e sobre os dois coloca-se uma das conchas toroidais; em seguida, a segunda concha toroidal é sobreposta à primeira, formando o toróide; sobre ele são apoiados o segundo disco de isopor e de alumínio. O conjunto assim formado assemelha-se a um "waffer", cujo recheio é o toróide e onde os discos de isopor funcionam como amortecedores e distribuidores da pressão exercida sobre a câmara, quando do aparafusamento das varetas de rosca que passam através das extremidades de todos os discos. As fotos anexas ao texto dão uma idéia melhor das etapas de montagem do sistema. Note-se que os discos apresentam recortes que permitem o acesso à região central da cavidade, a três pontos na sua parte superior e a um ponto na parte inferior.

\subsubsection{Construção e Instalação das Antenas para Excitação da Cavidade}

Uma vez garantido o contato elétrico entre as conchas, por meio do suporte e dos cuidados com as bordas, a etapa subseqüente foi prover a cavidade de orifícios que permitissem sua 
excitação por meio de uma antena e o acesso ao seu interior para medidas experimentais. Contudo, a preocupação em não alterar excessivamente os contornos da cavidade funcionou como um limite ao número de perfurações da parede do toróide. Este limite terminou conferindo maior importância às posições dos orifícios, que foram escolhidas de maneira a propiciar um grande número de arranjos experimentais, visando a excitação e a deteção dos modos ressonantes. Há seis orifícios no equador; quatro deles alinhados ao longo de um diâmetro do toróide e os outros dois alinhados a $90^{\circ}$ em relação aos primeiros. No topo, ao longo da direção toroidal, existem mais três furos nas posições $0^{\circ}, 90^{\circ}$ e $180^{\circ}$. Um esquema da distribuição dos orifícios sobre a câmara é mostrado nas Figuras 5 e 6 no Apêndice.

Note-se que os orifícios no equador são quadrados e aqueles no topo são circulares. Fsta distinção resultou da necessidade de utilizar equipamentos diferentes na perfuração de um e de outro. No equador foi usada uma fresa e no topo uma furadeira.

Quando um orifício qualquer não está sendo utilizado, pequenas tampas de cobre (semelhantes a botões) são usadas para fechá-lo, garantindo uma maior uniformidade do contorno.

O diâmetro dos orifícios, as dimensões das antenas e a escolha dos conectores onde elas seriam montadas foram determinados um em função do outro, e levando em conta o fato de que, quanto menores estes dispositivos, menor a perturbação da cavidade. Por isto, todos os orifícios têm $4 \mathrm{~mm}$ de diâmetro e os conectores escolhidos são da série SMA. No caso dos conectores, pesou também o desempenho na faixa de freqüência até $4 \mathrm{GHz}$.

Dois tipos de antena foram montados sobre receptáculos fêmea SMA. O primeiro tipo corresponde à antena de dipolo elétrico, que nada mais é que um eletrodo soldado ao conector. O segundo tipo corresponde à antena de dipolo magnético, cuja forma é a de uma espira (loop) de corrente retangular. Para cada tipo de antena foram montados três exemplares de tamanhos diferentes, mas tanto num caso, como no outro, isto significou mudar somente o comprimento das antenas. Deste modo, os comprimentos das antenas elétricas ficaram: $24 \mathrm{~mm}$ (grande), $20 \mathrm{~mm}$ (médio) e $17 \mathrm{~mm}$ (pequeno). Do seu lado, os comprimentos das antenas magnéticas ficaram: $23 \mathrm{~mm}$ (grande), $19 \mathrm{~mm}$ (médio) e $15 \mathrm{~mm}$ (pequeno).

O material usado na confecção das antenas foi fio de cobre esmaltado de 0,6 mm de diâmetro. Este diâmetro precisava ser pequeno para garantir as dimensões reduzidas das antenas, evitando que elas tocassem nas paredes da cavidade quando introduzidas pelos orifícios.

A fixação das antenas na cavidade requereu o projeto e a construção de um suporte em cobre para o receptáculo fêmea SMA. Um esquema deste suporte é dado na Figura 7 no Apêndice, onde se deve observar as pequenas dimensões da peça.

A colocação deste suporte no equador exigiria o seu aparafusamento ou a sua soldagem nas paredes da câmara, mas ambos eram desaconselháveis por causa dos riscos de danificar o toróide. Sendo assim, decidiu-se pela fixação do suporte no topo da cavidade, pois sua colocação neste ponto podia ser feita de outro modo.

Antes de fixar o suporte, porém, foi preciso acertar a curvatura da sua área de contato com a superfície do toróide. Para isto, recortes de uma lixa d'água fina ( $\left.\mathrm{n}^{0} 500\right)$ foram 
assentados sobre a superfície da cavidade e o suporte friccionado sobre a lixa numa única direção, de modo que o desgaste do cobre fosse desigual, acompanhando os contornos da superfície toroidal. O controle do processo foi feito visualmente e o momento de parar decidido com base na acomodação do suporte.

A maneira encontrada para fixar o suporte, sem agredir os contornos do toróide, foi a sua colagem. No entanto, isto também não pôde ser feito como de costume; pois em geral, as colas são isolantes elétricos e a interface entre o suporte e a superfície da cavidade precisava ser condutora. A solução foi envolver o suporte das antenas com araldite, sendo que o procedimento para obter o resultado desejado foi o seguinte: passando um parafuso através dos orifícios da cavidade e do suporte, eles foram alinhados e o suporte imobilizado, garantindo-se o contato elétrico também; em seguida, para evitar que a araldite escorre-se pela parede da câmara toroidal, um anel de massa epóxi foi colado sobre o toróide, envolvendo o suporte à distância. Feito isto, a araldite foi preparada e aquecida (para se liquefazer), sendo despejada em torno do suporte na área delimitada pelo anel de epóxi. Depois que a cola secou o parafuso foi removido. Dois suportes para antenas foram fixados desta maneira sobre o topo da câmara, como pode ser visto nas fotos anexas.

A qualidade do contato elétrico entre os suportes e a cavidade foi verificada por meio da medida da resistência entre eles. Considerando um ponto na borda equatorial da concha e outro no suporte a resistência deu $\leq 0,06 \Omega$.

A instalação das antenas na cavidade é feita mediante o seu aparafusamento nos suportes e para sua conexão com o analizador de rede a ser usado nas medidas experimentais, foram montados cabos coaxiais com os conectores SMA e o cabo RG-58 da Pirelli. Há três cabos com $0,5 \mathrm{~m}$ e três cabos com $1,0 \mathrm{~m}$ de comprimento. As curvas típicas para o coeficiente de transmissão destes cabos são mostradas nas Figuras 8 e 9 no Apêndice. Observe-se que a faixa de freqüência em que eles foram utilizados começa em $0,1 \mathrm{GHz}$ e termina em 4,0 GHz.

\subsubsection{Cuidados Finais com a Cavidade}

Antes de fechar a cavidade para as medidas experimentais, a sua superfície interna foi lixada com uma fina palha de aço, polida com KAOL e lavada com acetona. No decorrer da coleta dos dados experimentais, foi verificado que os dois últimos passos acima precisavam ser repetidos sempre que a cavidade era aberta, isto para garantir a reprodutibilidade. Fste e outros detalhes do processo de medidas serão discutidos no próximo capítulo. 


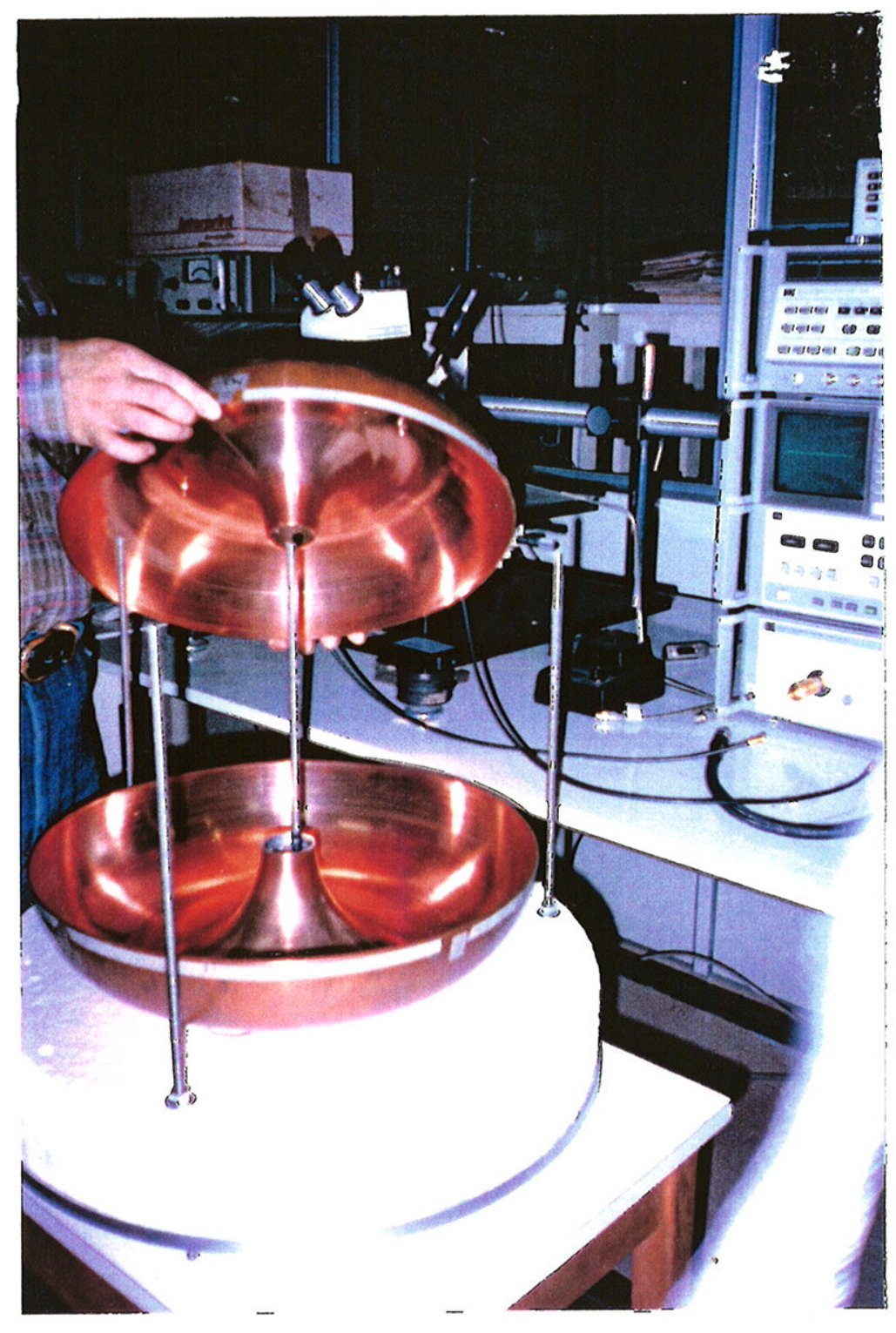

Foto 3.1 : Etapa de Montagem da Cavidade Toroidal e do seu Suporte 


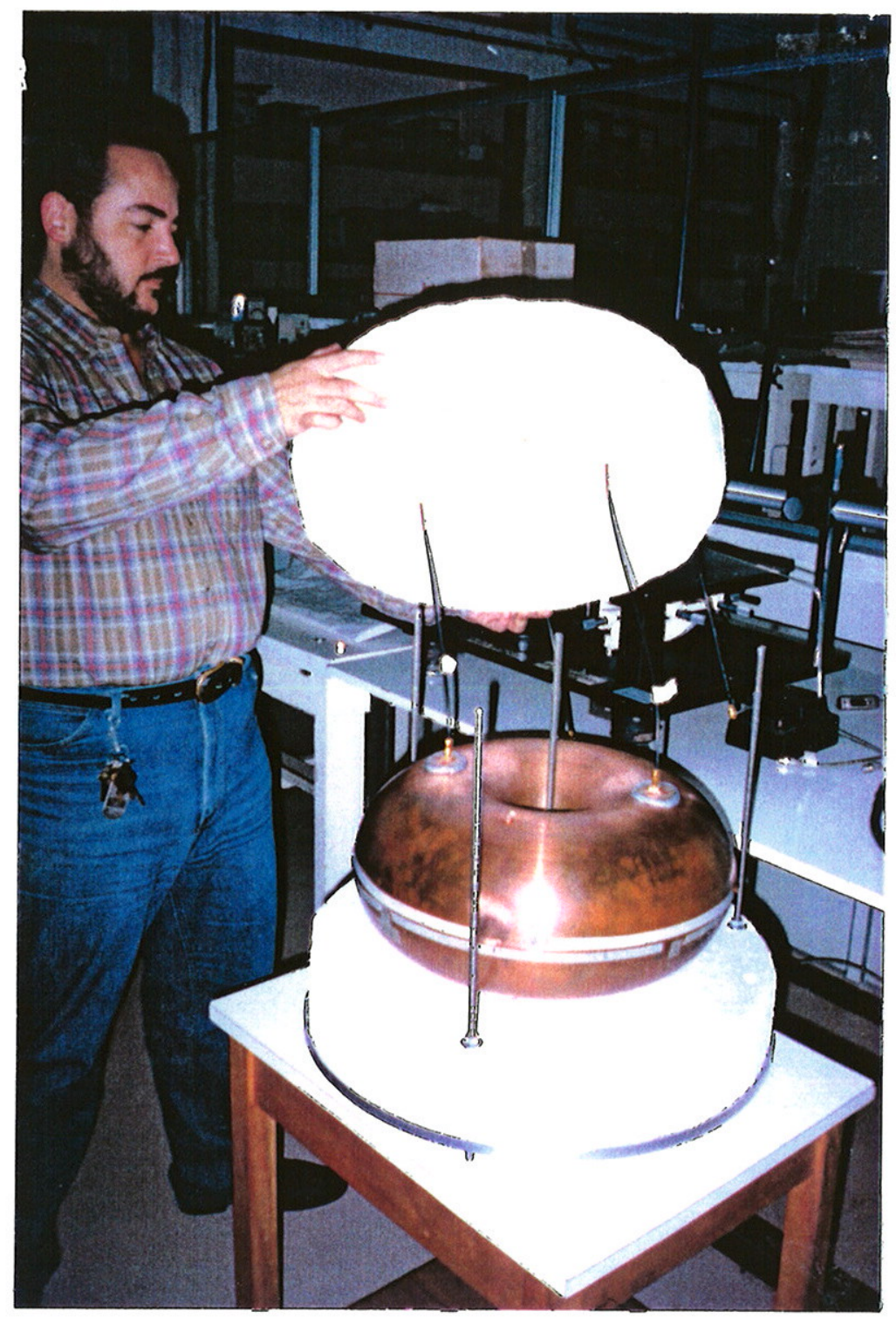

Foto 3.2 : Etapa de Montagem da Cavidade Toroidal e do seu Suporte 


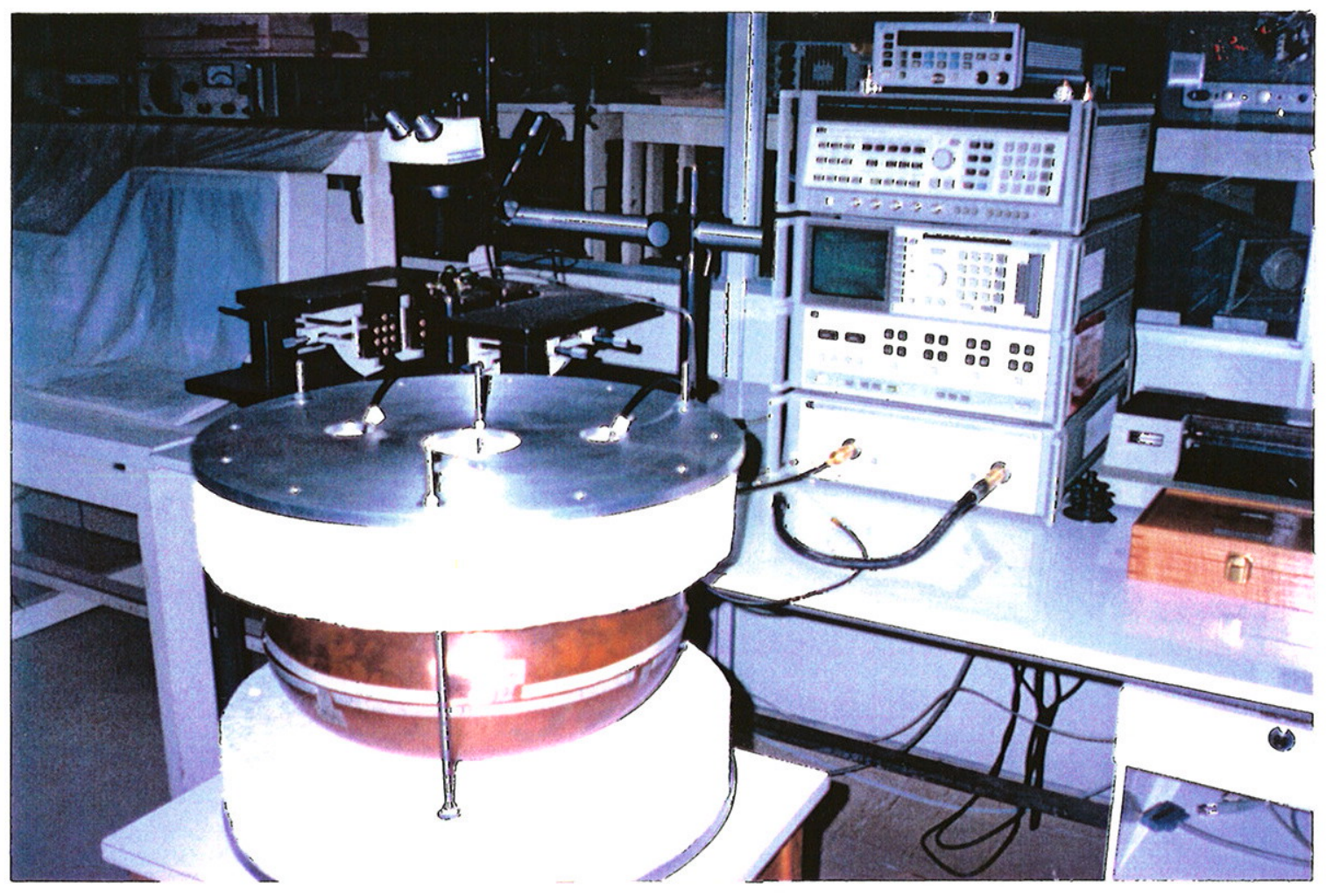

Foto 3.3 : Cavidade Toroidal e Suporte Montados (ao fundo se vê o Analisador de Rede HP-8510B) 


\section{Capítulo 4}

\section{DADOS EXPERIMENTAIS}

Este capítulo é dedicado à descrição do trabalho realizado para se obter os dados experimentais. Como todos os capítulos anteriores ele está organizado em seções, as quais refletem os vários aspectos em torno da obtenção dos dados. A montagem experimental inclue a cavidade, com as antenas instaladas, e um analisador de rede composto de três módulos. No diagrama de blocos abaixo, esta montagem é mostrada esquematicamente.

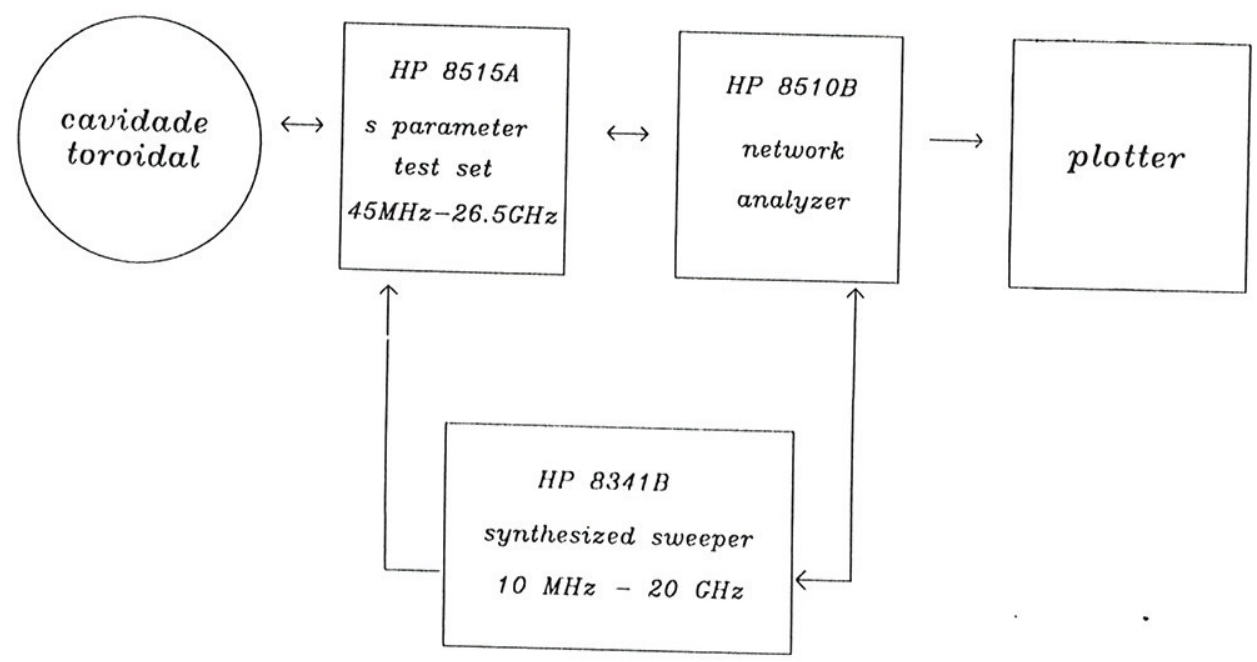




\section{1 Últimos Ajustes Experimentais da Cavidade}

Todos os ensaios experimentais foram precedidos por uma limpeza da superfície interna. e das bordas das conchas toroidais, onde elas eram polidas com KAOL e lavadas com acetona, conforme já mencionado no final do capítulo anterior. Além disto, as antenas e seus suportes também eram limpos com acetona a cada nova série de medidas. Estas precauções se mostraram necessárias para garantir a reprodutibilidade dos dados.

Como consequência do fato das dimensões das conchas não serem exatamente as mesmas, a sobreposição delas requereu certos cuidados. Cautelosamente, foi procurada a posição relativa das conchas que melhor ajuste das bordas proporcionava; esta posição foi marcada e sempre que as conchas precisavam ser sobrepostas, o eram, nesta posição.

Embora o suporte da cavidade dispusesse de treze varetas de rosca para sua montagem, verificou-se que era possível usar apenas quatro (a vareta central e três outras na extremidade dos discos, à $120^{\circ}$ uma da outra). As porcas e contra-porcas utilizadas, nestas quatro varetas, foram parafusadas com um torquímetro que garantia um aperto de 0,9 N.m (ou 8 lb-in), permitindo as mesmas condições mecânicas em todos os ensaios experimentais.

Depois de montada, a cavidade tinha a junção das duas metades pintada com uma tinta à base de prata (Leitsilber 204), para eliminar possíveis vazamentos de microondas quando ela fosse excitada. A maneira prática de verificar a ocorrência destes vazamentos era tocar a junção das conchas toroidais com a cavidade em funcionamento e observar o comportamento do sinal. Do mesmo modo, a qualidade do terra era verificada tocando o toróide com as mãos e observando a resposta do sinal.

\subsection{Descrição do Equipamento de Medida}

O equipamento utilizado nas medidas experimentais (veja o diagrama de blocos na página anterior) é capaz de excitar e detectar, ele próprio, os modos ressonantes eletromagnéticos da cavidadc toroidal. Elc ć constituído de três módulos distintos: um sintctizador dc freqüências com varredura em freqüência (HP 8341B Synthesized Sweeper $10 \mathrm{MHz}$ $20 \mathrm{GHz}$ ), responsável pela geração do sinal; um analisador de rede (HP 8510B Network Analyzer), responsável pelo processamento da resposta da cavidade e uma unidade sensora (HP 8515A S Parameter Test Set 45MHz-26,5 GHz). Além disto, na saída da unidade sensora é conectado um cabo especial (HP 85132-60004 7mm Flexible Test Port Cable). O conjunto é comercialmente conhecido pelo nome de Analisador de Rede - HP 8510B. Sendo um equipamento com tecnologia digital, ao selecionar uma faixa de freqüencia para medida, esta faixa é amostrada com um determinado número de pontos. O equipamento permite escolher entre 51, 101, 201, 401 e 801 pontos de amostragem. No caso deste trabalho, foi decidido o uso do maior número possível de pontos, com o objetivo de aumentar a precisão das medidas, ou seja: 801 .

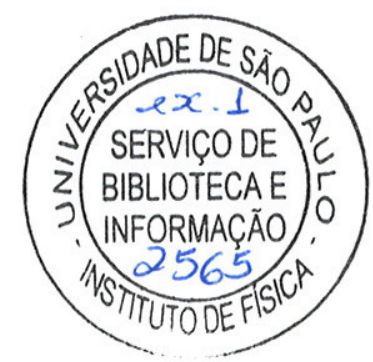


O sinal gerado pelo sintetizador tem as seguintes características: a resolução em freqüência é $\leq 3 \mathrm{~Hz}$, a máxima potência de saída é de $10 \mathrm{~mW}$ e a estabilidade de $1 \times 10^{-9}$ por dia, depois de 72 horas de aquecimento. A resolução e a estabilidade são garantidas por um oscilador à cristal, mantido em temperatura constante no interior de um forno.

O módulo analisador de rede permite a visualização da resposta em freqüência da cavidade, por meio de uma tela semelhante à de um osciloscópio e, além disto, têm duas saídas para registros impressos. Uma delas, ligada a uma plotter, imprime o gráfico visto na tela. A outra saída, ligada a uma impressora matricial, imprime uma tabela com os valores da abscissa e da ordenada deste mesmo gráfico. É possível, também, escolher o tipo de unidade de escala a ser usada na ordenada, bem como definir qualquer faixa de freqüência para ser mostrada na abscissa.

Um outro recurso que o analisador oferece é um marcador ("marker"), por meio do qual um determinado ponto do gráfico (amplitude $\times$ freqüência) pode ser destacado e o valor da sua abscissa medido com precisão.

Para a medida das auto-freqüências da cavidade, o parâmetro de espalhamento escolhido foi o coeficiente de reflexão de tensão $S_{11}\left(\mathrm{~V}_{\text {refletida }} / \mathrm{V}_{\text {incidente }}\right)$; desta maneira, o princípio físico das medidas é claro: ao varrer uma faixa de freqüência qualquer e encontrar uma ressonância, a reflexão de tensão cai, devido ao casamento do sinal enviado pelo gerador com a cavidade, isto provoca uma queda no nível do sinal observado $\left(S_{11}\right)$ na tela do equipamento, assinalando a ocorrência da ressonância. A freqüência deste ponto era medida com o auxílio do marcador.

Uma outra característica importante do HP 8510 B é que ele precisava ser calibrado para medir o parâmetro $S_{11}$, qualquer que fosse a faixa de freqüência de interesse. Deste modo, a cada faixa de freqüência que aparece neste trabalho corresponde uma calibração do equipamento. Esta calibração consistia em medir três padrões de carga: um curto-circuito $\left(S_{11}=1 \mid \underline{180^{\circ}}\right)$, um aberto $\left(S_{11}=1 \mid \underline{0^{\circ}}\right)$ e uma carga casada de $50 \Omega\left(S_{11}=0 \mid \underline{0^{\circ}}\right)$, guardando os valores como referência, para posterior comparação com as medidas da cavidade. Além disto, a calibração era feita sempre no mesmo ponto: a extremidade livre do cabo HP conectado na saída do módulo sensor. Posteriormente, nesta extremidade foram ligados os cabos das antenas.

\subsection{Aspectos Experimentais da Instalação das Antenas}

Dada as características do HP 8510B, a excitação da cavidade e a detecção das suas ressonâncias puderam ser feitas num mesmo ponto, pela mesma antena. Como a câmara toroidal dispõe de dois suportes para a sua instalação, foi possível manter uma antena elétrica e uma magnética conectadas à cavidade; isto permitiu a comparação de resultados 
experimentais em situações idênticas.

Embora os suportes estejam situados no topo do toróide, durante a coleta de dados foi verificado que era possível excitar a cavidade por um dos orifícios no equador. Nestes casos, para manter em posição o receptáculo sobre o qual a antena estava montada, era. necessário pressioná-lo contra as paredes da câmara com as mãos. Apesar disto, não se observou efeitos deletérios no comportamento da cavidade.

É importante notar que as antenas magnéticas admitiam duas orientações: em uma delas, o campo magnético criado era paralelo ao eixo toroidal $\left(B_{\phi}\right)$ e na outra o campo era perpendicular a este eixo $\left(B_{\psi}\right)$. Estas orientações foram designadas "paralela $(/ /)$ " e "perpendicular $(\perp)$ ", respectivamente. Ao contrário, a antena elétrica foi orientada sempre radialmente. Um cuidado adicional no manuseio das antenas foi o uso de um mesmo cabo para uma mesma antena, ao longo de todo o experimento.

$\mathrm{O}$ fato das antenas propiciarem um certo número de arranjos, levou à necessidade de relacioná-los; ou seja: a cavidade pode ser excitada através de uma antena elétrica ou magnética, seja pelo topo ou pelo equador da câmara toroidal; o comprimento das antenas pode variar e no caso das magnéticas, elas admitem duas orientações distintas. Note-se que o comportamento da cavidade em todas estas situações foi estudado.

\subsection{Obtenção dos Dados}

Como comentado anteriormente, medindo o coeficiente de reflexão de tensão $S_{11}$ em função da freqüência, foi possível detectar as ressonâncias da cavidade. A relação entre estas grandezas era mostrada graficamente pelo HP $8510 \mathrm{~B}$, sendo que na ordenada $\left(S_{11}\right)$ foi usada uma escala logaritmica (em dB's) e na abscissa (freqüência) uma escala linear. A medida das freqüências ressonantes foi feita com o uso do marcador ("marker"), diretamente da tela do Analisador de Rede.

O complemento à caracterização de uma dada ressonância era a medida do seu índice de mérito $(Q)$, feita a partir da relação:

$$
Q=\frac{f_{\text {ressonante }}}{f_{2}-f_{1}}
$$

onde $f_{2}-f_{1}$ corresponde à largura da curva de ressonância, a $3 \mathrm{~dB}$ 's do valor de pico. Note-se que para realizar esta medida era necessário expandir o pico ressonante, considerando uma faixa de freqüência mais estreita ( $Q$ elevado). No entanto, os valores de freqüência necessários ao cálculo de $Q$ não foram obtidos diretamente da tela, mas da tabela impressa com os valores da abscissa (freqüência) e ordenada $\left(S_{11}\right)$. Este procedimento garantiu resultados mais precisos para o índice de mérito, cujos valores eram bastante altos (da ordem de $10^{4}$ ). Por causa destes valores também, na maioria dos gráficos a serem mostrados os picos ressonantes aparecem como linhas estreitas, uma vez que $f_{2}-f_{1}$ era pequeno.

$\mathrm{O}$ fato do HP $8510 \mathrm{~B}$ trabalhar com amostragens, trouxe o seguinte problema: ao definir uma faixa de freqüência a ser investigada, como garantir que os pontos amostrados 
coincidissem com as eventuais ressonâncias da cavidade? Uma das providências neste sentido foi escolher 801 pontos de amostragem; entretanto, ainda foi necessário encontrar, empiricamente, a maior largura da faixa de freqüência que não mascarava a resposta da. cavidade. Depois de ensaios específicos para este fim, o valor considerado satisfatório foi $200 \mathrm{MHz}$. Assim, a cavidade foi excitada com freqüências crescentes a intervalos regulares de $200 \mathrm{MHz}$.

As próximas três sub-seções descrevem de forma minuciosa a obtenção dos dados, os quais são apresentados de forma resumida na última seção deste capítulo.

\subsubsection{Excitação da Cavidade pelo Topo}

Os primeiros dados foram obtidos com a antena elétrica (grande) instalada no topo da câmara toroidal. Os gráficos nas Figuras 1 e 2 mostram os resultados encontrados. Note-se que de $45 \mathrm{MHz}$ até $800 \mathrm{MHz}$ não foi observada nenhuma ressonância; como este resultado se reproduziu em todos os arranjos experimentais, é possível dizer que a cavidade não apresenta modos ressonantes neste intervalo de freqüência. $\mathrm{Na}$ faixa de $800 \mathrm{MHz}$ a 1,0 GHz apareceu uma única ressonância em 950,5 MHz, a qual está assinala.da no gráfico (Figura 1). Embora este pico ressonante tenha sido expandido, a medida do seu índice de mérito $(Q)$ não foi possível porque sua amplitude era inferior a $3 \mathrm{~dB}$ 's. Deve-se notar, por outro lado, que o sinal em $837,0 \mathrm{MHz}$ não se caracterizou como um modo ressonante, pois ao expandir a faixa da freqüência em torno dele, o sinal desapareceu.

A faixa de 1,0 a $1,2 \mathrm{GHz}$ apresentou duas ressonâncias: uma em $1,08475 \mathrm{GHz}$ e outra em 1,182 GHz, a qual está assinalada no gráfico (Figura 2). A primeira destas duas ressonâncias tinha amplitude menor que $3 \mathrm{~dB}$ 's, mas o índice de mérito $(Q)$ da segunda ficou em torno de $6 \times 10^{4}$.

A excitação da cavidade com a antena magnética (grande) foi o passo seguinte. Os resultados podem ser vistos nos gráficos das Figuras 3, 4, 5 e 6 . Note-se que o intervalo de 45 a $800 \mathrm{MHz}$ não é mostrado nestas Figuras, uma vez que não foram observadas ressonâncias nesta faixa de freqüência novamente. Lembrando que a antena magnética admitia duas orientações, deve-se notar que os dois primeiros gráficos correspondem à orientação paralela $(/ /)$ e os dois últimos à orientação perpendicular $(\perp)$.

Os modos ressonantes encontrados entre $800 \mathrm{MHz}$ e $1,0 \mathrm{GHz}$ para a antena paralela foram: 913,25 e 953,5 MHz (Figura 3). Infelizmente, nenhum dos dois ofereceu condições (amplitude $\geq 3 \mathrm{~dB}$ 's) para que a medida do índice de mérito $(Q)$ fosse feita. Note-se que as duas auto-freqüências são diferentes daquela encontrada com a antena elétrica. $\mathrm{Na}$ faixa de 1,0 a 1,2 GHz (Figura 4) as ressonâncias obtidas foram: 1,08475 e 1,182 GHz; ou seja, as mesmas da antena elétrica. Esta coincidência, além de corroborar a medida das frequiências, permite ilustrar as diferenças na excitação da cavidade decorrentes das diferenças entre as antenas. Comparando as Figuras 2 e 4, percebe-se de imediato a inversão nas amplitudes dos sinais; o que sugere que uma antena pode ser mais adequada que outra na excitação de determinado modo. Isto estaria ligado à configuração do campo eletromagnético no interior do toróide, nas vizinhanças da sua superfície. 
As ressonâncias obtidas com a antena magnética na orientação perpendicular entre $800 \mathrm{MHz}$ e 1,0 GHz foram: 950,5 e 953,75 MHz (Figura 5). Estes resultados coincidem com os anteriores, confirmando as medidas feitas previamente. Na faixa de 1,0 a $1,2 \mathrm{GHz}$ (Figura 6) um único modo ressonante foi detectado em 1,18175 $\mathrm{GHz}$, coincidindo com os dados obtidos anteriormente, também. No entanto, em nenhum destes três casos foi possível medir o índice de mérito $(Q)$.

Os gráficos nas Figuras 1, 3 e 5 ilustram um fato comum a todo o processo de medida, em que os sinais da antena magnética perpendicular eram, em geral, mais baixos que os das outras duas antenas.

\subsubsection{Excitação da Cavidade pelo Equador}

Como observado na Seção 1.3 deste Capítulo, a excitação da cavidade pelo equador foi uma. possibilidade descoberta durante a tomada de dados. No entanto, os procedimentos para a obtenção dos dados foram os mesmos adotados na excitação pelo topo. Por exemplo: a varredura em freqüência se estendeu de $45 \mathrm{MHz}$ até $1,2 \mathrm{GHz}$, a intervalos de $200 \mathrm{MHz}$.

Assim como aconteceu com a. excitaçâo pelo topo, também não foram encontradas ressonâncias na faixa de 45 a $800 \mathrm{MHz}$ com qualquer uma das antenas.

Entre $800 \mathrm{MHz}$ e $1,0 \mathrm{GHz}$ (Figura 7) a antena elétrica excitou dois auto-modos: um em $913,25 \mathrm{MHz}$ e outro em $953,5 \mathrm{MHz}$. Os respectivos índices de mérito $(Q)$ deram: $4,2 \times 10^{3}$ e $3,9 \times 10^{4}$. Observe-se que estes modos ressonantes apareceram anteriormente, mas os seus $Q^{\prime}$ s não tinham sido medidos. Estes fatos reforçam a hipótese, já levantada, de que determinadas antenas seriam mais convenientes para a excitação de ressonâncias específicas.

$\mathrm{Na}$ faixa de 1,0 a 1,2 GHz (Figura 8) a única ressonância detectada foi em 1,0845 GHz, com um $Q>6 \times 10^{4}$. Note-se, novamente, que este auto-modo tinha aparecido quando a cavidade fora excitada pelo topo, mas sem a possibilidade de medida de $Q$.

As ressonâncias obtidas com a antena magnética na orientação paralela entre $800 \mathrm{MHz}$ e 1,0 GHz foram: 951,0 e 953,5 MHz (Figura 9). Contudo, não foi possível medir o índice de mérito nesta configuração de antena. Da mesma forma, repetindo um comportamento verificado na excitação pelo topo com a antena elétrica, o sinal em $837,5 \mathrm{MHz}$ desaparecia quando se abria a faixa de freqüência em torno dele. No intervalo de 1,0 a $1,2 \mathrm{GHz}$ (Figura 10) os modos ressonantes encontrados foram: 1,0845 e 1,182 GHz. Destes dois, o primeiro teve o seu $Q$ medido $\left(4,4 \times 10^{4}\right)$.

Finalmente, a antena magnética na orientação perpendicular excitou uma ressonância em 953,5 MHz (Figura 11) e outra em 1,08475 GHz (Figura 12). No entanto, apenas para a segunda auto-freqüência houve condições de medir o índice de mérito $(Q)$, cujo valor encontrado foi $5,8 \times 10^{4}$.

Durante a apresentação dos dados, ficou claro que a medida do índice de mérito $(Q)$ esteve condicionada ao fato da amplitude da ressonância ser maior que $3 \mathrm{~dB}$ 's. É preciso ilustrar esta situação, bem como a situação oposta, em que a medida de $Q$ era possível. Os gráficos das Figuras 13 e 14 cumprem esta função. Observe-se que a ressonância mostrada. 
nos dois gráficos é a mesma, embora a medida de $Q$ só possa ser feita através da curva da Figura 13. Fsta diferença de amplitude vem corroborar a hipótese de que determinadas antenas são mais convenientes que outras na excitação de determinados modos, pois a Figura 13 foi obtida com o uso da antena elétrica, enquanto que a Figura 14 foi obtida com a antena magnética paralela; sendo que todas as duas estavam posicionadas no equador.

No final da Seção 1.3, comenta-se os arranjos que as antenas propiciaram. Comparandose o número de arranjos ali relacionados com aqueles já comentados, verifica-se que ainda é preciso dizer algo sobre o uso de antenas com diferentes comprimentos.

\subsubsection{Dados Complementares}

Nas Figuras 15 e 16 são mostrados dois gráficos obtidos em condições semelhantes: a faixa de freqüência (2,5 a 3,0 GHz), a posição da antena (no topo) e o seu tipo (elétrica) são os mesmos. No entanto, o comprimento de cada antena é progressivamente maior (médio e grande) e o que se vê é um aumento correspondente no número de ressonâncias, até o limite máximo atingido com a maior antena. Fmbora estes dados tenham sido obtidos com a antena elétrica, o comportamento da cavidade quando se usava a antena magnética era o mesmo. Isto mostra porque nos dados apresentados anteriormente, somente as antenas grandes foram utilizadas. Outro detalhe interessante que deve ser apontado, é o grande número de modos ressonantes presentes, em contraste com os intervalos pesquisados nas duas subseções precedentes. Este rápido aumento no número de auto-modos, revelou-se uma outra característica da cavidade toroidal.

\subsection{Resumo dos Dados Obtidos}

Para uma melhor análise dos dados, em confronto com os resultados teóricos disponíveis, a tabela abaixo traz um resumo deles. Observe-se que na tabela relativa aos dados obtidos pelo topo, há uma faixa de freqüência adicional com três ressonâncias; elas apareceram somente nas circunstâncias anotadas, mas com grande reprodutibilidade, embora os seus índiccs de mérito não tcnham sido obtidos. 


\begin{tabular}{|c|c|c|c|c|}
\hline & \multicolumn{4}{|c|}{ TOPO } \\
\hline freqüência $(\mathrm{GHz})$ & ant. elét & ant. mag// & ant. mag $\perp$ & $Q$ \\
\hline $0,045-0,800$ & s/ resson. & s/ resson. & s/ resson. & - \\
\hline $0,800-1,000$ & & 913,25 & & n.m. \\
\hline & & 953,50 & 953,75 & n.m. \\
\hline $1,000-1,200$ & 1,084 & 1,084 & 1,084 & n.m. \\
\hline & 1,182 & 1,182 & 1,182 & $6,0 \times 10^{4}(\mathrm{e})$ \\
\hline $1,200-1,400$ & & & 1,206 & n.o. \\
\hline & & 1,266 & 1,266 & n.o. \\
\hline & & 1,341 & 1,341 & n.o. \\
\hline
\end{tabular}

Tabela 4.1 : Ressonâncias observadas com excitação da cavidade pelo topo (n.m.=não mensurável; n.o.=aquele que não se procurou medir).

\begin{tabular}{|c|c|c|c|c|}
\hline & \multicolumn{4}{|c|}{ EQUADOR } \\
\hline freqüência $(\mathrm{GHz})$ & ant. elét & ant. mag// & ant. mag $\perp$ & $Q$ \\
\hline $0,045-0,800$ & s/ resson. & s/ resson. & s/ resson. & - \\
\hline $0,800-1,000$ & 913,25 & & & $4,2 \times 10^{3}$ \\
\hline & 953,50 & 953,50 & 953,50 & $3,9 \times 10^{4}$ \\
\hline $1,000-1,200$ & 1,0845 & 1,0845 & 1,08475 & $4,4 \times 10^{4}(/ /)$ \\
\hline & & & & $5,8 \times 10^{4}(\perp)$ \\
\hline & & & & $>6,0 \times 10^{4}(\mathrm{e})$ \\
\hline & & 1,182 & & n.m. \\
\hline
\end{tabular}

Tabela 4.2 : Ressonâncias observadas com excitação da cavidade pelo equador (n.m.=não mensurável). 


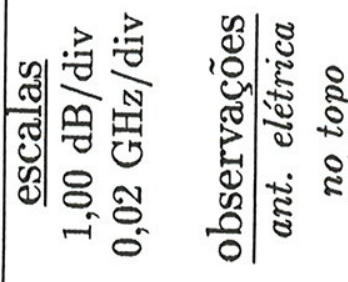

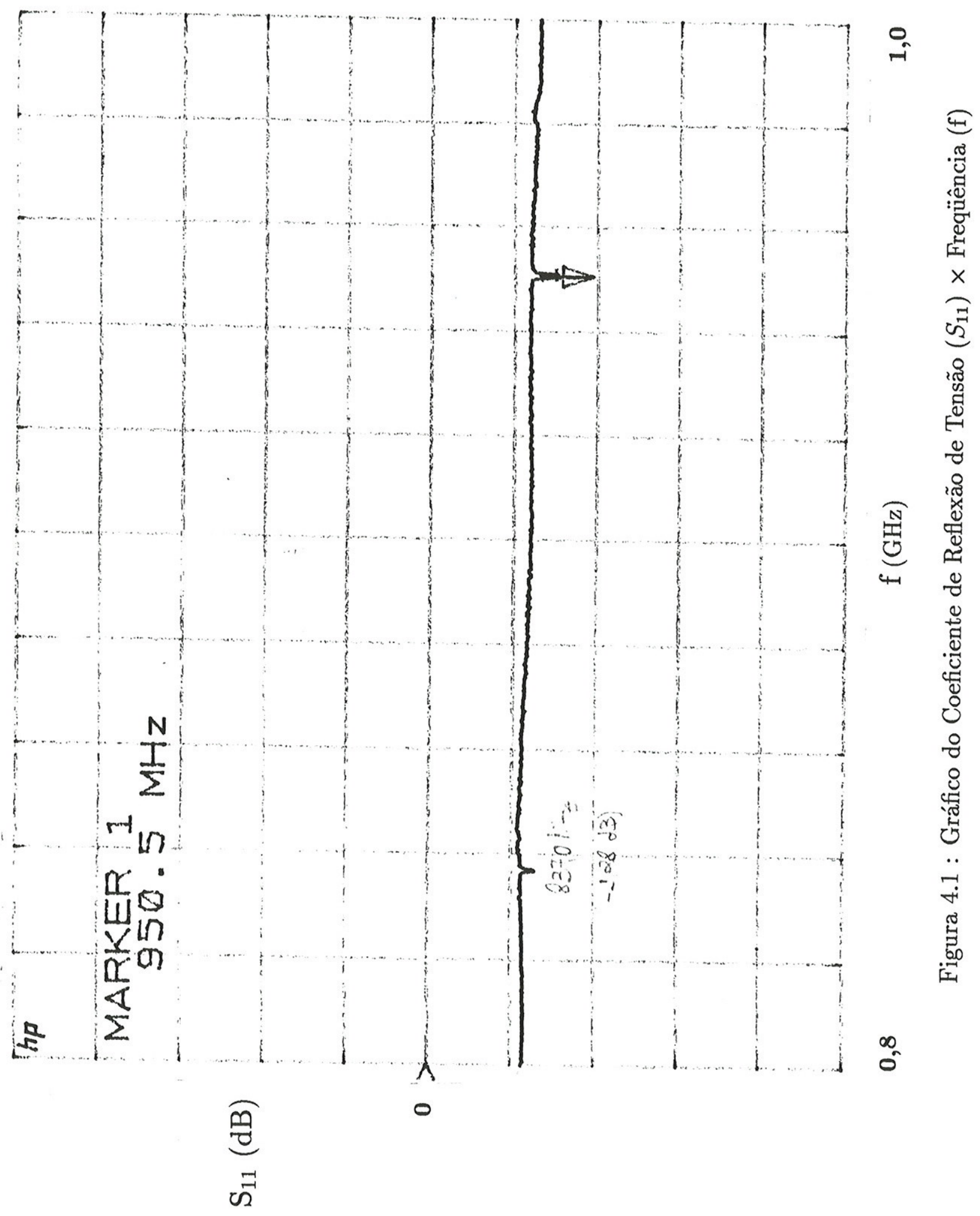




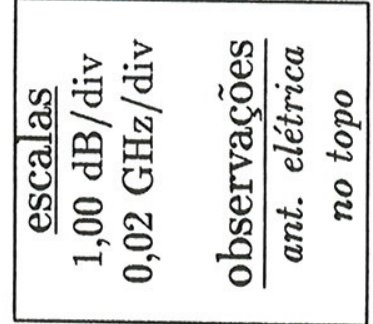

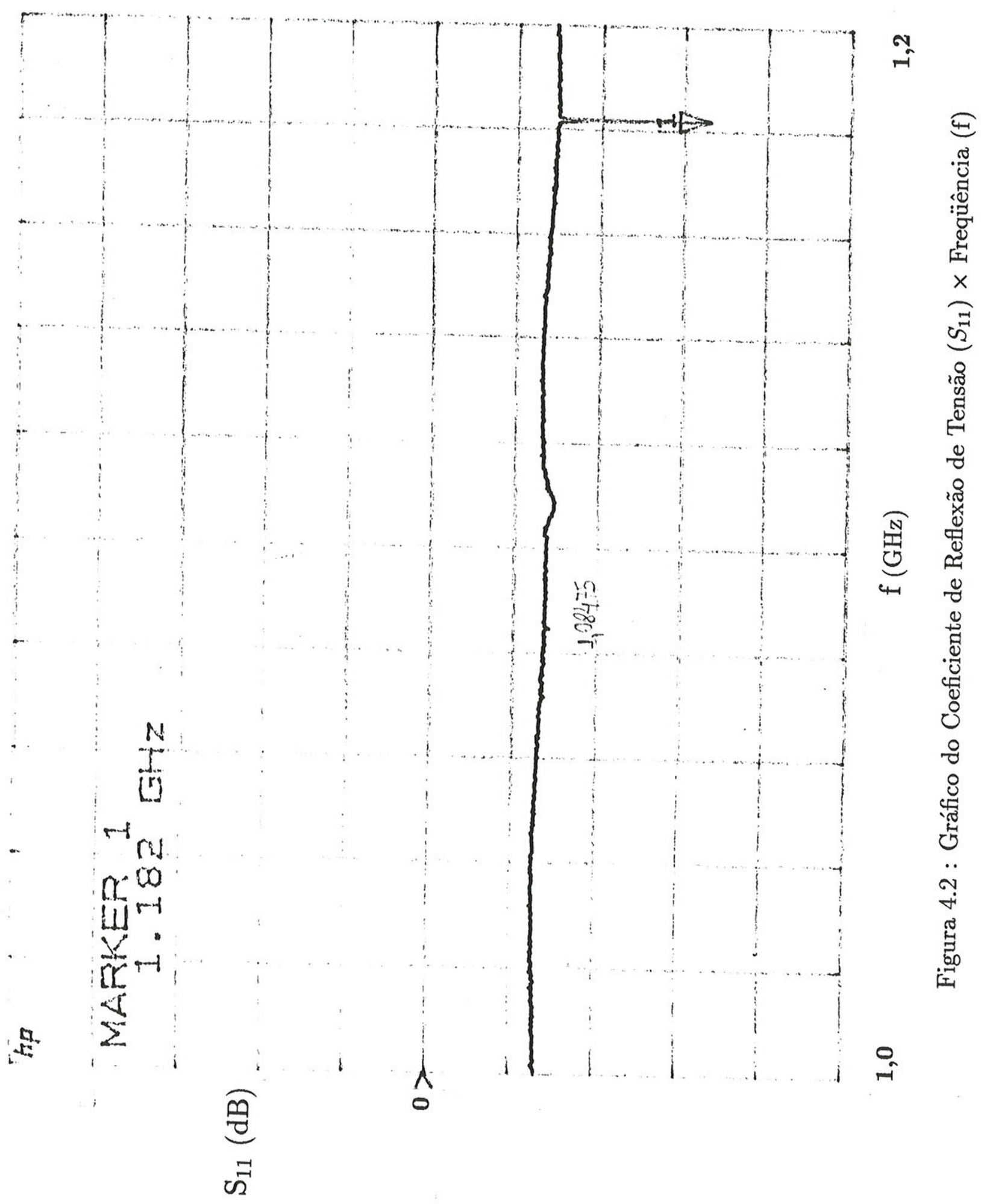




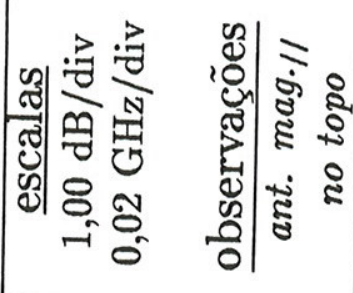






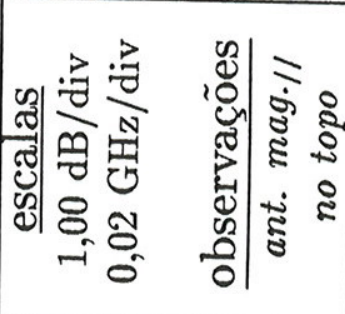

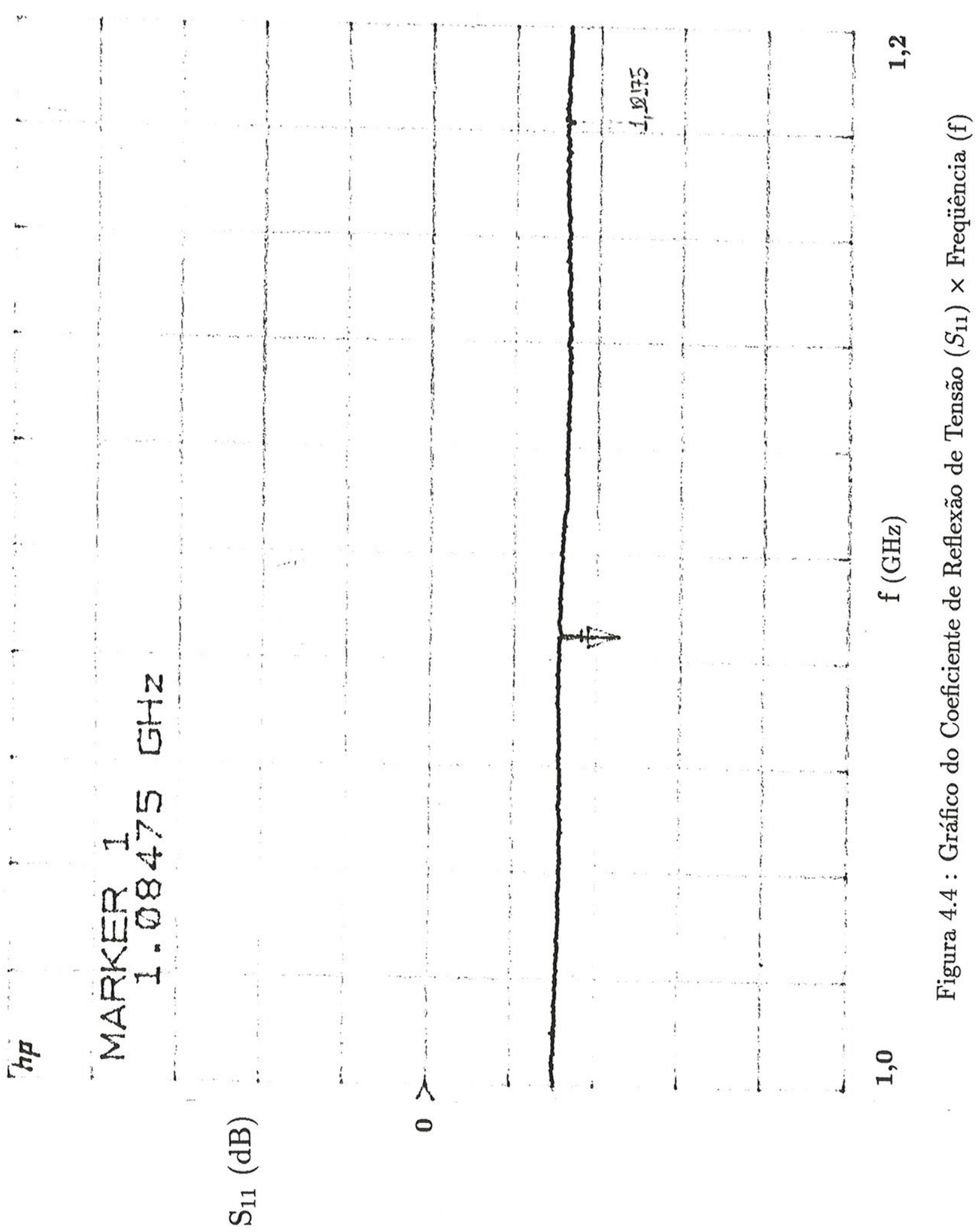




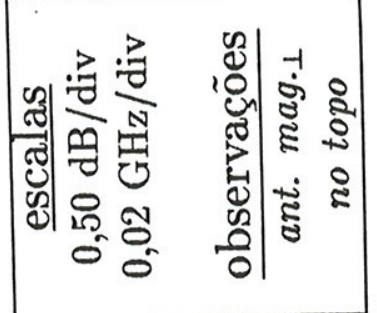

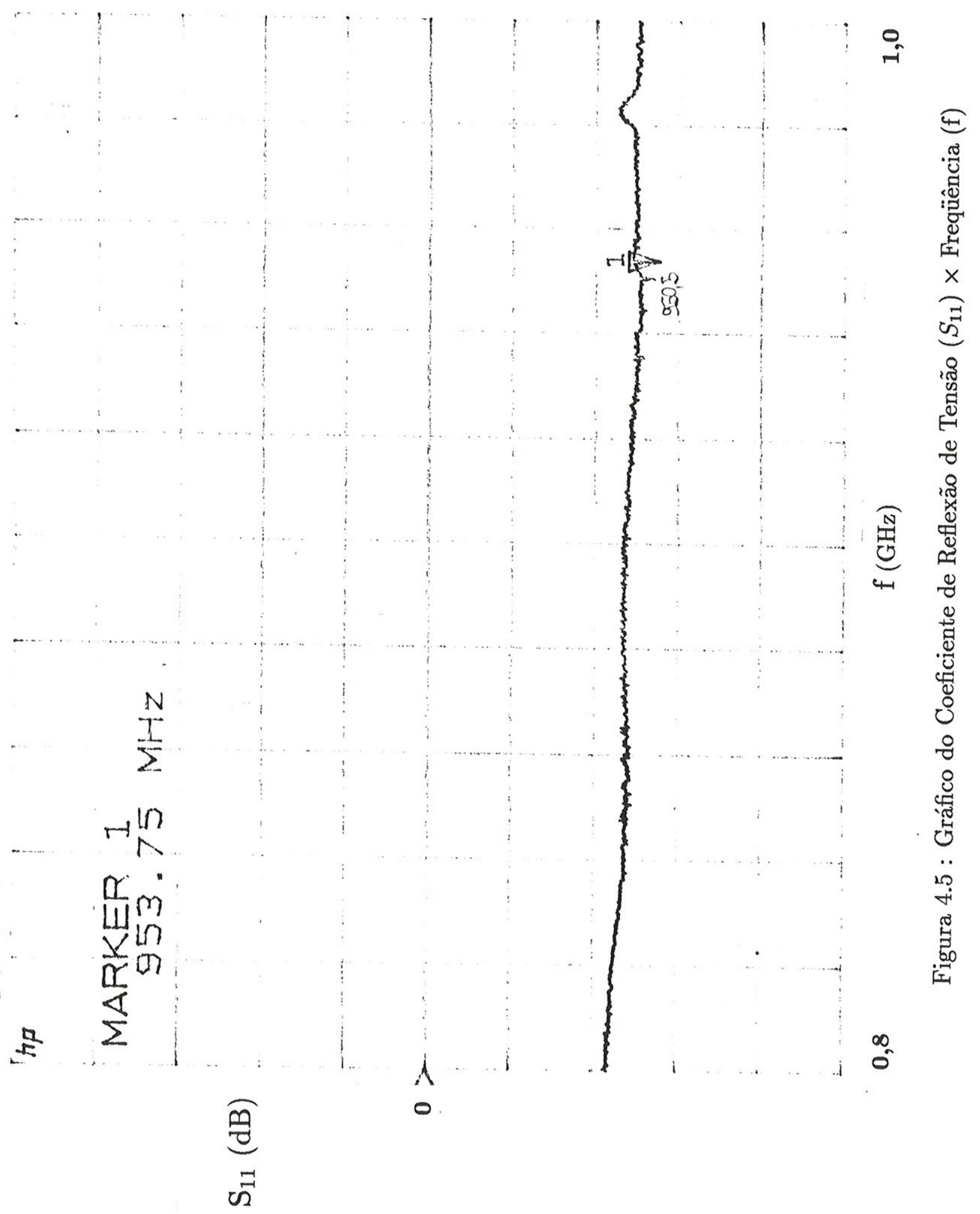




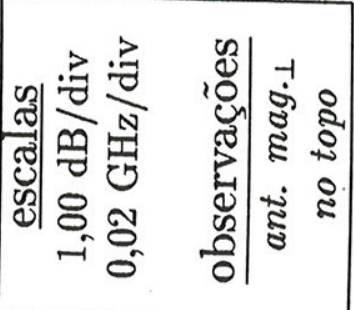

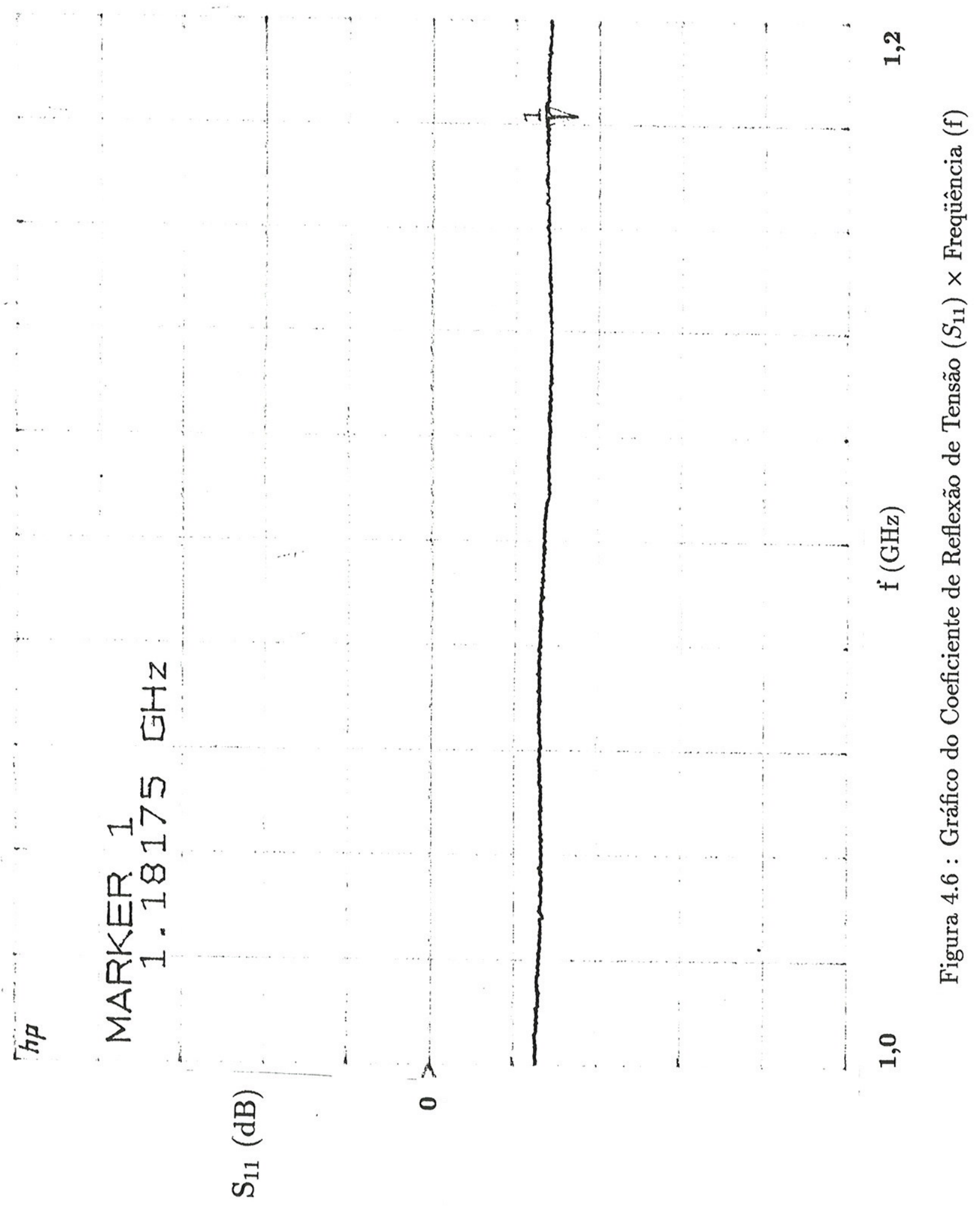



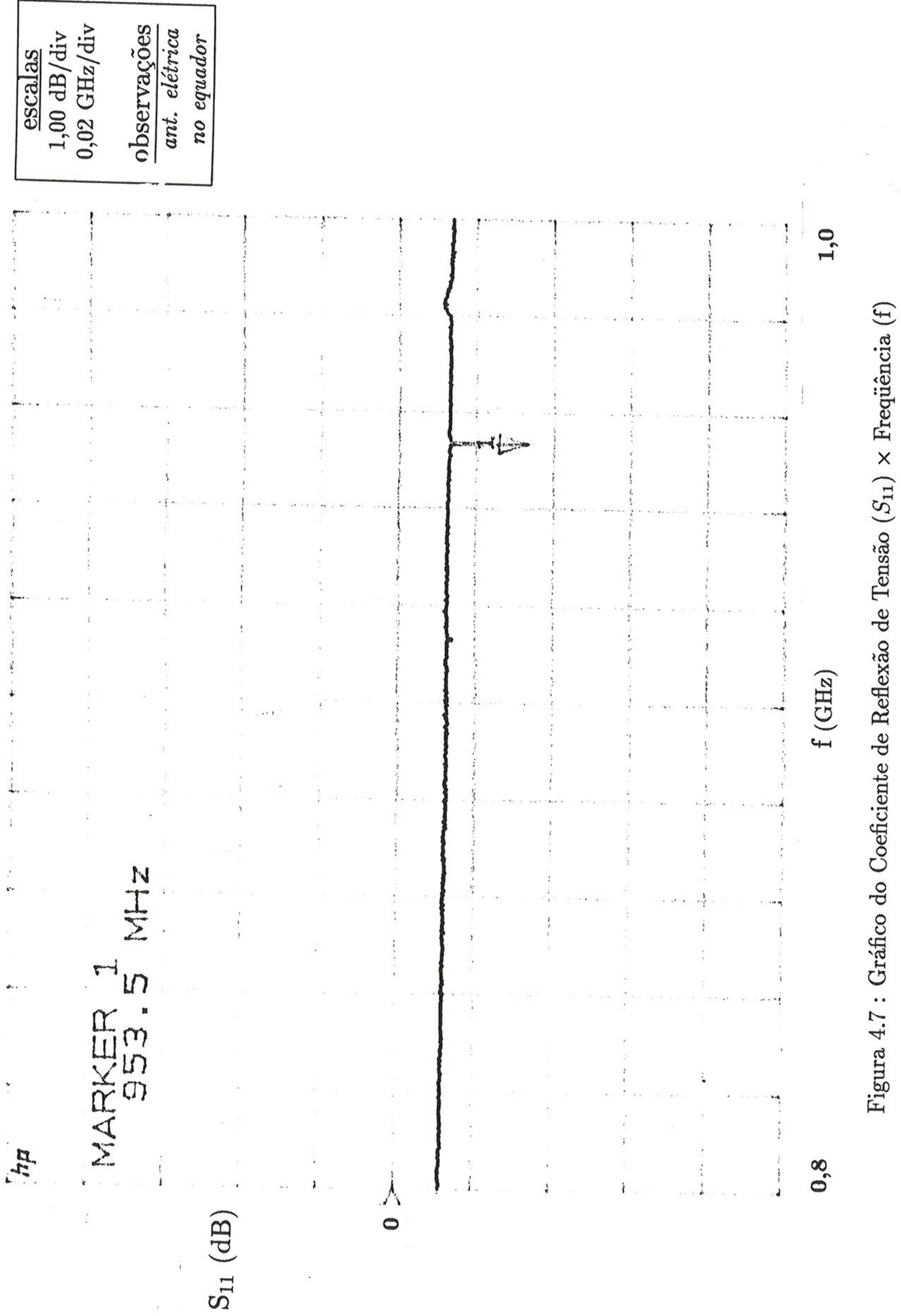


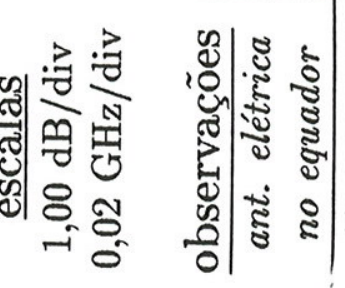

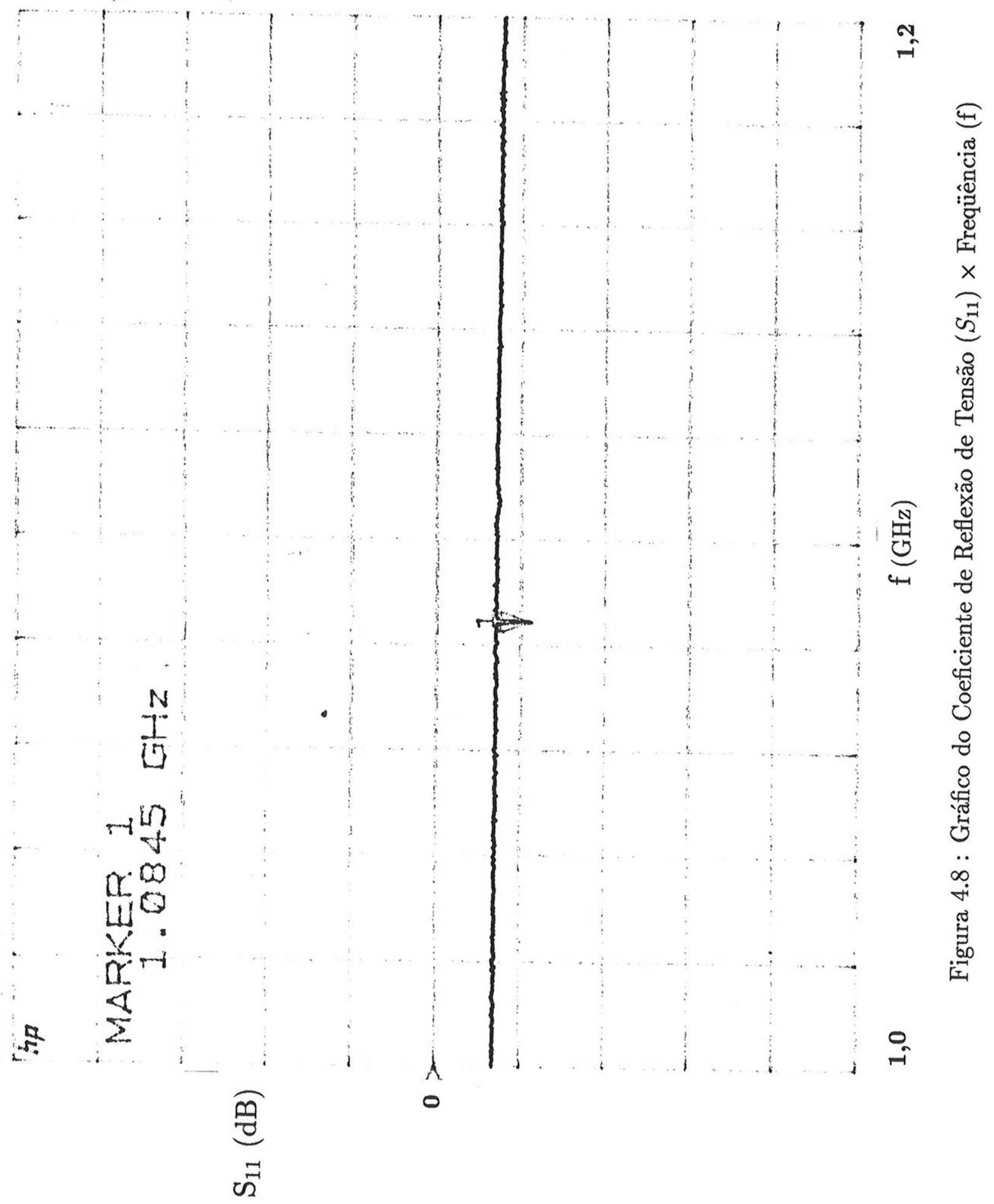



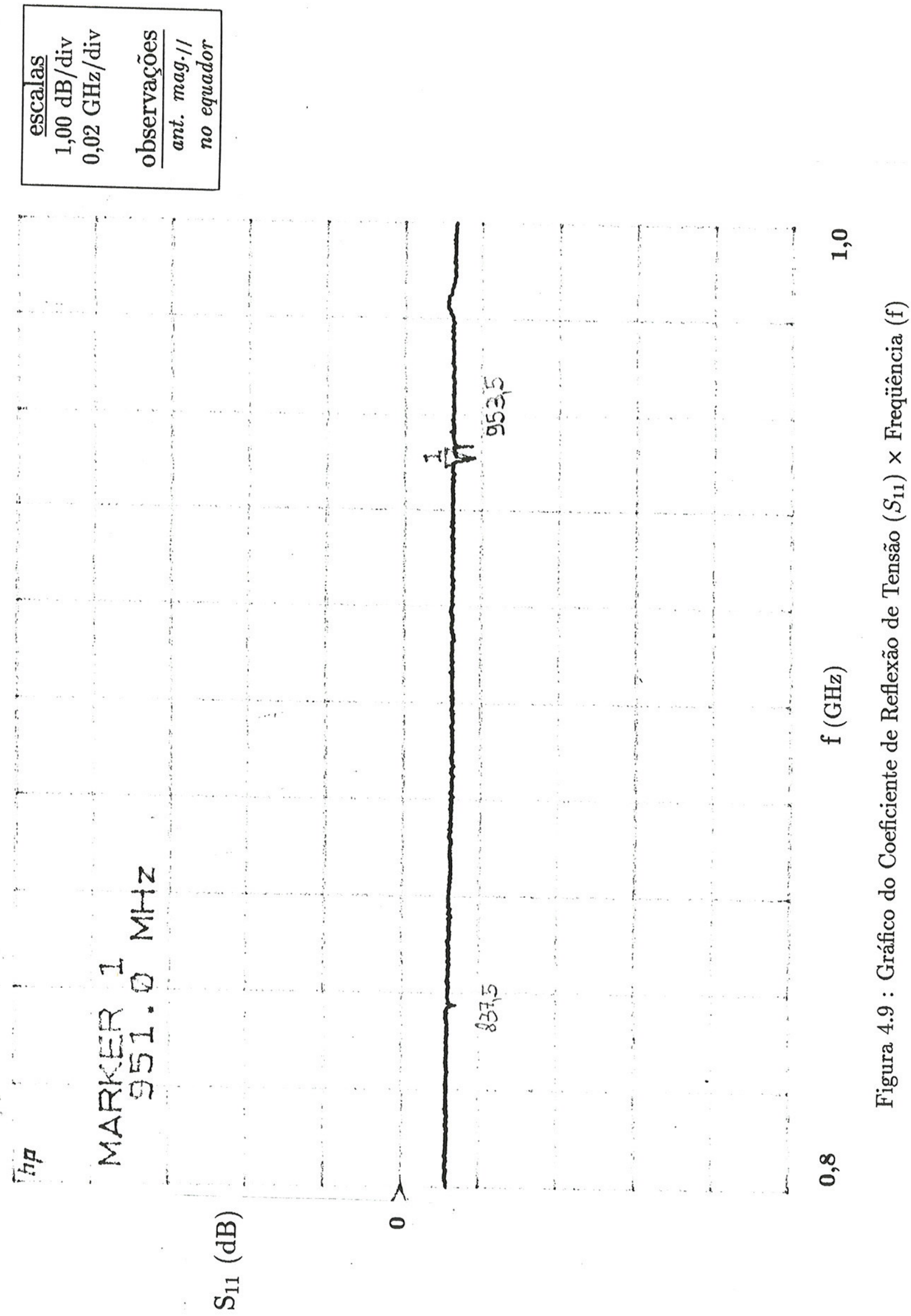

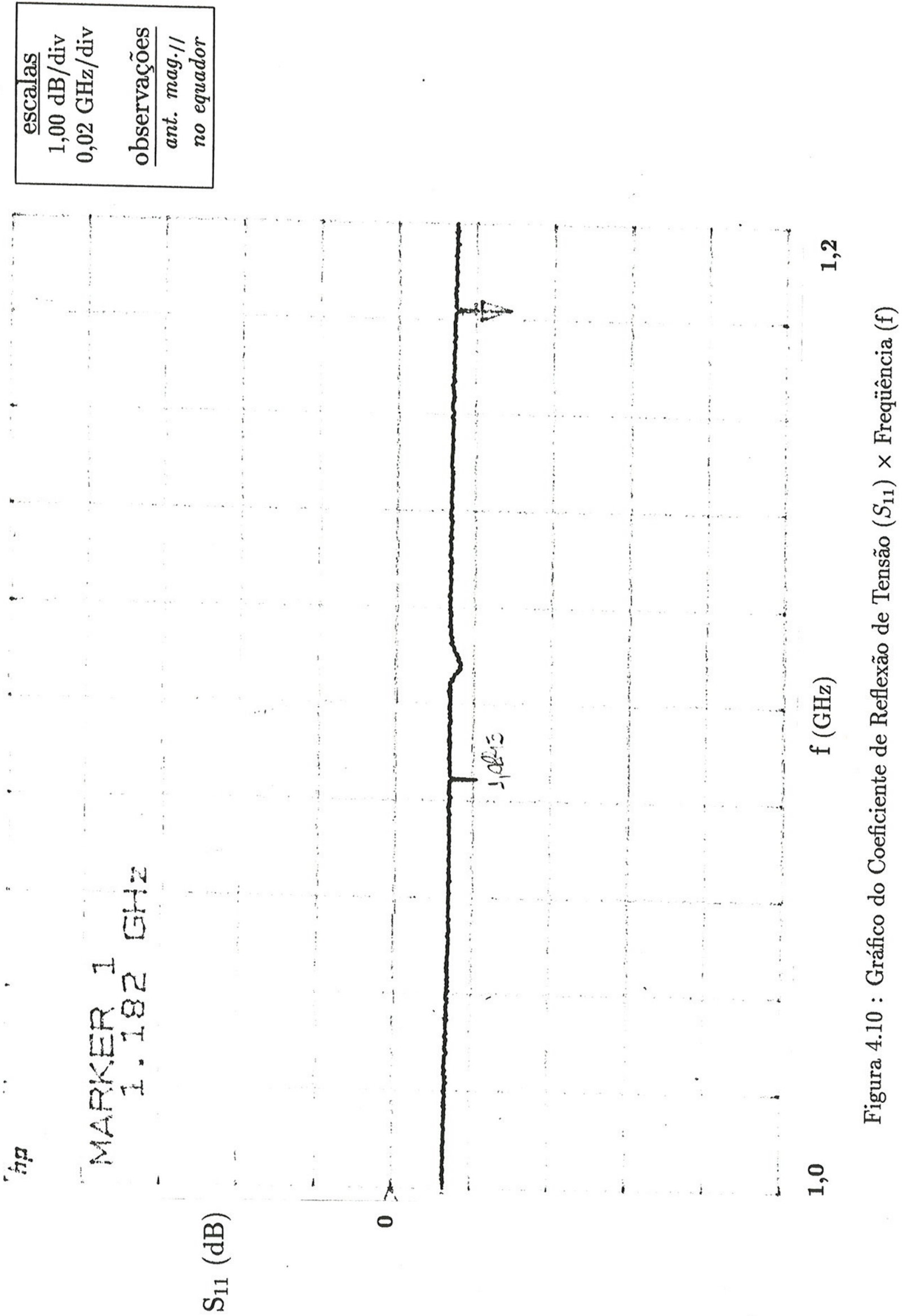

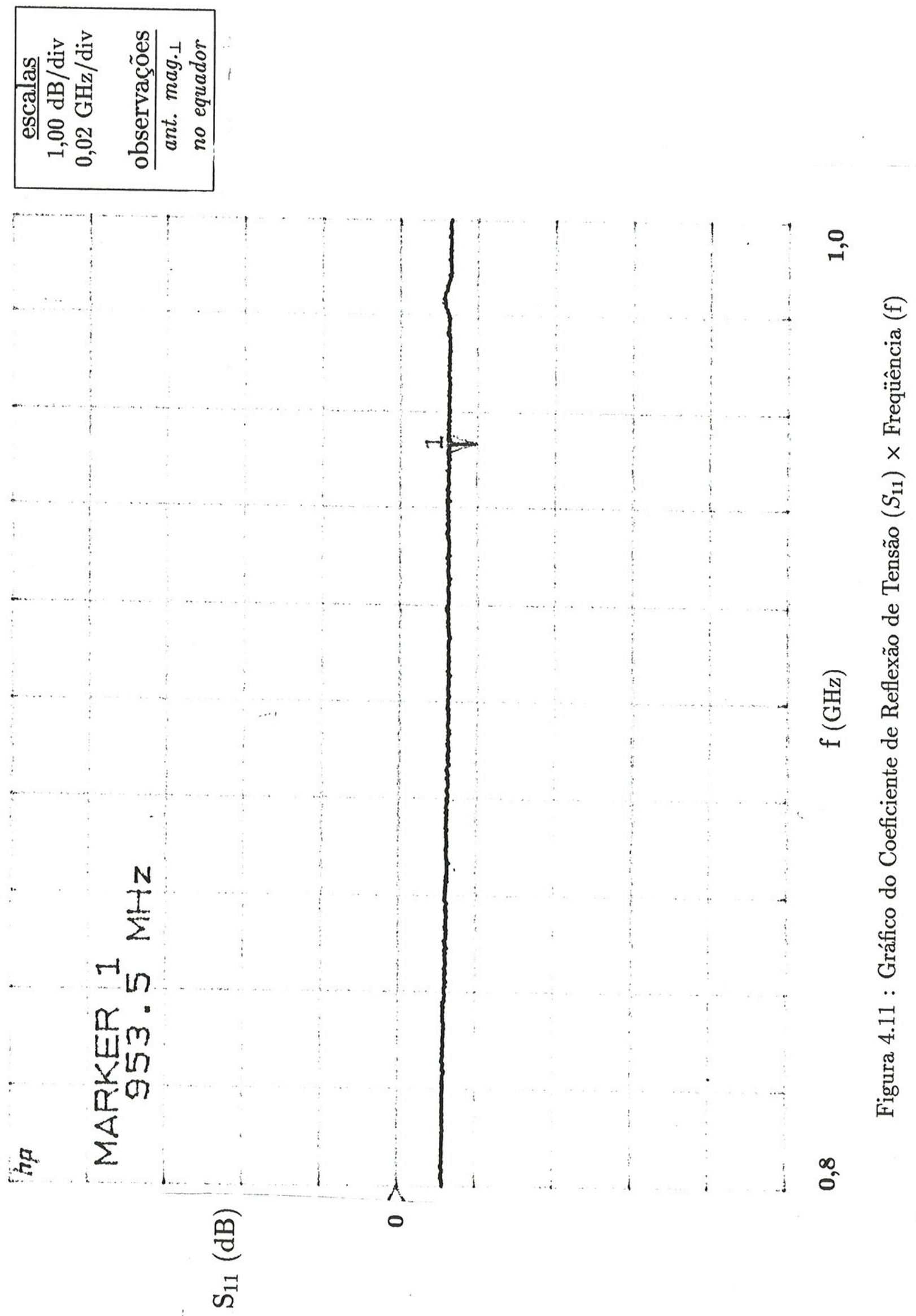


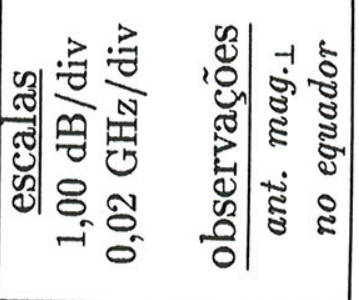

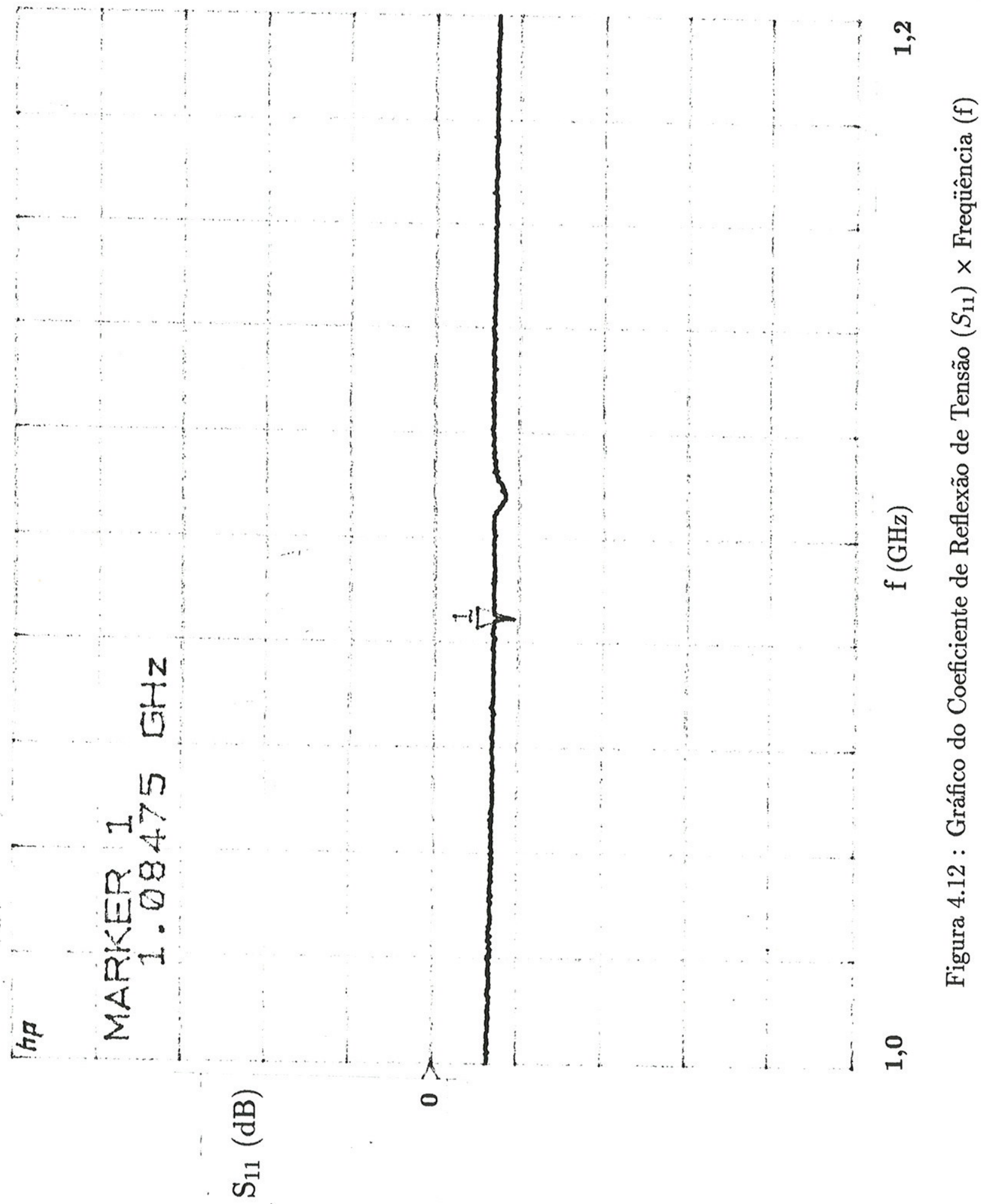



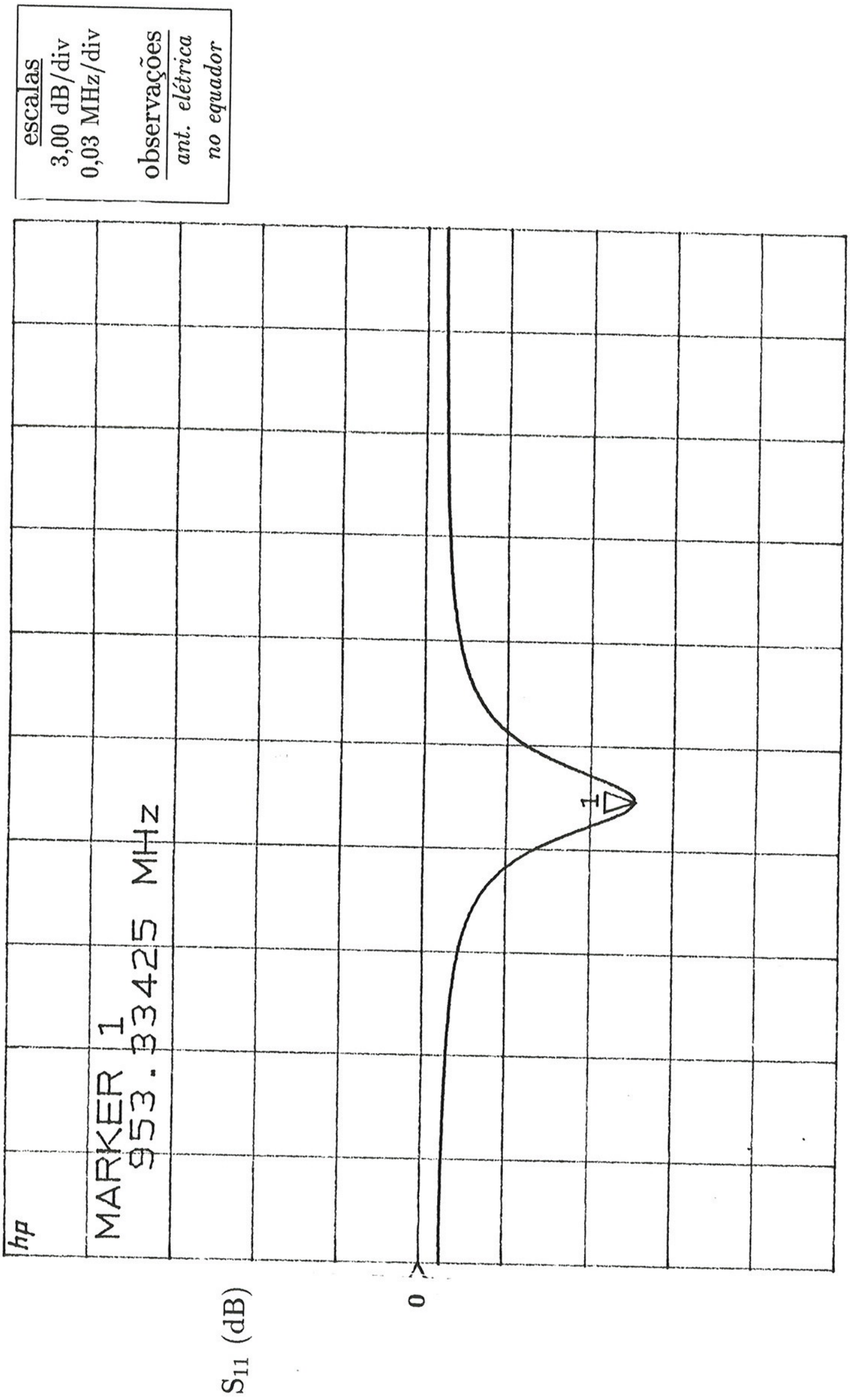

คู

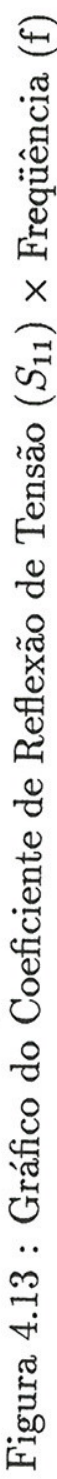

กู 

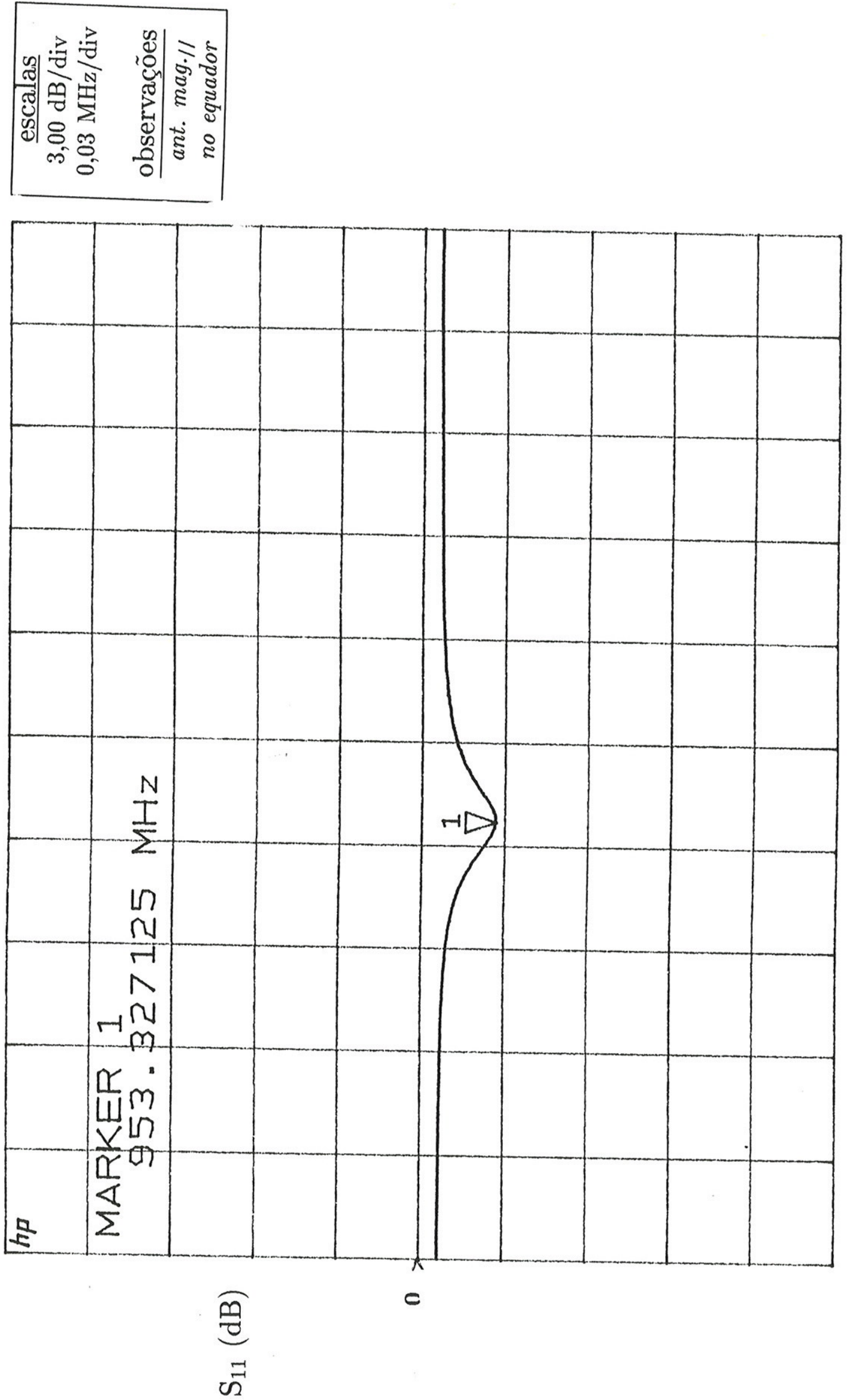

กิ

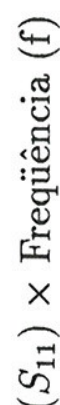

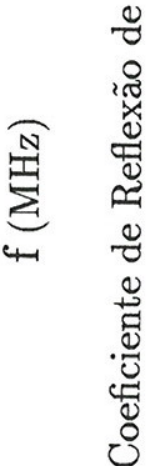

웅

速

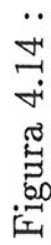

กิ 

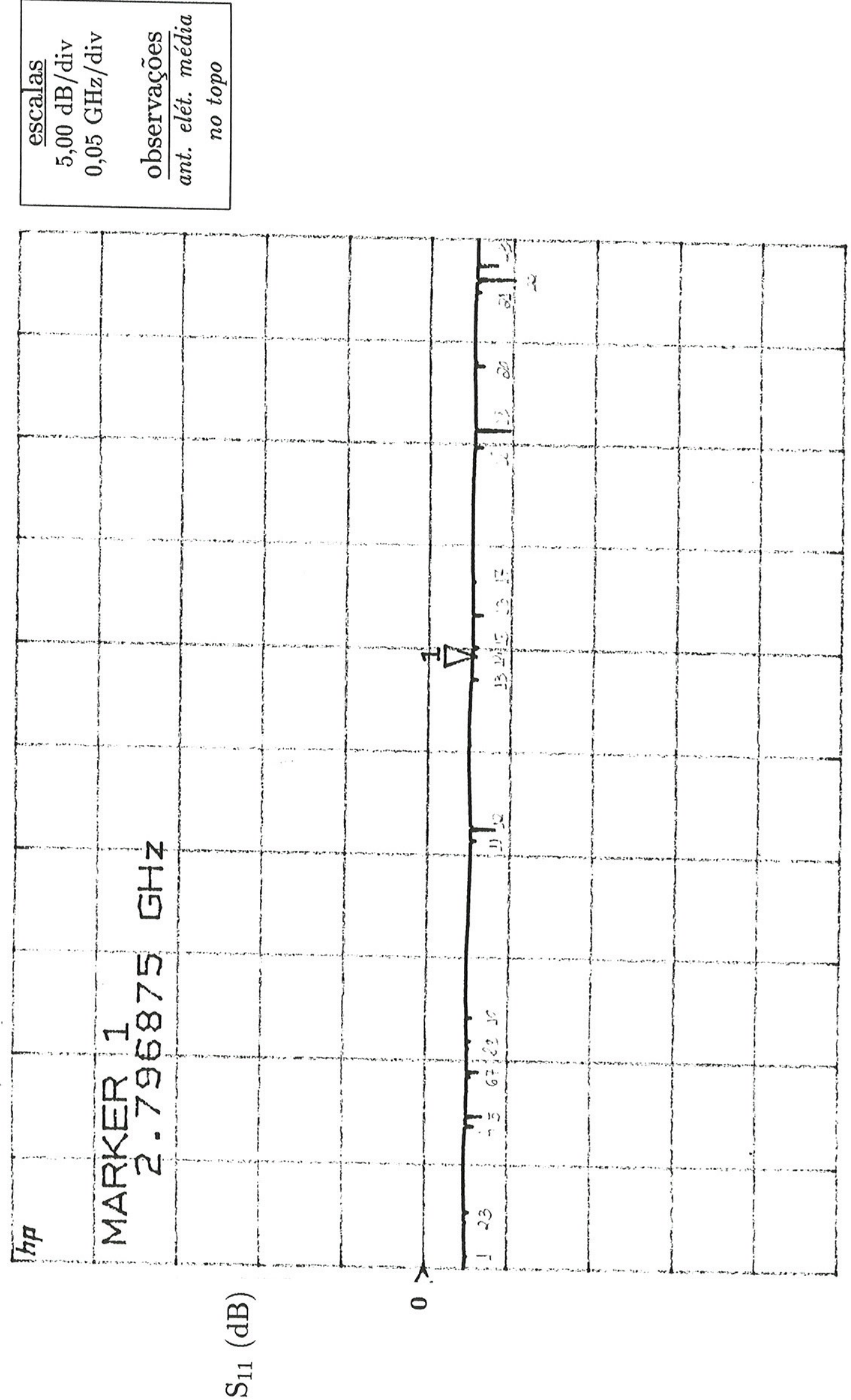

ค่

$\underbrace{\sqrt[N]{J}}_{4}$

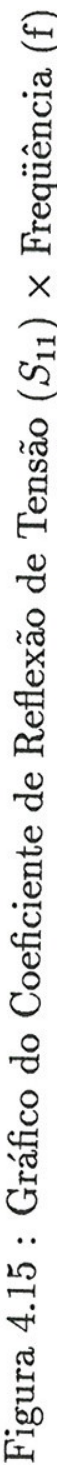

กิ 


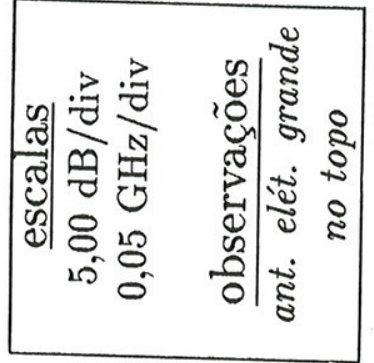

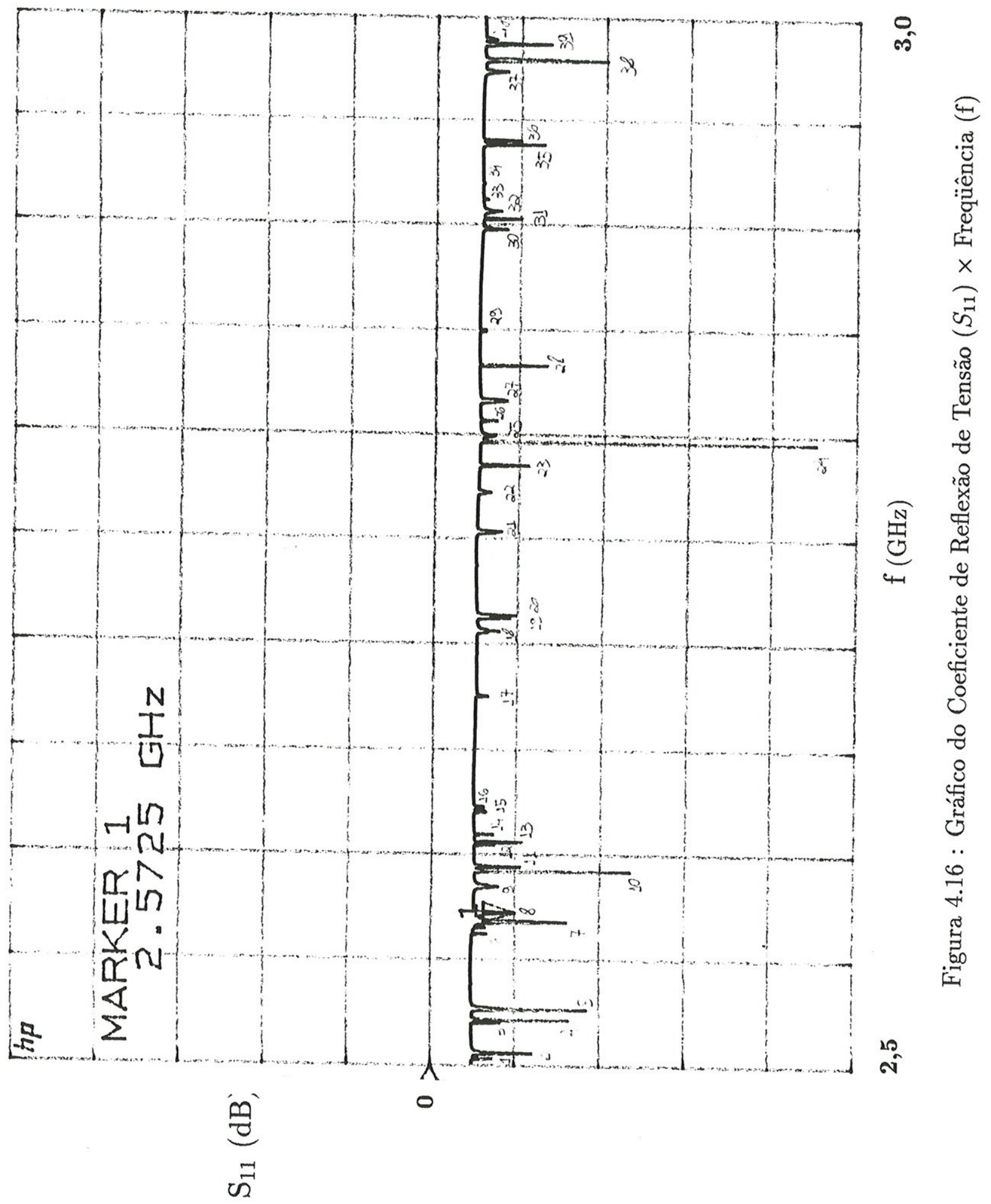




\section{Capítulo 5}

\section{ANÁLISE DOS RESULTADOS}

Os resultados deste trabalho são de dois tipos. No Capítulo 2 foram apresentados resultados teóricos e no Capítulo 4 dados experimentais. Isto conduz a duas análises distintas, pois é preciso comparar os resultados teóricos obtidos com outros modelos e todos estes com os dados experimentais. Assim, as duas Seções deste Capítulo são dedicadas a estas comparações.

\subsection{Análise dos Resultados Teóricos}

Os modelos escolhidos para comparação com este trabalho, são aqueles cujos principais aspectos foram resumidos no início do Capítulo 2. No entanto, para confrontar as relações de dispersão obtidas por Brambilla [4], Mishustin [5], Cap [6] e Janaki [11], é preciso reescrevê-las de modo conveniente, para que calculem o mesmo parâmetro. Assim, as relações ficam:

$$
\begin{aligned}
k r_{0}=\sqrt{x_{l j}^{2}+\frac{m^{2}}{s_{0}^{2}}} & \text { Brambilla e Mishustin } \\
k r_{0}=\sqrt{(2,4048)^{2}+\frac{m^{2}-1 / 4}{s_{0}^{2}}} & \text { Cap } \\
k r_{0}=\frac{k a}{\sqrt{s_{0}^{2}-1}} & \text { Este Trabalho e Janaki }
\end{aligned}
$$

Observe-se a padronização promovida nas três expressões: $k$ é o módulo do vetor de onda, $r_{0}$ o raio menor do toróide e $s_{0}$ a sua razão de aspecto. Além disto, os índices $l$ e $m$ que aparecem nas fórmulas, estão sempre relacionados com as variáveis angulares poloidal e toroidal, respectivamente. Por outro lado, $x_{l j}$ designa tanto a raiz da função de Bessel de primeira espécie, como da sua derivada. 
Note-se que a equação obtida por Janaki é formalmente idêntica à nossa; contudo, os valores das raízes $k a$ são diferentes, como se verá adiante.

Nas Figuras 1, 2 e 3 são mostrados os gráficos de $k r_{0}$ em função do inverso da razão de aspecto $\left(1 / s_{0}\right)$ para os números de modo poloidal $l=0,1$ e 2 , respectivamente. Observe-se que para cada valor de $l$ foram considerados os números de modo toroidal $m=0$ e 1 ; sendo que as curvas relativas aos dados deste trabalho foram obtidas a partir da solução hipergeométrica. A solução por Frobenius não foi plotada por causa de sua semelhança com a solução hipergeométrica.

O primeiro fato que chama a atenção nos gráficos é a convergência do valor de $k r_{0}$ para $2,4048(l=0), 3,8317(l=1)$ e $5,1356(l=2)$ quando a razão de aspecto aumenta muito (o que equivale ao limite cilíndrico do toróide). Isto é natural no caso dos resultados de Brambilla, Mishustin e Cap, uma vez que estas raízes da função de Bessel aparecem explicitamente nas relações de dispersão. Contudo, no caso de Janaki e deste trabalho, o limite a.testa a coerência interna do modelo, ao incorporar os resultados da cavidade cilíndrica. É importante notar que estas raízes da função de Bessel correspondem aos modos TM no cilindro. No entanto, os modos ressonantes da cavidade toroidal têm as seis componentes de campo.

A medida que a razão de aspecto diminui, as diferenças entre os resultados se tornam mais evidentes e eles podem ser reunidos em dois grupos: para Brambilla, Mishustin e Cap, o autovalor de um dado modo ressonante toroidal está muito próximo do seu correspondente cilíndrico, podendo aumentar ligeiramente ou mesmo permanecer igual a ele. $\mathrm{O}$ presente trabalho e o de Janaki prevêem que o autovalor aumente consideravelmente com o decréscimo da razão de aspecto. Outra diferença entre as previsões dos dois grupos diz respeito à separação entre modos de mesmo $l$. Para nós e Janaki, ela aumenta a medida que aumentam os valores de $l$ e $m$ considerados e diminuem os da razão de aspecto. Note-se que os autovalores obtidos por Janaki são sempre maiores do que aqueles encontrados neste trabalho.

Como citado anteriormente, os modos da cavidade toroidal têm as seis componentes de campo, em geral. Isto não significa que estruturas semelhantes a de um modo TE não estejam presentes. O fato deste trabalho não prever a ocorrência de modos cujo limite cilíndrico possa ser caracterizado como TE, pode estar relacionado com as condições de contorno satisfeitas apenas aproximadamente; como observado no Capítulo 2. É importante lembrar que os termos de primeira ordem, que aparecem nas componentes $E_{\psi}$ e $E_{\phi}$, foram descartados sob os argumentos de que estão incompletos e têm magnitude inferior aos termos dependentes de $\mathcal{F}(s, l, m, k a)$ (os termos de ordem zero). Contudo, uma análise do comportamento de $\mathcal{F}$ em função de $s$ para um dado conjunto $l, m$ e $k a$, revelou que a função é monotônica em quase todo o intervalo de variação de $s$, com a exceção dos valores em torno de $s_{0}$ (onde, precisamente, se exige que a função seja nula). Isto faz com que a derivada $d \mathcal{F} / d s$, em torno de $s_{0}$, admita valores que podem tornar as parcelas de primeira ordem comparáveis àquelas de ordem zero nas equações 2.105 e 2.107. Obviamente, isto enfraquece a hipótese da magnitude inferior, conferindo maior importância à necessidade de incluir efeitos de ordem superior na solução do problema. Observe-se, também, que os trabalhos de Cap e Janaki não prevêem a ocorrência de modos TE. 
Para maior clareza na designação dos modos ressonantes é conveniente adotar uma nomenclatura. Assim, tomando emprestado do limite cilíndrico os termos TM e TE, atribui-se um conjunto de três índices a cada um deles. O primeiro corresponde ao valor de $l$ (o número de modo poloidal), o segundo indica a ordem da raiz considerada $\left(1^{\underline{a}}, 2^{\underline{a}}\right.$, etc) e o terceiro dá o valor de $m$ (o número de modo toroidal). Dessa maneira, os modos da Figura 1 são classificados como $\mathrm{TM}_{010(1)}$. É preciso analisar, agora, a concordância destes resultados teóricos com os dados experimentais.

\subsection{Análise dos Dados Experimentais}

A Tabela 5.1 permite comparar as auto-freqüências medidas com as ressonâncias previstas teoricamente pelos vários modelos considerados, sendo que todas as freqüências estão dadas em $\mathrm{GHz}$.

Note-se que os dados experimentais apresentam um melhor acordo com os resultados de Brambilla e Mishustin, uma vez que as discrepâncias entre os valores variam de 0,3\% a $9,0 \%$, dependendo do caso. Entre os resultados obtidos neste trabalho, aqueles derivados da solução por Frobenius se ajustam melhor; mesmo assim, a menor diferença está por volta de $44 \%$. No caso das auto-freqüências calculadas através da solução hipergeométrica, esta diferença mínima passa para $59 \%$. Os resultados de Janaki mostram um desempenho semelhante aos obtidos com a solução hipergeométrica, pois a menor diferença relativa entre seus resultados e os dados é de $68 \%$. As auto-freqüências previstas por Cap formam dois grupos. As três primeiras apresentam um acordo razoável com a experiência (em torno de $25 \%$ ), mas a partir delas as discrepâncias aumentam muito, chegando a $90 \%$.

F́, importante observar que o sinal detectado à freqüência de $950,5 \mathrm{MHz}$ foi descartado para efeito de comparação com as previsões teóricas, desde que não foi possível medir o seu índice de mérito em qualquer dos arranjos das antenas.

A fraca concordância entre os dados e as previsões teóricas dos modelos desenvolvidos neste trabalho pode ter duas causas. A primeira é de natureza teórica e já foi referida na. Seção anterior: as condições de contorno aproximadas parecem ter excluído os modos cujo limite cilíndrico corresponde aos modos TE. Em apoio a esta hipótese, observe o modo $\mathrm{TM}_{010}$ em 1,316 GHz (Frobenius) ou 1,450 GHz (Hipergeométrica). Se ele fosse deslocado para a mesma posição relativa no espectro, que ocupa no caso de Brambilla e Mishustin, a discrepância entre os valores teórico e experimental cairia para $21 \%$ e $34 \%$, bem menores que os atuais $44 \%$ e $59 \%$. Além disto, a ordem em que os modos TM aparecem é a mesma nos dois espectros. A outra possível fonte de desacordo entre os dados e as previsões envolve a escolha da razão de aspecto da cavidade. $\mathrm{O}$ valor $s_{0}=1,25$ foi escolhido para atender a dois requisitos: propiciar uma boa separação entre as a.uto-frequiências, ao mesmo tempo em que validava a condição $s_{0}>1$, presente nas expansões 2.43 e 2.51. 
Certamente o primeiro requisito foi satisfeito; no entanto, com o segundo isto pode não ter acontecido, de maneira que a comparação entre modelo e experiência tenha sido prejudicada. Pode ser que $s_{0}=1,5$ tivesse sido mais conveniente.

Além dos valores de freqüência coincidentes, a medida do índice de mérito $(Q)$ das ressonâncias em $0,913 \mathrm{GHz}, 0,953 \mathrm{GHz}$ e $1,182 \mathrm{GHz}$ foi obtida com a antena elétrica numa configuração que favorece a excitação de modos TE, como Brambilla e Mishustin prevêem. Da mesma maneira, a ressonância em 1,084 $\mathrm{GHz}$ apresentou o maior $Q$; como seria esperado de um modo predominantemente TM, uma vez que as perdas resistivas tendem a ser menores, pelo fato das correntes percorrerem trajetórias poloidais preferencialmente. Finalmente, embora não tenha sido possível medir o $Q$ da ressonância em 1,206 GHz, ela foi detectada numa situação favorável à excitação de modos TM também. Se estes indícios reforçam o acordo dos dados com os resultados de Brambilla e Mishustin, o pequeno volume de dados experimentais não permite descartar a possibilidade de um acordo fortuito cntrc os resultados tcóricos de Brambilla c Mishustin c as medidas. 


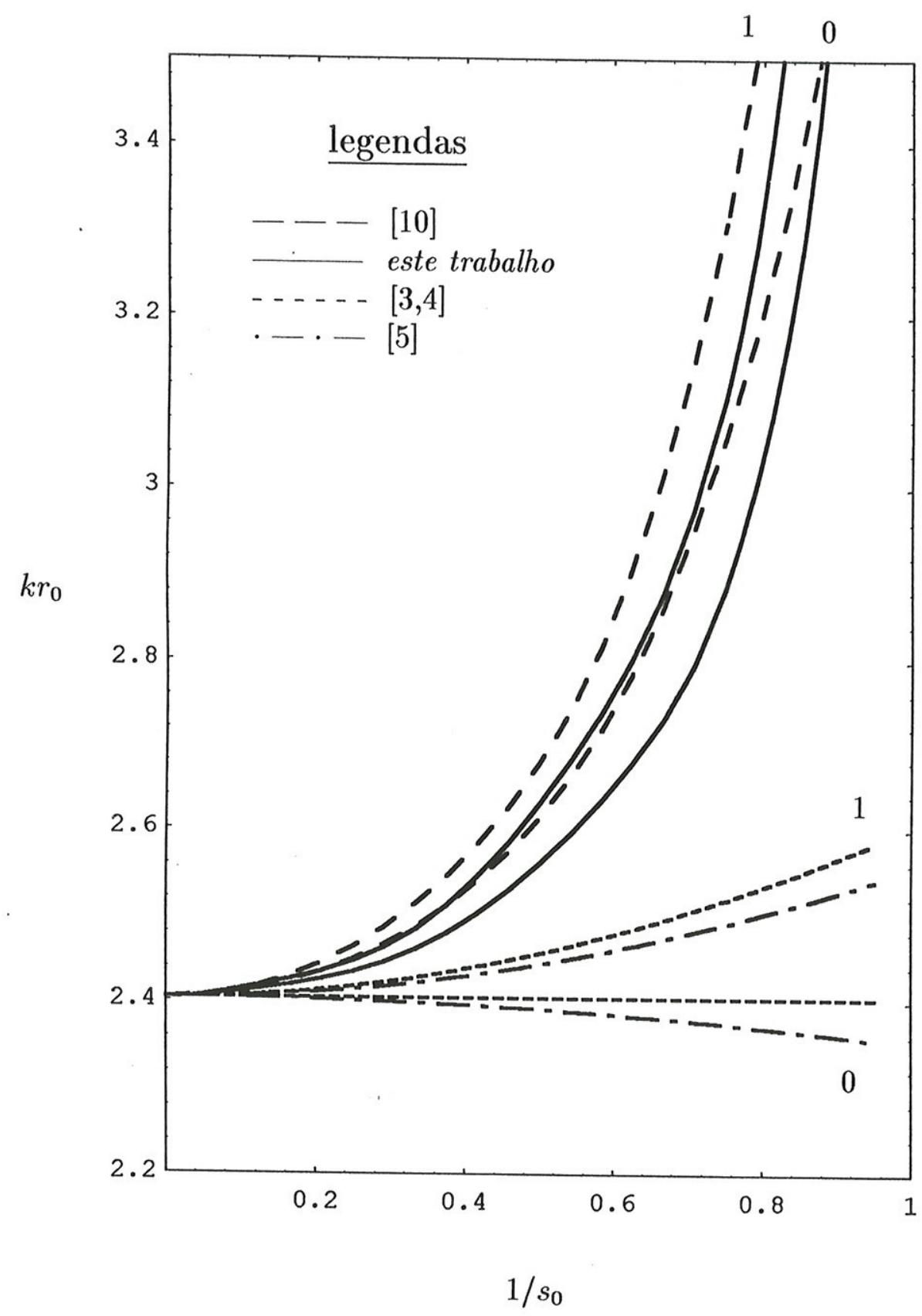

Figura 5.1 : Autovalores Teóricos $\left(k r_{0}\right) \times$ Inverso da Razão de Aspecto $\left(1 / s_{0}\right)$; $\mathrm{n} \underline{\underline{0}}$ de modo poloidal $l=0$ e $\mathrm{n} \underline{\mathrm{o}}$ de modo toroidal $m=0$ e 1 (as curvas estão identificadas pelos respectivos valores de $m$ ) 


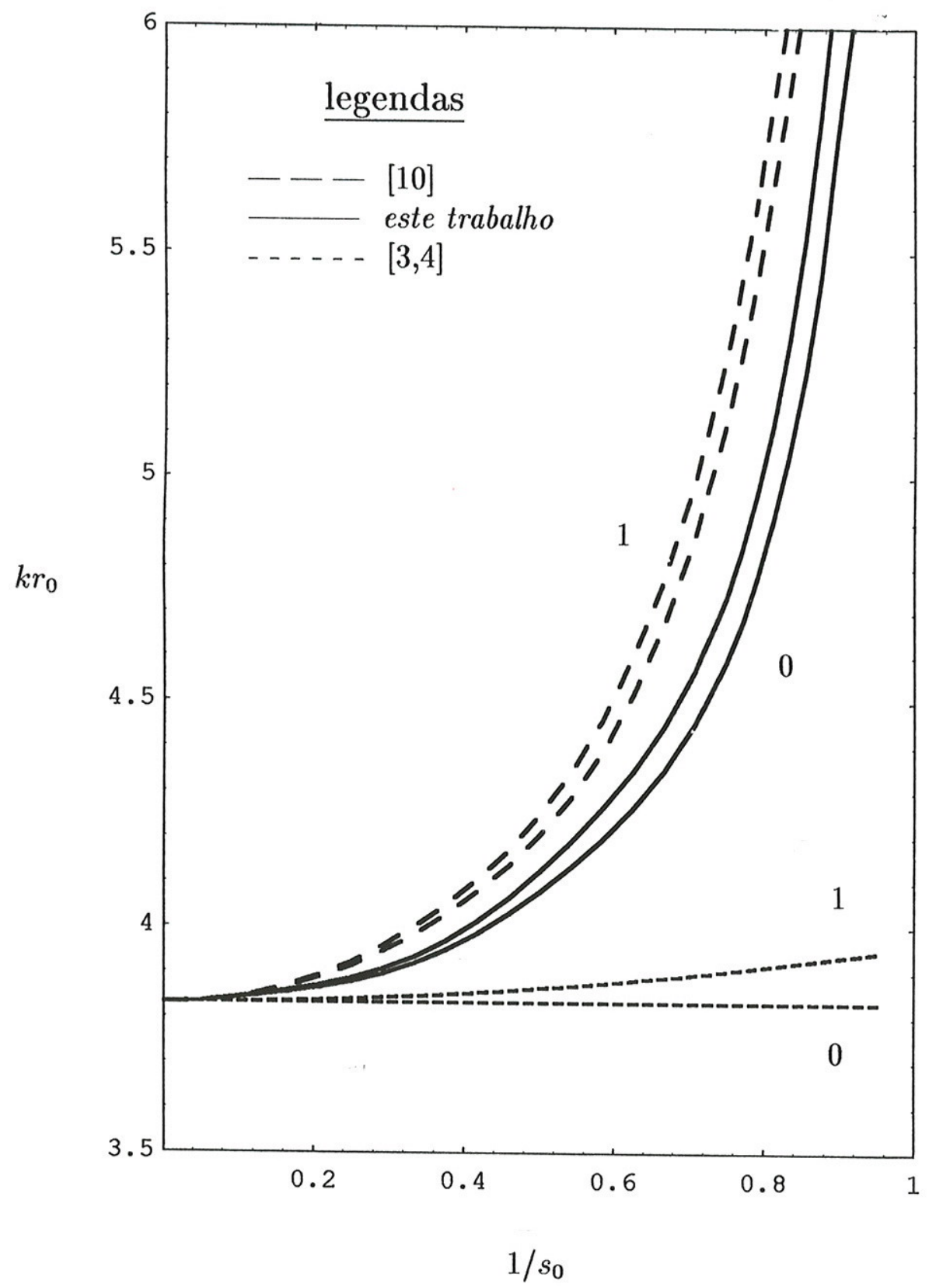

Figura 5.2 : Autovalores Teóricos $\left(k r_{0}\right) \times$ Inverso da Razão de Aspecto $\left(1 / s_{0}\right)$; $\mathrm{n} \underline{\underline{0}}$ de modo poloidal $l=1$ e $\mathrm{n} \underline{\mathbf{o}}$ de modo toroidal $m=0$ e 1 (as curvas estão identificadas pelos respectivos valores de $m$ ) 


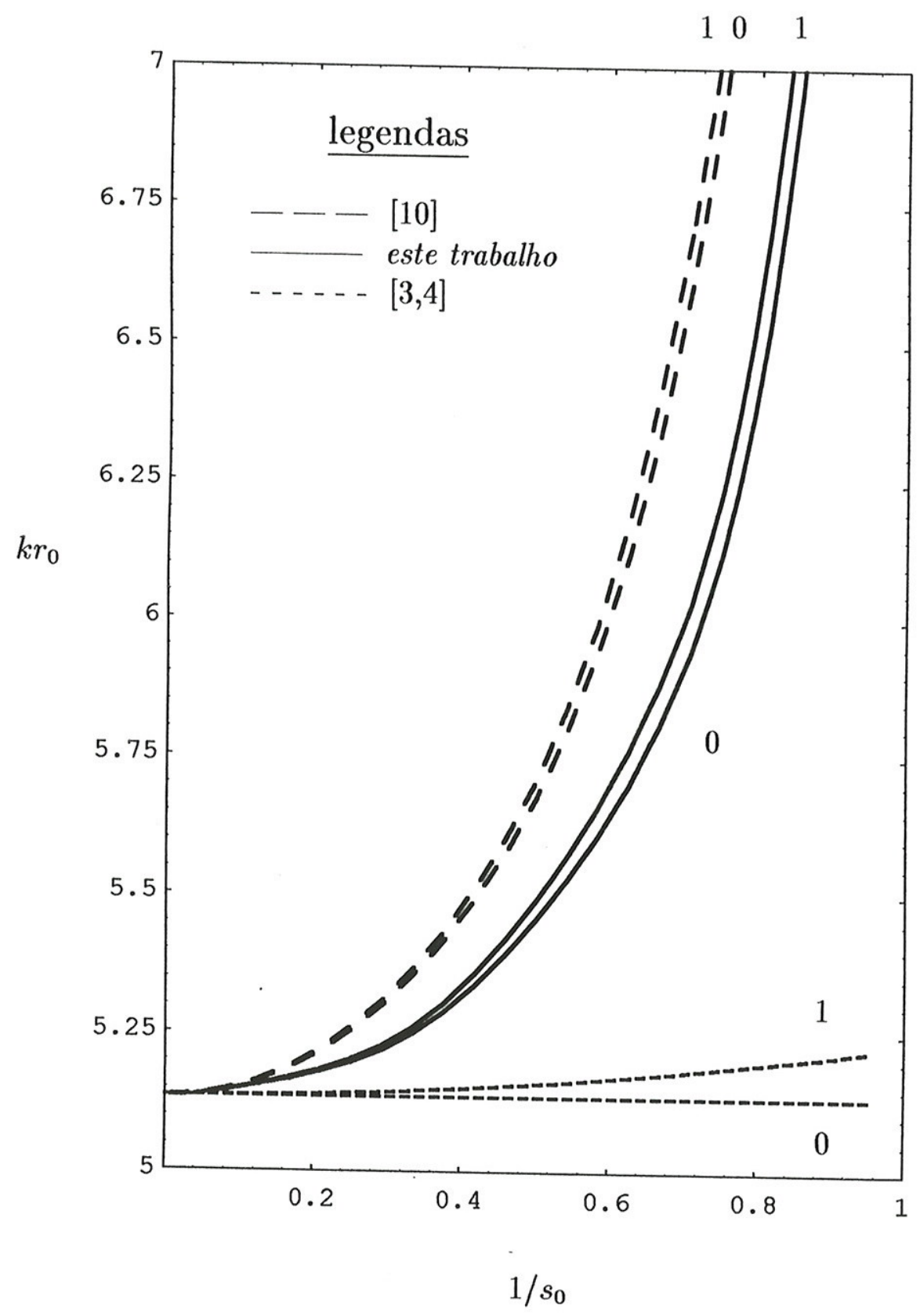

Figura 5.3 : Autovalores Teóricos $\left(k r_{0}\right) \times$ Inverso da Razão de Aspecto $\left(1 / s_{0}\right)$; $\mathrm{n} \underline{\mathrm{o}}$ de modo poloidal $l=2$ e $\mathrm{n} \underline{\mathrm{o}}$ de modo toroidal $m=0$ e 1 (as curvas estão identificadas pelos respectivos valores de $m$ ) 


\begin{tabular}{|c||c|c|c|c|c|}
\hline \multicolumn{1}{|c||}{ Exp. } & \multicolumn{5}{c|}{ Teoria } \\
\hline & Bramb./Mish. & Cap & Janaki & Frobenius & Hipergeom. \\
\hline 0,913 & $0,879 \mathrm{TE}_{110}$ & $1,132 \mathrm{TM}_{010}$ & $1,531 \mathrm{TM}_{010}$ & $1,316 \mathrm{TM}_{010}$ & $1,450 \mathrm{TM}_{010}$ \\
\hline 0,953 & $0,958 \mathrm{TE}_{111}$ & $1,195 \mathrm{TM}_{011}$ & $1,696 \mathrm{TM}_{011}$ & $1,445 \mathrm{TM}_{011}$ & $1,592 \mathrm{TM}_{011}$ \\
\hline 1,084 & $1,148 \mathrm{TM}_{010}$ & $1,366 \mathrm{TM}_{012}$ & $2,074 \mathrm{TM}_{012}$ & $1,775 \mathrm{TM}_{012}$ & $1,956 \mathrm{TM}_{012}$ \\
\hline 1,182 & $1,165 \mathrm{TE}_{112}$ & $1,611 \mathrm{TM}_{013}$ & $2,636 \mathrm{TM}_{110}$ & $1,995 \mathrm{TM}_{110}$ & $2,307 \mathrm{TM}_{110}$ \\
\hline 1,206 & $1,210 \mathrm{TM}_{011}$ & $1,902 \mathrm{TM}_{014}$ & $2,722 \mathrm{TM}_{111}$ & $2,077 \mathrm{TM}_{111}$ & $2,402 \mathrm{TM}_{111}$ \\
\hline 1,266 & $1,379 \mathrm{TM}_{012}$ & $2,220 \mathrm{TM}_{015}$ & $3,037 \mathrm{TM}_{112}$ & $2,216 \mathrm{TM}_{013}$ & $2,445 \mathrm{TM}_{013}$ \\
\hline 1,341 & $1,444 \mathrm{TE}_{113}$ & $2,556 \mathrm{TM}_{016}$ & $3,559 \mathrm{TM}_{210}$ & $2,304 \mathrm{TM}_{112}$ & $2,665 \mathrm{TM}_{112}$ \\
\hline
\end{tabular}

Tabela 5.1: Auto-freqüências experimentais e teóricas (em GHz). 


\section{Capítulo 6}

\section{OBSERVAÇÕES FINAIS}

Este Capítulo é dedicado às conclusões do trabalho realizado na caracterização teórica e experimental da cavidade ressonante toroidal, e às indicações para desenvolvimentos futuros.

\subsection{Conclusões}

A elaboração de tratamentos teóricos que descrevessem os modos ressonantes da cavidade toroidal, vem merecendo a atenção dos físicos há vinte anos. No entanto, durante este período nenhuma medida experimental foi feita, de maneira que os dados obtidos neste trabalho representam a primeira tentativa de confrontar teoria e experiência, pelo menos em toróides com secção transversal circular. Neste sentido, pode-se dizer que os objetivos pretendidos foram alcançados, pois a comparação entre os dados e os resultados teóricos permitiu discriminar os acertos e desacertos de cada modelo.

Entre os tratamentos escolhidos para comparação com os dados experimentais, aquele desenvolvido por Brambilla [4] e Mishustin [5] foi o que melhor previu as primeiras autofreqüências, embora eles não tenham feito nenhuma estimativa para os índices de mérito correspondentes. De qualquer maneira, como o volume de dados experimentais ainda é relativamente pequeno, não se pode dizer que este tratamento seja definitivo.

A relação de dispersão proposta por Cap [6] apresenta um desempenho mais limitado, pois a partir da quinta ressonância prevista $(1,902 \mathrm{GHz})$, as diferenças relativas com as freqüências medidas aumentam muito. Note-se que todos os modos previstos por Cap têm um limite cilíndrico TM, o que não é razoável. Este mesmo problema aparece nos resultados obtidos por Janaki e Dasgupta [11] e no presente trabalho. Contudo, a razão pela qual ele ocorre (condições de contorno aproximadas) está mais aparente nestes casos do que no trabalho de Cap. Da mesma maneira, a solução para ele também está mais patente: a consideração de efeitos de ordem superior. De qualquer forma, a concordância com as freqüências experimentais não foi muito boa. 


\subsection{Indicações para Desenvolvimentos Futuros}

Tal como a análise dos resultados, as indicações para desenvolvimentos futuros podem ser separadas em duas categorias: teórica e experimental. Do ponto de vista teórico seria importante resolver o problema numericamente, pois isto garantiria uma solução precisa. (atć o momento incxistcntc) para comparação com os dados cxpcrimcntais disponívcis. É importante observar que esta solução deve permitir o cálculo das auto-freqüências e dos índices de mérito correspondentes, para uma verificação mais completa. A equação de partida para este a.taque ao problema poderia ser a Equação 2.37. Fsta iniciativa., porém, deve ser complementada com esforços que visem uma solução analítica. Por exemplo: incluir efeitos de ordem superior nas duas soluções encontradas neste trabalho. Isto faria com que as condições de contorno fossem satisfeitas de maneira mais completa, levando a uma relação de dispersão mais realista e criando a possibilidade de calcular o índice de mérito $(Q)$.

A caracterização experimental da cavidade toroidal deve não apenas prosseguir na linha. iniciada (mcdida das auto-frcqüchncias c $Q$ 's corrcspondentcs), como sc ampliar. É possívcl tentar medir os números de modo $l$ e $m$, excitando a cavidade por um orifício e captando o sinal por outro, diferentemente do que foi feito aqui. Além disto, seria interessante verificar como a cavidade responderia à excitação por antenas instaladas em pontos mais internos. Um outro passo seria o mapeamento dos campos elétrico e magnético no interior do toróide. A construção de uma câmara toroidal com maior razão de aspecto permitiria. a verificação da dependência dos modos com este parâmetro da cavidade.

Lembre-se que em todos estes desenvolvimentos teóricos e experimentais é suposto que a cavidade está vazia. Por outro lado, este trabalho pode representar a etapa inicial de uma nova linha de pesquisa em aquecimento do plasma por rádio-freqüência; na qual a etapa subsequente seria incluir o plasma como meio de propagação das ondas. Nesta segunda fase, os modos ressonantes de uma cavidade toroidal terão que ser calculados novamente e testados experimentalmente, quem sabe num tokamak. 


\section{Apêndice A}

\section{DESENHOS TÉCNICOS}

Neste anexo ao texto principal, são apresentados os desenhos técnicos relacionados com a montagem do arranjo experimenta.l. Todas ạs Figuras foram referidas no Capítulo 3.
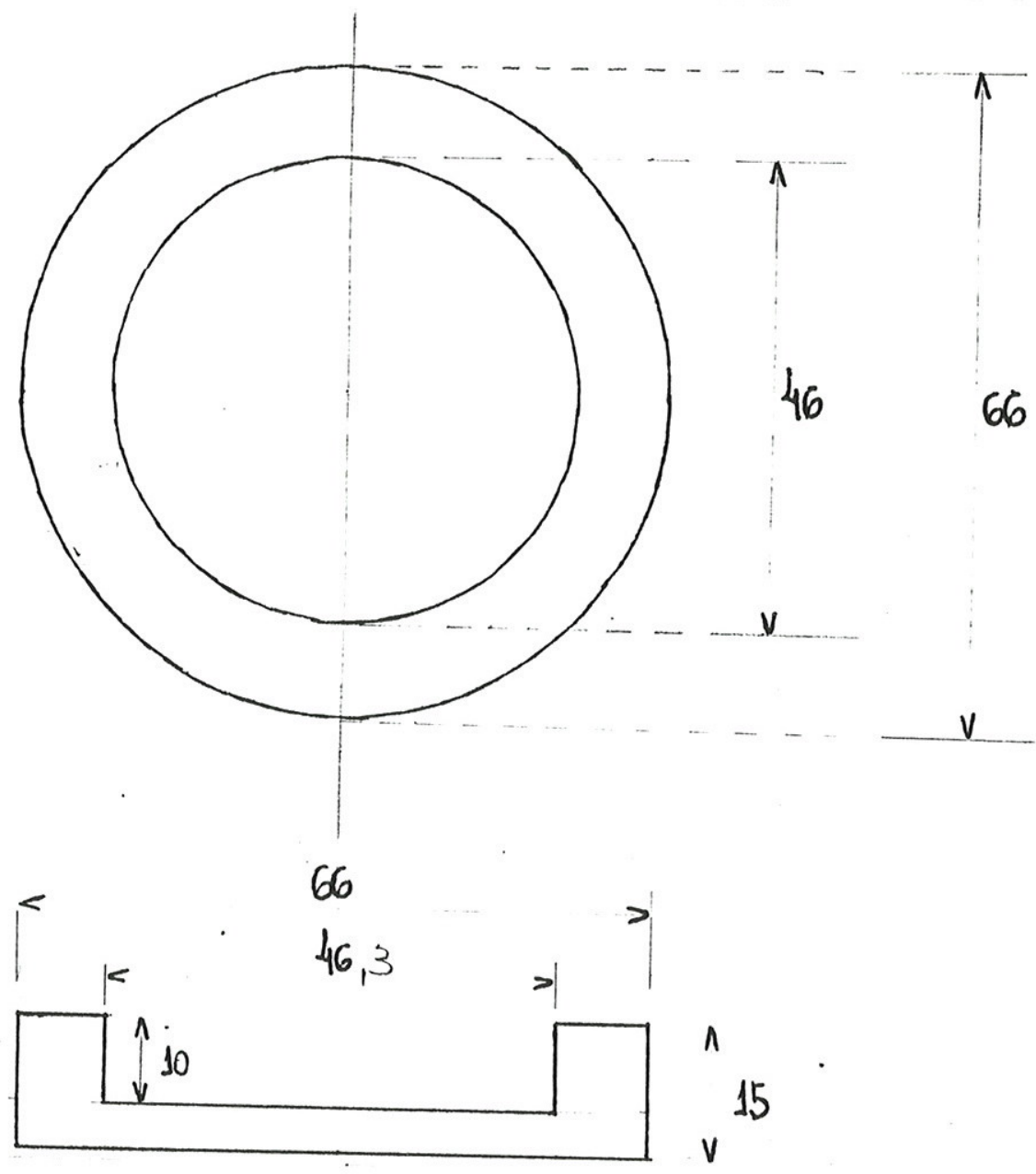

Figura A.1 : Esboço do Estampo (Fêmea) para Confecção dos Anéis de Estanho 


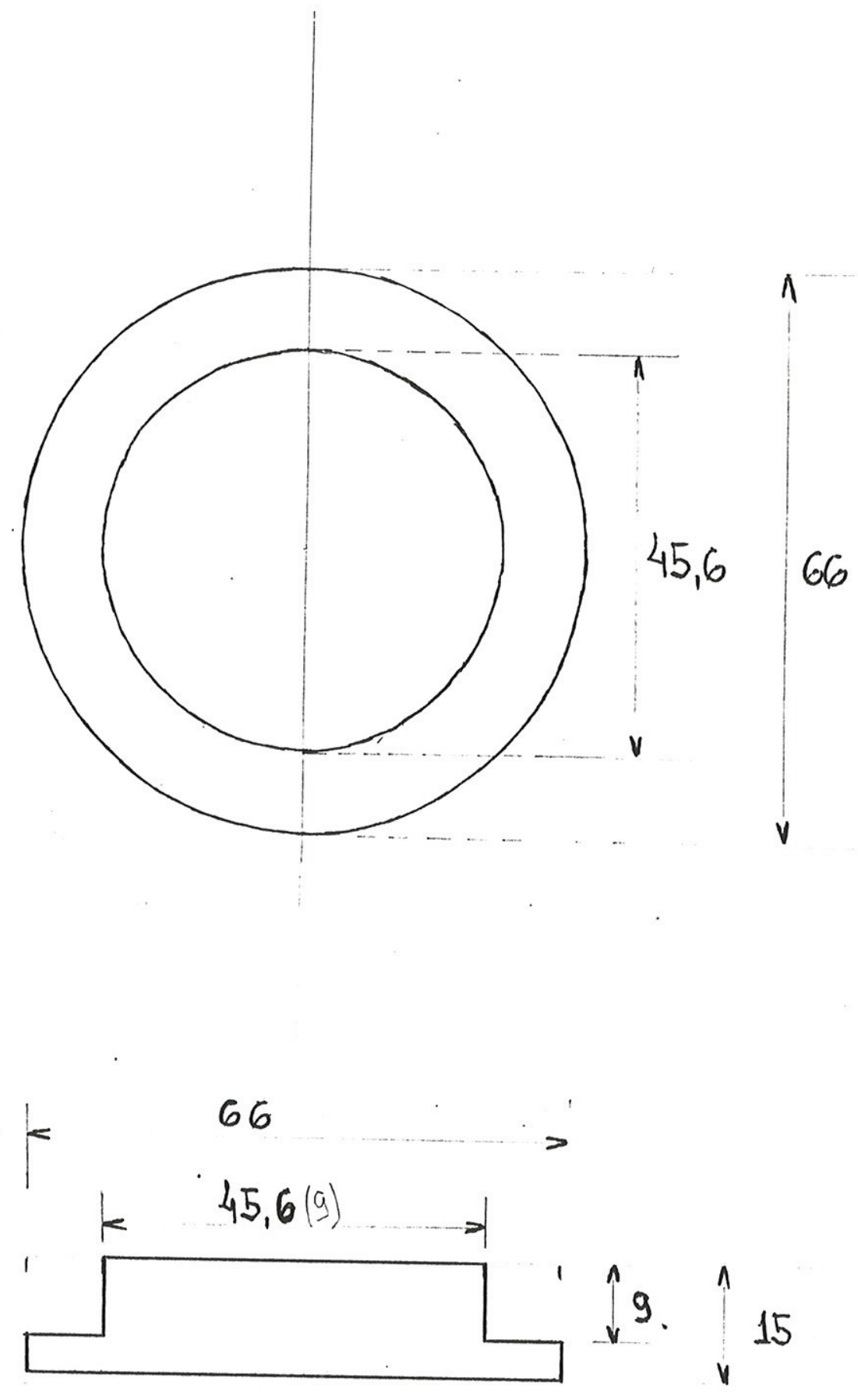

Figura A.2 : Esboço do Estampo (Macho) para Confecção dos Anéis de Estanho 


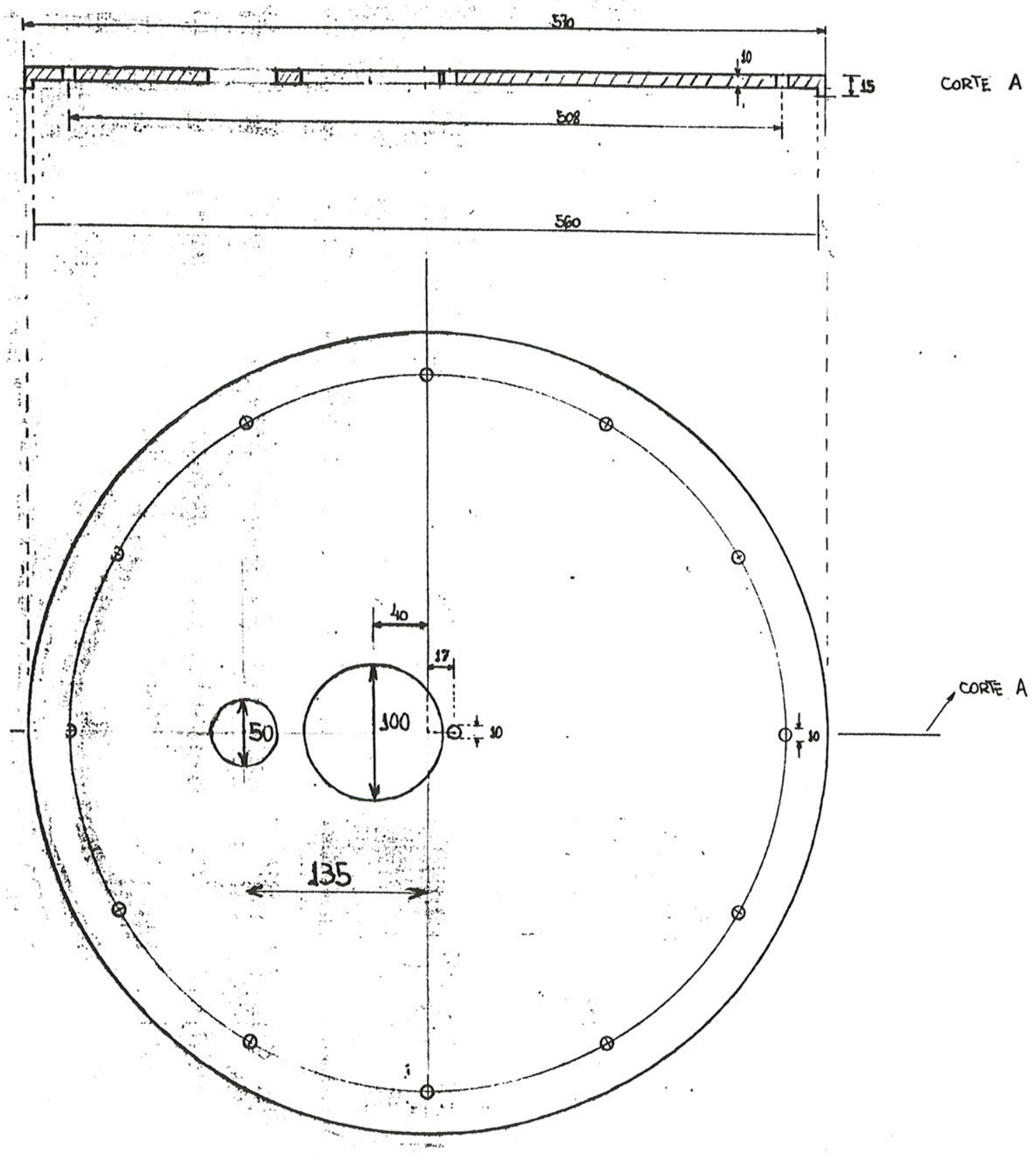

Figura A.3 : Esboço do Disco Inferior do Suporte da Cavidade 


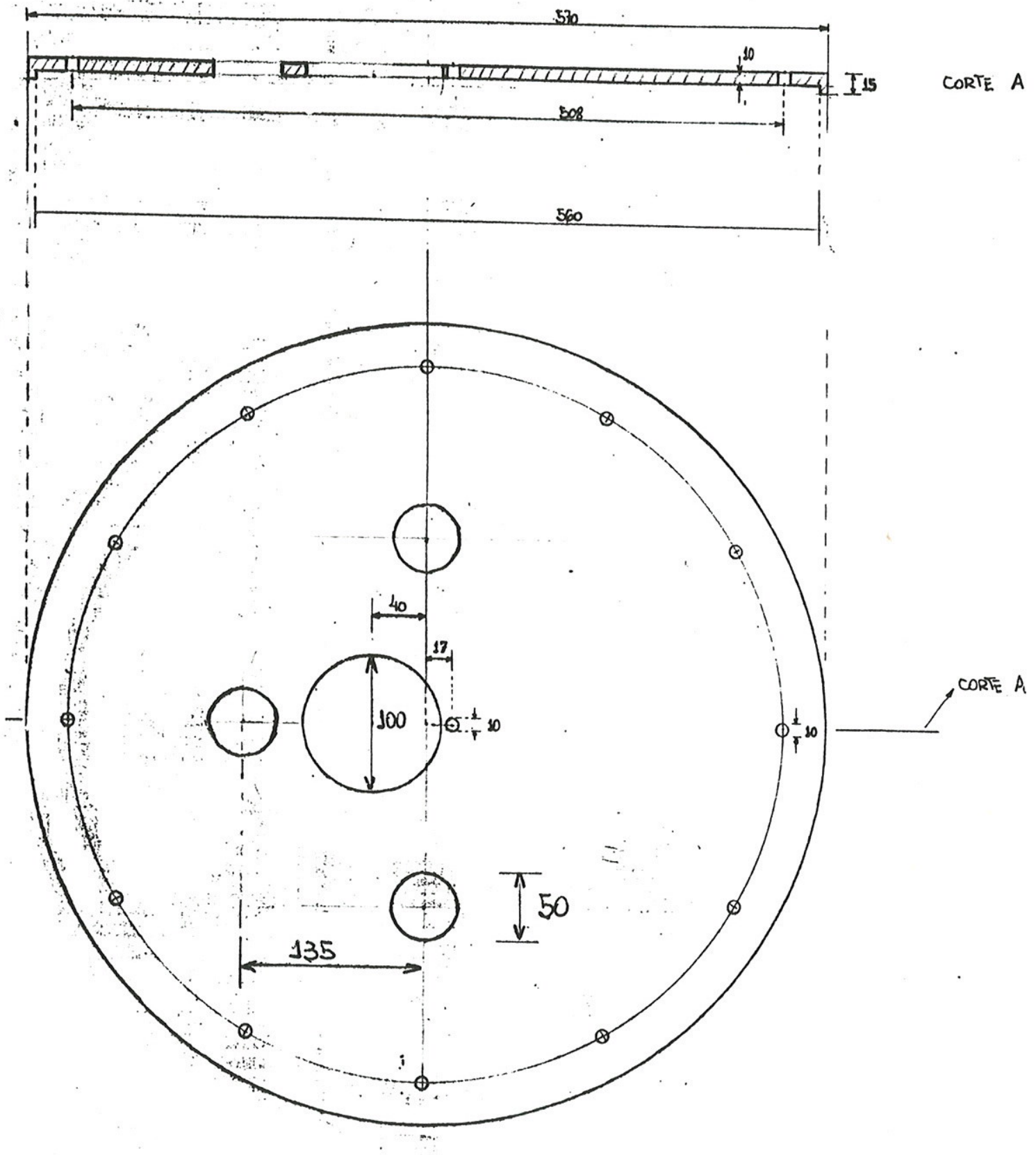

Figura A.4 : Esboço do Disco Superior do Suporte da Cavidàde 


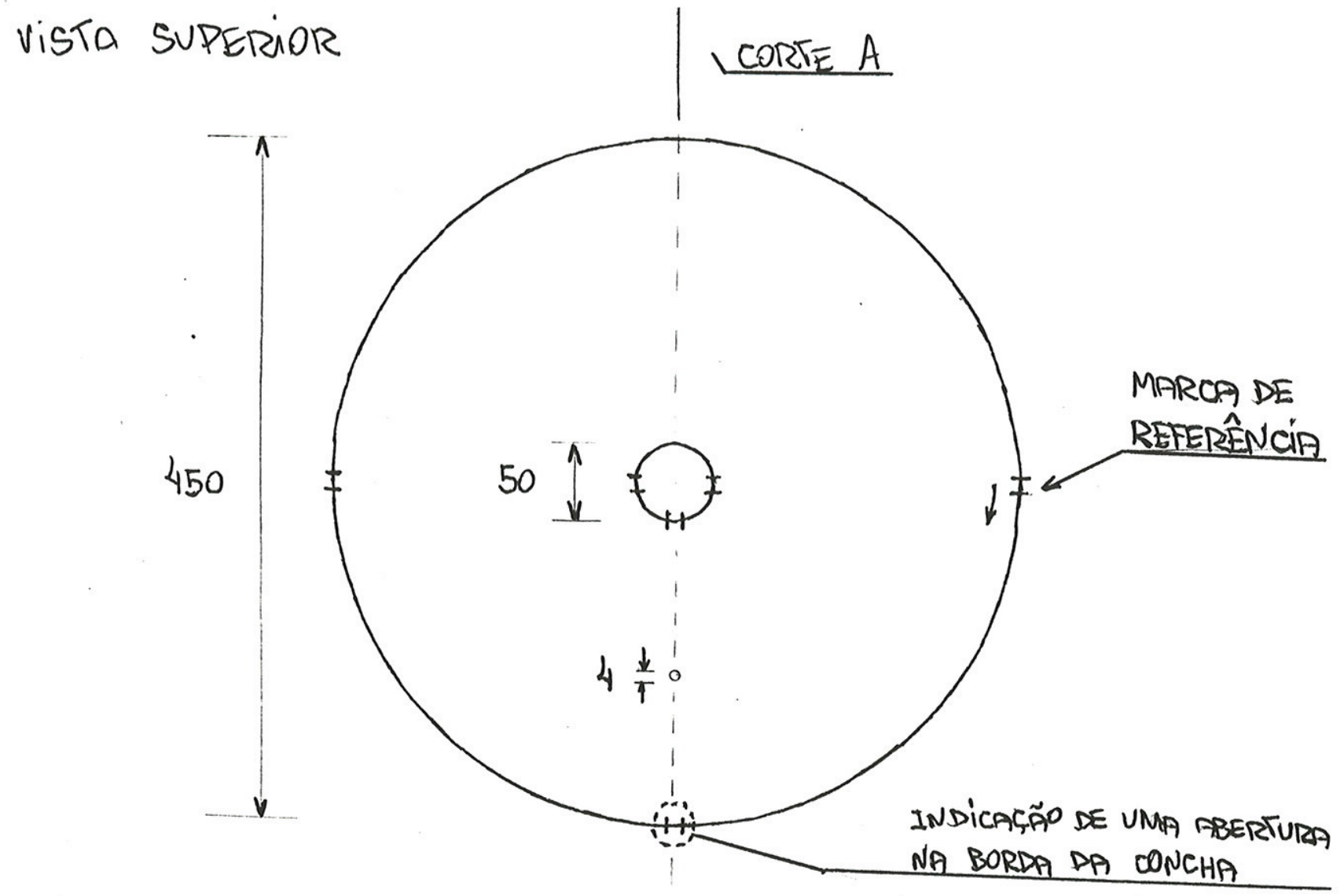

VIsTa DO

CORTE A

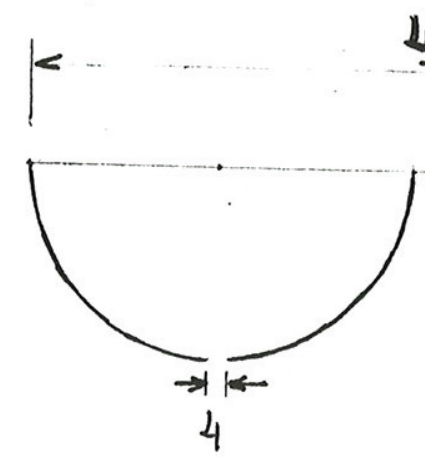

450

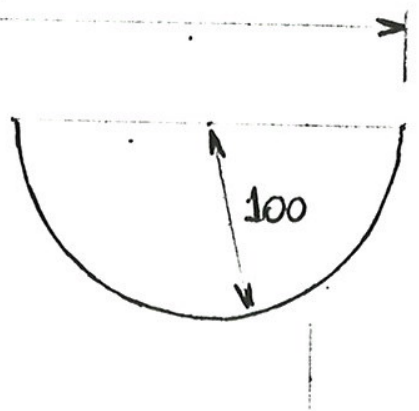

DETALHE DAS abERTURATS WA BORPA PA CONCHA

Figura A.5 : Esquema da Distribuição dos Orifícios sobre a Concha 1 

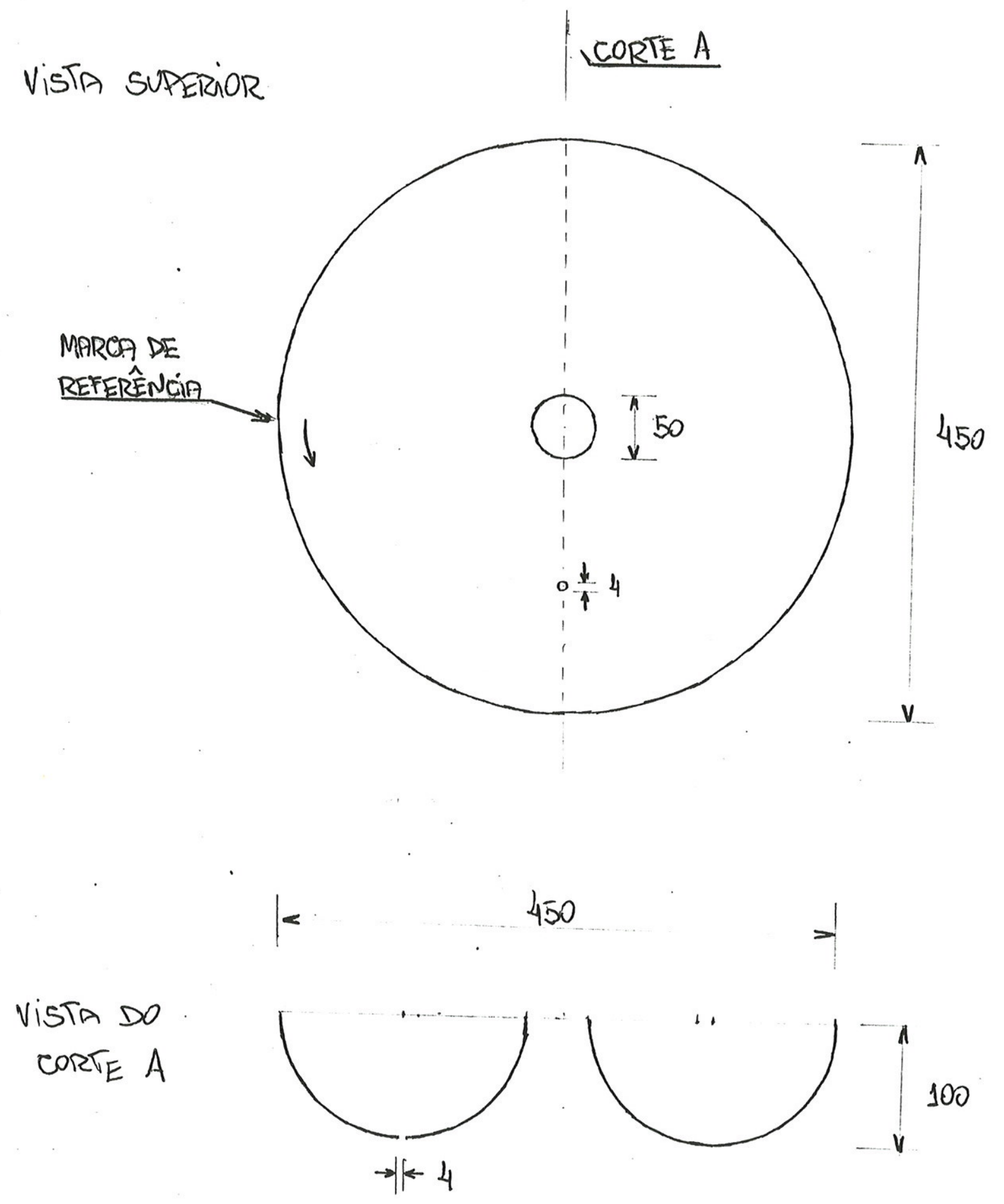

Figura A.6 : Esquema da Distribuição dos Orifícios sobre a Concha 2 

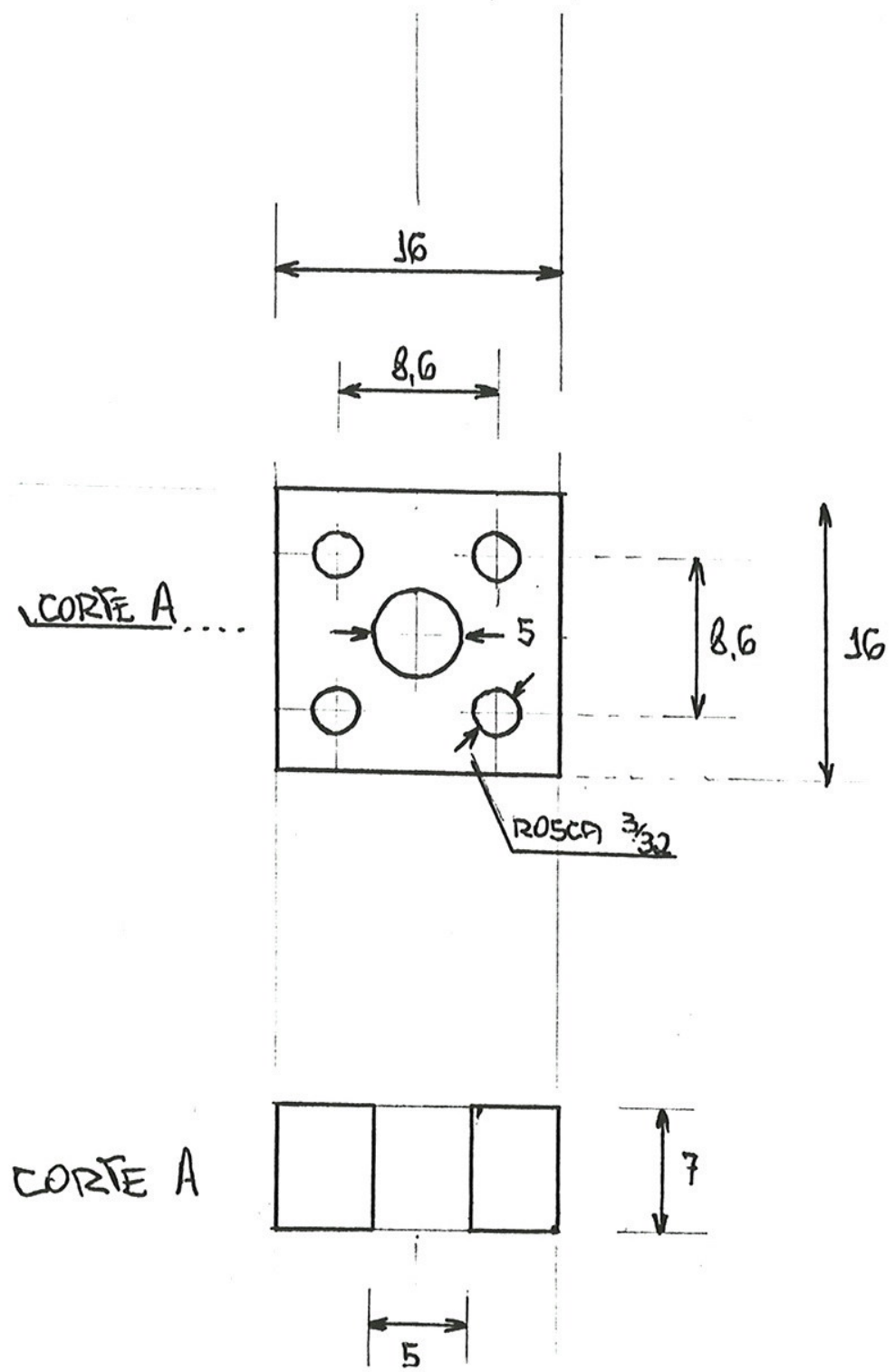

Figura A.7 : Suporte para Conector de RF da Série SMA 

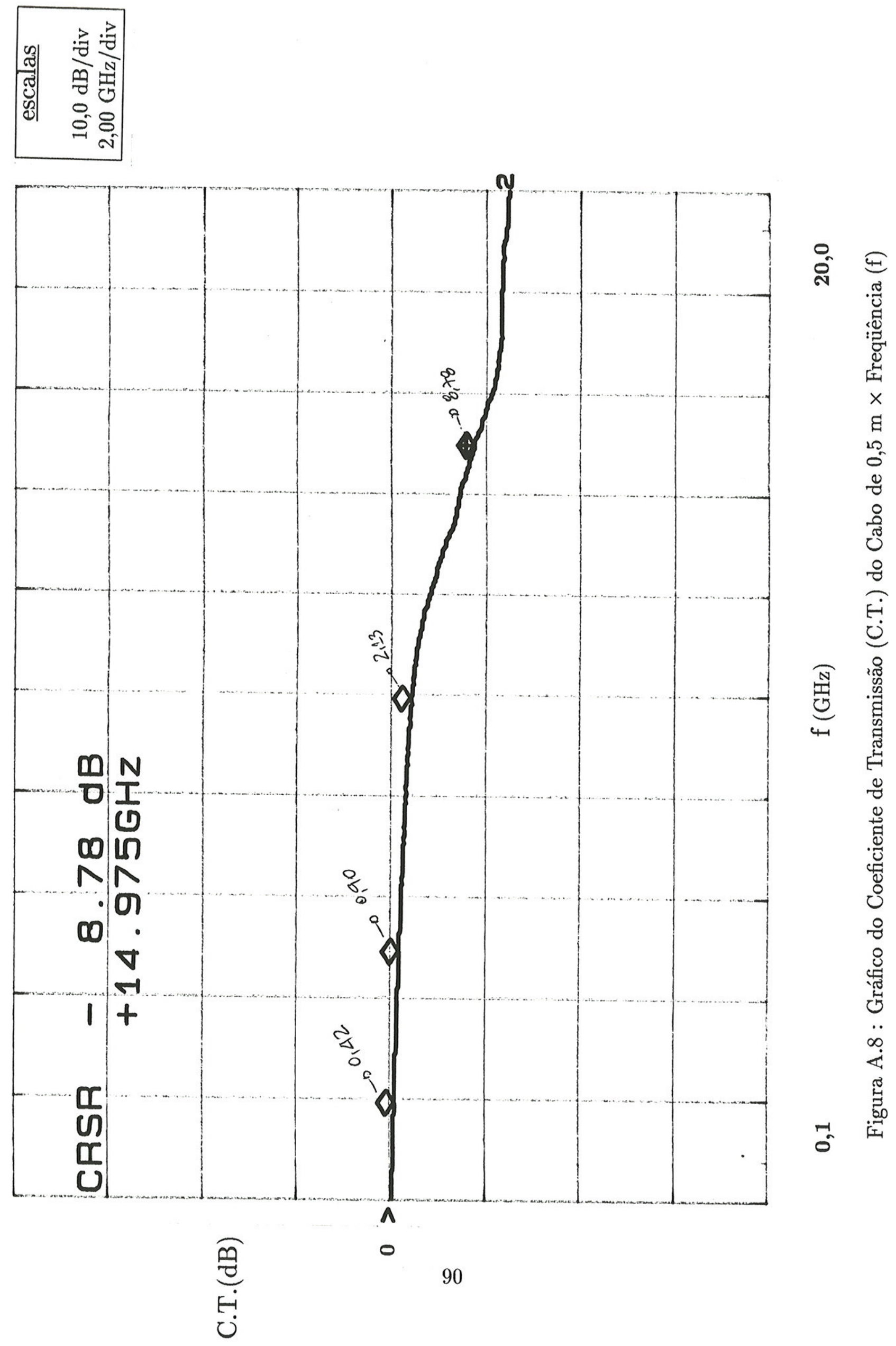

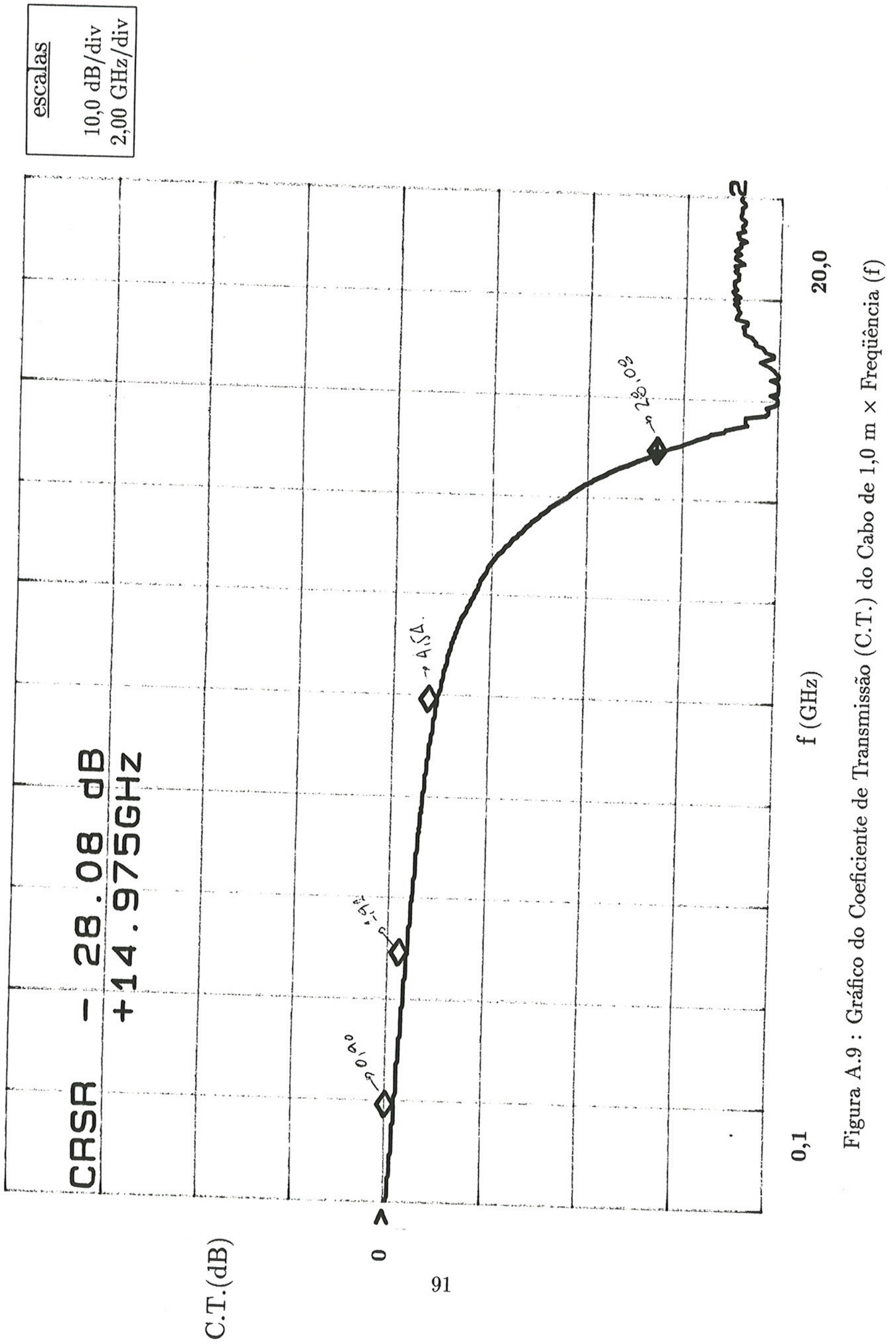


\section{Apêndice B}

\section{REFERÊNCIAS}

1. R.A.Cairns; Radiofrequency Heating of Plasmas, Adam Hilger (1991).

2. N.V.Ivanov et alii; Sov.Phys.Tech.Phys; vol.18, 326 (1973).

3. J.D.Love; J.Plasma Phys., vol.14, 25 (1975).

4. M.Brambilla, U.Finzi; IEEE Trans. Plas. Sci., vol. PS-2, 112 (1974).

5. B.A.Mishustin, V.I.Sheherbakov; Sov. Phys. - Tech. Phys., vol.22, 298 (1977).

6. F.Cap, R.Deutsch; IEEE Trans. Microwave Theory-Tech., vol.MTT 26, 478 (1978).

7. F.Cap, R.Deutsch; IFFF, Trans. Microwave Theory-Tech., vol. MTT-28, 700 (1980).

8. J.Lileg, B.Schnizer, R.Keil; AEU, vol.37, 359 (1983).

9. R.Keil, J.Jager, B.Schnizer, J.Lileg; Kleinheubacher Berichte, vol.26, 1983.

10. R.Keil; AEU, vol. 38, 30 (1984).

11. M.S.Janaki, B.Dasgupta; IEEE Trans.Plas. Sci, vol. PS-18, 78 (1990).

12. J.A.Stratton; Electromagnetic Theory, McGraw-Hill (1941).

13. P.Moon, D.E.Spencer; Field Theory for Engineers, D. van Nostrand (1961).

14. A.Erdélyi, W.Magnus, F.Oberhettinger, F.G.Tricomi; Higher Transcendental Functions - vol. 1, McGraw-Hill (1953).

15. M.Abramowitz, I.A.Stegun; Handbook of Mathematical Functions, Dover (1970).

16. A.Ferreira; IFUSP, Comunicação Privada, agosto de 1993.

17. A.Ferreira; IFUSP, Comunicação Privada, janeiro de 1994. 